\title{
Measurement of Airflow in Residential Furnaces
}

\author{
Peter J. Biermayer, James Lutz, Alex Lekov
}

\author{
Energy Analysis Department \\ Environmental Energy Technologies Division \\ Ernest Orlando Lawrence Berkeley National Laboratory \\ University of California \\ Berkeley, California 94720
}

May 2004

This work was supported by the Assistant Secretary for Energy Efficiency and Renewable Energy, Office of Building Technologies of the U.S. Department of Energy under Contract No. DE-AC0376SF00098 


\section{Disclaimer}

This document was prepared as an account of work sponsored by the United States Government. While this document is believed to contain correct information, neither the United States Government nor any other agency thereof, nor the Regents of the University of California, nor any of their employees, makes any warranty, express or implied, or assumes any legal responsibility for the accuracy, completeness, or usefulness of any information, apparatus, product, or process disclosed, or represents that its use would not infringe privately owned rights. Reference herein to any specific commercial product, process or service by its trade name, trademark, manufacturer, or otherwise, does not necessarily constitute or imply its endorsement, recommendation, or favoring by the United States Government or any agency thereof, or the Regents of the University of California. The views and opinions of authors expressed herein do not necessarily state or reflect those of the United States Government or any agency thereof, or the Regents of the University of California. 


\section{Executive Summary}

\section{Purpose}

In order to have a standard for furnaces that includes electricity consumption or for the efficiency of furnace blowers to be determined, it is necessary to determine the airflow of a furnace or furnace blower. Lawrence Berkeley National Laboratory (LBNL) contracted with Energy Systems Laboratory (ESL) to do airflow testing, in order to determine if an existing test method for measuring blower airflow could be used to measure the airflow of a furnace, under conditions seen in actual installations. A secondary purpose for testing was to collect data and insights into the operating characteristics of various types of furnace blowers, to use in the analysis of the electricity consumption of furnaces. Results of this work maybe useful for making potential modifications to test procedures.

\section{What ESL did}

ESL measured airflow on furnaces with three types of blower and motor combinations installed. During the testing, ESL also collected additional data, including data on power consumption, static and total pressure, and blower speed. ESL tested the entire furnace including the blower as one unit. In addition, a typical furnace circulating blower was also tested by itself, outside of the furnace. The Lab tested three combinations consisting of two blower wheel types and three different motors. These included: (1) a forward-curved blower wheel with a typical permanent split capacitor (PSC) motor, (2) a forward-curved blower wheel with an electronically-commutated motor (ECM) - which has energy-saving potential as well as other benefits, and (3) a prototype blower, consisting of a backward-inclined blower wheel matched to an ECM motor prototype, which is being developed as an energy-saving alternative to conventional furnace blowers.

\section{What LBNL learned}

LBNL found unexpected results for the new types of blowers with ECM motors. We also determined that more detail is required in the existing test procedures to ensure stand-alone blowers and furnaces with internally mounted blowers are tested in a consistent way. In summary:

- $\quad$ Simply specifying the current American National Standards Institute/Air Movement and Control Association/American Society of Heating, Refrigerating and Air-conditioning Engineers (ANSI/AMCA 210/ASHRAE 51) Laboratory Methods of Testing Fans for Aerodynamic Performance Rating ,test procedure is not sufficient for ensuring that consistent procedures are used in testing;

- $\quad$ There is difficulty in testing some types of blowers with ECM motors;

- $\quad$ There is no uniform, single method of testing and comparing airflow and efficiency of competing furnace blower and motor technologies;

- $\quad$ There is no furnace test procedure specifically for measuring furnace blower performance and efficiency (blower energy is currently measured only as part of the total furnace energy, and is not linked to performance or efficiency); and 
- $\quad$ Blowers using ECM and other newly developed technologies may have different performance characteristics than conventional blowers and can affect energy consumption in actual applications.

\section{Recommended Next Steps}

- Discuss test procedures with manufacturers and trade associations to determine the causes of variation between Energy Systems Laboratory (ESL)'s test results and theirs;

- $\quad$ Perform additional testing to resolve problems discovered in airflow and power measurements;

- Develop a standard method to compare the performance and efficiency of competing furnace blower and motor technologies and their effect on furnace energy use and power consumption; and

- $\quad$ Do additional testing to characterize energy usage of blowers for use in energy consumption analysis in actual installations.

Benefits of Additional Research and Analysis

- $\quad$ Additional research and analysis provides a basis for future air handler or furnace energy efficiency test procedures;

- Manufacturers of efficient motor/blower combinations would benefit from a consistent method to compare and specify the efficiency or energy consumption of motors/blowers in air handlers or furnaces; and

- A common method for comparing and specifying the efficiency or energy consumption of motors/blowers in air handlers and furnaces, could provide a basis for giving credit for more efficient technologies. 


\section{TABLE OF CONTENTS}

1.0 OBJECTIVES $\ldots \ldots \ldots \ldots \ldots \ldots \ldots \ldots \ldots \ldots \ldots \ldots \ldots \ldots \ldots \ldots$

2.0 INTRODUCTION $\ldots \ldots \ldots \ldots \ldots \ldots \ldots \ldots \ldots \ldots \ldots \ldots \ldots \ldots \ldots$

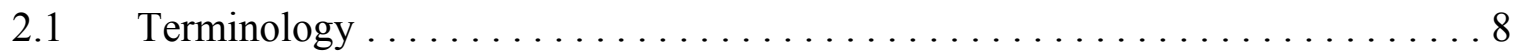

2.2 Furnace Circulating-Air Blowers and Motors $\ldots \ldots \ldots \ldots \ldots \ldots \ldots$

3.0 TESTING PROCEDURES $\ldots \ldots \ldots \ldots \ldots \ldots \ldots \ldots \ldots \ldots \ldots \ldots \ldots \ldots$

3.1 Determination of Furnace Airflow -- Current Practice . . . . . . . . . . . 9

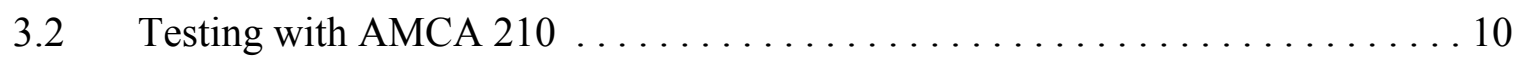

4.0 TESTING CARRIED OUT AT ENERGY SYSTEMS LABORATORY . . . . . . 10

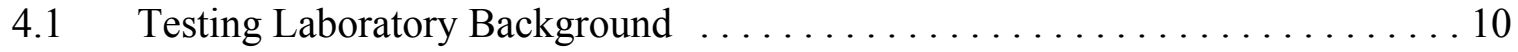

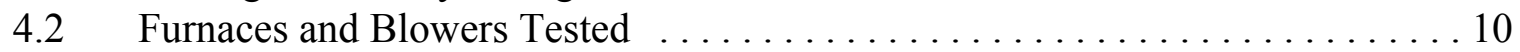

4.3 Data Provided in the Product Literature $\ldots \ldots \ldots \ldots \ldots \ldots \ldots \ldots \ldots \ldots$

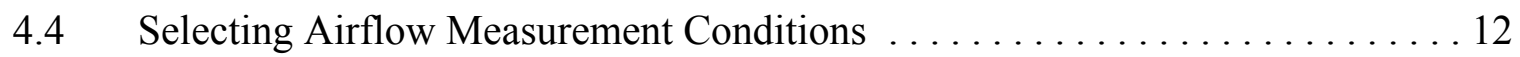

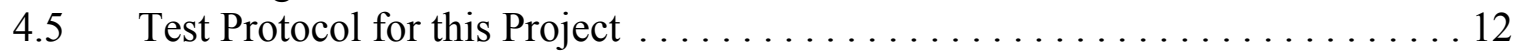

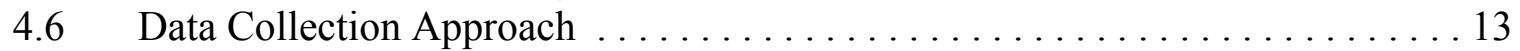

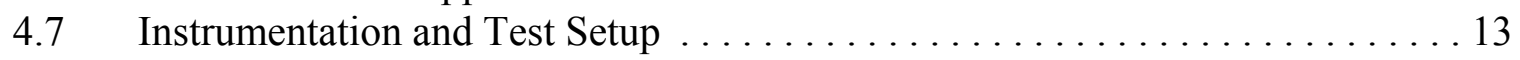

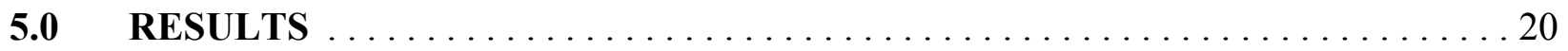

5.1 Results of using AMCA 210 to Measure Airflow of Furnaces . . . . . . . . 20

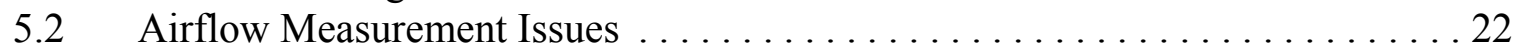

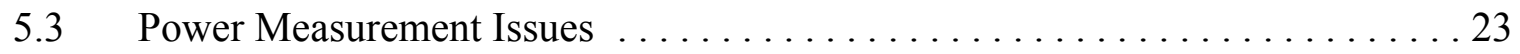

5.4 Possible Energy Savings for Furnace Blowers $\ldots \ldots \ldots \ldots \ldots \ldots \ldots \ldots \ldots$

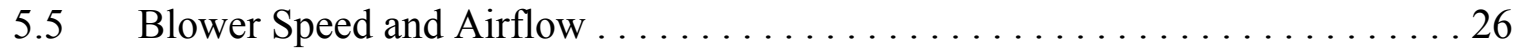

5.6 Blower Curve Characteristics at Multiple Blower Speeds . . . . . . . . . . 27

5.7 PSC Blower Curves with and without the Blower Installed in the Furnace . . . 28

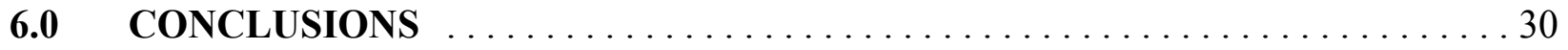

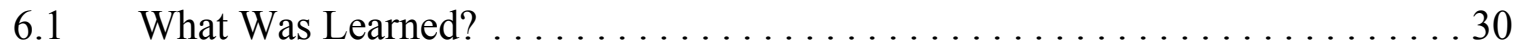

6.2 What Needs to be Done to Resolve Issues? . . . . . . . . . . . . . . 30

6.3 Additional Issues to Address with Further Research . . . . . . . . . . . . . 30

6.4 Benefits of Additional Research and Analysis $\ldots \ldots \ldots \ldots \ldots \ldots \ldots \ldots \ldots$

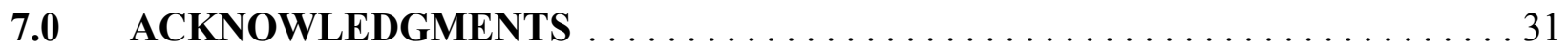




\section{APPENDICES}

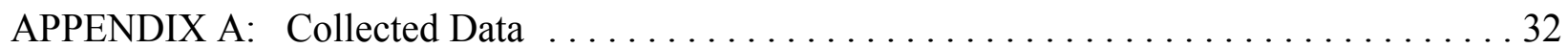

PSC furnace at high speed

PSC furnace at medium speed

PSC furnace at low speed

PSC blower only at high speed

PSC blower only at medium speed

PSC blower only at low speed

ECM 2.3 furnace at high speed

ECM 2.3 furnace at medium speed

ECM 2.3 furnace at low speed

ECM 4.0 furnace at high speed

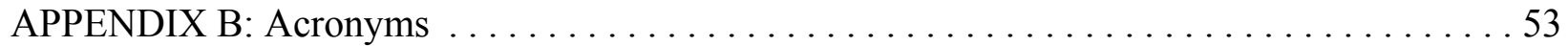

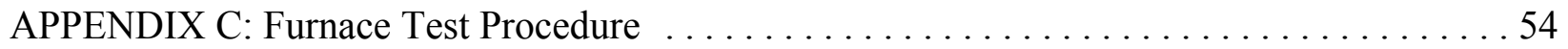

APPENDIX D: Instrumentation and Testing Details $\ldots \ldots \ldots \ldots \ldots \ldots \ldots \ldots \ldots \ldots \ldots \ldots \ldots$

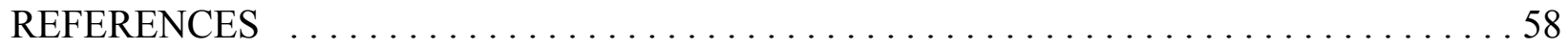




\section{LIST OF TABLES}

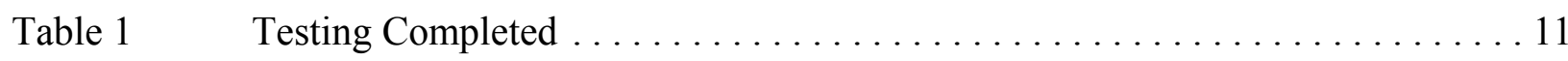

\section{LIST OF FIGURES}

Figure $1 \quad$ Schematic of Airflow Apparatus . . . . . . . . . . . . . . . . . . . . 14

Figure 2 Airflow Measurement Apparatus at Energy System Laboratory .......... 15

Figure 3 Furnace Mounted to Inlet of the Airflow Apparatus $\ldots \ldots \ldots \ldots \ldots \ldots \ldots . \ldots 16$

Figure $4 \quad$ Testing a Stand Alone Blower . . . . . . . . . . . . . . . . . . . . . . . 17

Figure $5 \quad$ Airflow Nozzles in Airflow Apparatus $\ldots \ldots \ldots \ldots \ldots \ldots \ldots \ldots . \ldots . \ldots . \ldots . \ldots 18$

Figure $6 \quad$ Data Acquisition for Airflow Apparatus ...................... 19

Figure 7 Airflow versus Static Pressure for Three Motor/Blower Combinations . . . . . 21

Figure 8 Comparison with Manufacturer's Reported Airflow Versus

Static Pressure Data ................................ 21

Figure 9 Airflow Efficiency versus Static Pressure at Highest Blower Speed . . . . . 25

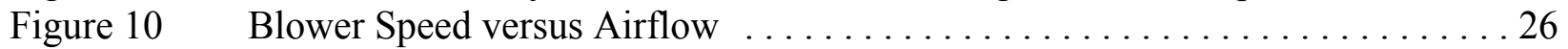

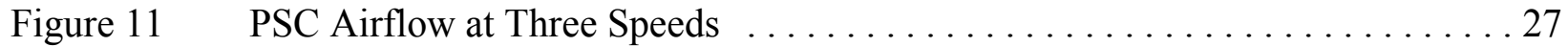

Figure $12 \quad$ ECM 2.3 Airflow at Three Speeds ........................ 28

Figure 13 Comparing Blower Curves With and Without the Furnace ............. 29 


\subsection{OBJECTIVES}

Electricity consumption of furnaces depends upon their airflow capacity. Other factors affecting furnace electricity consumption include the flow resistence of the system (the pressure drop across the blower) and the design of the air handler. Although manufacturers report airflow information in product literature, there is currently no standard method for determining the airflow through a furnace. There are, however, methods of measuring the airflow of furnace circulating-air blowers, using an Air Movement and Control Association (AMCA) test standard referred to as AMCA 210.

The primary objectives of this project were to:

- Gauge the appropriateness of AMCA 210 for determining the airflow capacity of a furnace circulating-air blower and identify potential testing difficulties; and

- Identify any potential issues with regard to testing different types of motor and blower combinations, especially those utilizing new, variable-speed technologies and electronic controls.

In addition, a secondary objective was to generate independent data on furnace airflow and power consumption for typical blowers and for blowers using newer technologies.

\section{$2.0 \quad$ INTRODUCTION}

\section{$2.1 \quad$ Terminology}

The term "blower" in this report refers to the furnace circulating-air blower, meaning the blower or fan in a furnace that is used to circulate the conditioning air through the furnace and system ductwork. Since most manufacturer literature provides airflow information referenced to static pressure, most Figures in this report also refer to static pressure. The report also uses the term "external static pressure" (ESP); for the purposes of this report, this term is interchangeable with "static pressure", and refers to the pressure differential between the furnace air outlet and the furnace inlet when the entire furnace is used, or the pressure differential between the blower air outlet and the blower inlet when the blower is tested outside of the furnace. Because ductwork is not added to the furnace inlet or blower inlet, the inlet static pressure is considered to be free air, or at 0 gauge pressure. See Appendix B for additional acronyms and definitions.

\subsection{Furnace Circulating-Air Blowers and Motors}

LBNL contracted with the Energy Systems Laboratory (ESL) at Texas A\&M University to test blowers with both forward- and backward-bladed blower wheels. Most residential circulating-air blowers use a blower wheel with forward-curved blades. However, a prototype blower manufactured by General Electric (GE) has backward-inclined blower blades. GE chose this configuration because of its possibilities for being more efficient. 
The two basic types of motors used in the blowers tested for this report were:

- $\quad$ PSC motors - PSC motors are permanent split capacitor single-phase induction motors. The majority of residential furnaces currently use PSC motors. The desired air flow is set by a field technician, fixing fan speed(s) by altering jumpers on the electric motor control board.

- $\quad$ ECM motors - ECM motors are permanent-magnet, brushless DC motors. (For more information, go to www.GEindustrial.com, and enter keyword: ECM) ${ }^{1}$. In furnaces, these motors typically are combined with controls that allow the installer to set the desired airflow. The blower and its controller are designed to vary the speed and torque of the motor to achieve the desired airflow, regardless of the ESP drop.

PSC motors used in furnace blowers typically have two, three or four speeds. The lower speed is often used in heating mode and the higher speeds are used in cooling mode, if the furnace is also used with a split-system air conditioner and the furnace blower is used to circulate cooling air. The different speeds are needed to satisfy the design airflow requirements of the furnace in the heating season and the evaporator coil in the cooling season. The speed control is accomplished by applying voltage to different sets of motor windings. This introduces slip, which slows the motor down, but at a considerable efficiency penalty. A PSC motor operating at part speed draws almost as much power as one operating at full speed.

Because the ECM's motor speed is designed to be electronically controlled, it typically can provide about 12 different blower speeds. The installer of the furnace can select a cooling airflow to match the airflow required by the evaporator coil installed. For example, a furnace could be fitted with a one-ton to five-ton coil; the blower speed would then be selected to provide the airflow needed for this size coil. The controls on an ECM motor are typically designed to speed up or slow down the motor speed as needed, to provide a selected airflow regardless of the static pressure (i.e., airflow resistence) of the ductwork. The ECM motor's construction and its speed-control technique are inherently more efficient than the PSC motor. Other technologies are also available to provide variable airflow, but were not tested in this study.

\subsection{TESTING PROCEDURES}

\subsection{Determination of Furnace Airflow -- Current Practice}

It is LBNL's understanding that the airflow and static pressures reported in product literature are typically determined using a "code tester", i.e., an airflow measurement apparatus based on the existing test procedure ANSI/AMCA 210/ASHRAE 51. However, LBNL only found anecdotal information on how furnace airflow is determined.

Furnaces with ECM blower motors are often designed to provide constant airflow across the entire range of ESPs. A consultant reported that at least one manufacturer uses a modified 
AMCA 210 method for furnaces with ECM blower motors. The motor controller is bypassed and the motor is set to run at specific speeds. Data collected based on the AMCA 210 test method is recorded at each motor speed. These measured operating parameters are then used, along with the motor control algorithm, to determine the power consumption at various static pressures for constant cubic-feet-per-minute $(\mathrm{Cfm})$ operation. The procedure used by this manufacturer may not be the same as that used by other manufacturers. LBNL also obtained anecdotal information that airflow is not always corrected to standardized conditions, as per AMCA 210 recommendations.

The current DOE test procedure does not provide for a measurement of airflow. See Appendix $\mathrm{C}$ for a brief discussion of the current DOE furnace test procedure. ${ }^{2}$

\subsection{Testing with AMCA 210}

The AMCA 210 test method provides procedures for testing blowers. It also specifies equations to correct airflow and power consumption to standard conditions. However, within this test standard, there can be differences in some of the testing details. These differences are due to choices regarding whether the airflow is measured on the duct inlet or outlet, and if Pitot tube traverses or flow nozzles are used. LBNL based the tests in this report on the test apparatus configuration shown in Figure 12 of the AMCA 210 test procedure. In this test configuration, the blower or furnace inlet is open to free air and the outlet is connected to the airflow apparatus.

The AMCA 210 test standard is identical to the ASHRAE Standard 51 and is an ANSI test method. ${ }^{3}$

\subsection{TESTING CARRIED OUT AT ENERGY SYSTEMS LABORATORY}

\subsection{Testing Laboratory Background}

LBNL contracted with the ESL ${ }^{4}$, which part of the Texas engineering Experiment Station (TEES) which is affiliated with Texas A\&M University (TAMU) and has a long history of testing blowers. In fact, ESL was previously an official test facility of AMCA (which now does all of its certification at its own laboratory). More in-depth information and discussion of the ESL facilities is available on the ESL web sites: http://www-esl.tamu.edu/about esl.html and http://www-esl.tamu.edu/lab/the lab.html.

\subsection{Furnaces and Blowers Tested}

ESL tested the three basic systems described below. LBNL selected two furnaces that were as similar as possible, except for their blower-motor types. The furnaces were rated at 88 $\mathrm{kBtu}$ input and are designed for use with up to a 4-ton air conditioner. The entire testing project at ESL consisted of testing three combinations of motors and blowers in the same-size furnace. The tested equipment was: 
- $\quad$ PSC motor with forward-inclined blower wheel

(Carrier 58CTA090-14, 88 kBtuh, 3.5 ton AC, 10x8 Blower Size, 1/3 hp motor);

- $\quad$ GE ECM 2.3 motor with forward-inclined blower wheel

(Carrier 58CVA090-16, 2-stage, 88 kBtuh, 1.5- 4 Ton AC, 10x8 Blower Size, 1/2 hp motor); and

- GE ECM 4.0 prototype motor combined with a prototype backward-inclined blower wheel. LBNL sent a blower scroll that was the same as the one in the furnace listed above (Carrier 58CVA090-16) to GE. GE installed their prototype blower wheel and ECM 4.0 motor. ESL then installed the prototype blower into the Carrier 58CVA090-16 furnace.

The initial intention was to test each of the above blower-motor combinations, both installed in a furnace and as a blower unit alone. However, because of difficulties in testing the individual ECM blower at static pressures down to 0.5 inches water gauge (in. wg.), and because of equipment operation problems with the prototype blower, LBNL modified this plan. Table 1 summarizes the completed testing.

Table 1 Testing Completed

\begin{tabular}{|c|c|c|c|c|c|c|}
\hline \multirow{2}{*}{$\begin{array}{c}\text { Blower } \\
\text { Speed }\end{array}$} & \multicolumn{2}{|c|}{ PSC } & \multicolumn{2}{c|}{ ECM 2.3 } & \multicolumn{2}{c|}{ ECM 4.0 } \\
\cline { 2 - 7 } & $\begin{array}{c}\text { Forward-curved blades } \\
\text { Blower in } \\
\text { furnace }\end{array}$ & $\begin{array}{c}\text { Blower } \\
\text { only }\end{array}$ & $\begin{array}{c}\text { Forward-curved blades } \\
\text { Blower in }\end{array}$ & $\begin{array}{c}\text { Blower } \\
\text { only }\end{array}$ & $\begin{array}{c}\text { Blower in } \\
\text { furnace }\end{array}$ & $\begin{array}{c}\text { Blower } \\
\text { only }\end{array}$ \\
\hline High & $\mathrm{x}$ & $\mathrm{x}$ & $\mathrm{x}$ & & $\mathrm{x}$ & \\
\hline Medium & $\mathrm{x}$ & $\mathrm{x}$ & $\mathrm{x}$ & & & \\
\hline Low & $\mathrm{x}$ & $\mathrm{x}$ & $\mathrm{x}$ & & & \\
\hline
\end{tabular}

\subsection{Data Provided in the Product Literature}

Manufacturers provide tables of airflow at a range of ESPs in the product literature of their furnaces. These tables include airflow at $0.5 \mathrm{in}$. wg of external static pressure. If the furnace has multiple settings to provide different amounts of airflow, the product literature will include tables of airflow by external static pressure for every setting.

Details on the furnaces tested can be found on the manufacturers' web sites below.

\section{Owners manuals:}


- http://www.commercial.carrier.com/details/0,1240,CLI1_DIV12_ETI3757,00.html?SMSESSION=NO

- http://www.commercial.carrier.com/wcs/literature_model_search/0,_CLI1_DIV12_ETI499,00.html?SMIDE $\mathrm{NTITY}=\mathrm{NO}$

\section{Product drawings:}

- http://www.residential.carrier.com/products/gas_furnaces/58cva_cvx.htm

For the PSC motor, the cfm is given for ESPs of 0.1 to 1.0 in. wg. for four speeds: low, med-low, med-high, and high.

For the ECM 2.3 motor, the airflow is given in cfm at static pressures from 0.1 to 1.0 ESP, for each operation mode. The ESP values are for the furnace with the air filter installed. Operating modes include low heat, high heat, air-conditioning capacities from 1.5 ton to 4 ton, and maximum airflow.

The GE blower ECM 4.0 is a prototype and did not come with a manual. However, GE provided information on this prototype in documents submitted to DOE. ${ }^{6}$ GE also sent ESL proprietary instructions on how to operate the motor. The ECM 4.0 is operated via the desktop computer and a communication program.

\subsection{Selecting Airflow Measurement Conditions}

Manufacturer literature typically categorizes the cooling capacity a furnace is designed to handle based on the maximum amount of airflow the furnace can deliver at 0.5 in. wg of ESP. A pressure drop across the furnace of $0.5 \mathrm{in}$. wg. represents the ESP of the furnace installed with an evaporating coil, and connected to typical household ductwork. ESL tested the units at 0.5 in. wg., as well as at a range of other ESPs (i.e., ten data points, including the lowest ESP at which the furnace could be tested).

\subsection{Test Protocol for this Project}

Although AMCA 210 is written as a test procedure for blowers, ESL used the test procedure to measure the airflow with the blowers installed in the furnace - in effect treating the entire furnace as a blower. In addition, ESL tested the PSC blower outside of the furnace.

ESL measured airflow and other measurements as specified by AMCA 210, using the setup shown in Figure 12 of the standard. ESL took measurements at the blower/furnace highspeed settings, as well as at the lowest and medium-low speeds, when possible. ESL provided data and fan curves corrected to standard temperature and pressure (air density), as per AMCA 210 equations, in addition to the original uncorrected data. At each point that it measured airflow, ESL also measured power consumption.

ESL measured the furnace airflow with the filter housing installed, but without the air 
filter installed. The air filter was removed to increase repeatability of the tests by eliminating another variable that could affect airflow. ESL performed all testing without an air conditioner evaporator coil installed and without the gas line connected.

\subsection{Data Collection Approach}

Typically, ESL tests airflow at ten points, including complete airflow shutoff. This is done in equal increments of airflow quantity (cfm). Using this approach allows ESL to take more measurements at the critical part of the curve, i.e., where the inflection point is in the curve. Typically, the data points are connected by a smooth curve based on fan affinity laws.

For this project, LBNL instructed ESL to instead measure ten data points based on even increments of static pressure at the furnace outlet. The original plan was to start at $0 \mathrm{in}$. wg static pressure and increase the airflow in $0.1 \mathrm{in.} \mathrm{wg} \mathrm{increments.}$

The departure from normal test point selection was due to how ECM motors are used in a furnace. Unlike PSC motors, an ECM motor operated with furnace control circuitry is designed to provide constant airflow, regardless of the external static pressure. It accomplishes this by controlling the speed and torque of the motor. The goal for this project was to test airflow with the furnace controlling the motor as it normally would in an actual installation.

\subsection{Instrumentation and Test Setup}

Figure 5.1 shows a schematic of the test flow apparatus. (See AMCA 210, Figure 12 for a detailed explanation. $)^{7}$ This test setup is typically used to test blowers of the size that would be installed in this equipment.

The furnace or blower is mounted to the inlet of the airflow apparatus that has an opening cut out of a piece of plywood that is attached to the inlet. The air passes through a series of three closely-spaced screens that even out the airflow, before flowing through one or more nozzles. The airflow measurement chamber has several nozzles of different sizes. Some of the nozzles are physically blocked off, to provide a pressure drop within an acceptable range across the nozzles. The pressure drop is measured by four equally-spaced pressure taps on either side of the nozzle bank. The air then passes through a second set of screens before moving on to a variable-speed blower that pulls the air out of the chamber. Adjusting the speed of the exit blower allows the static pressure at the inlet of the airflow apparatus to be varied. 


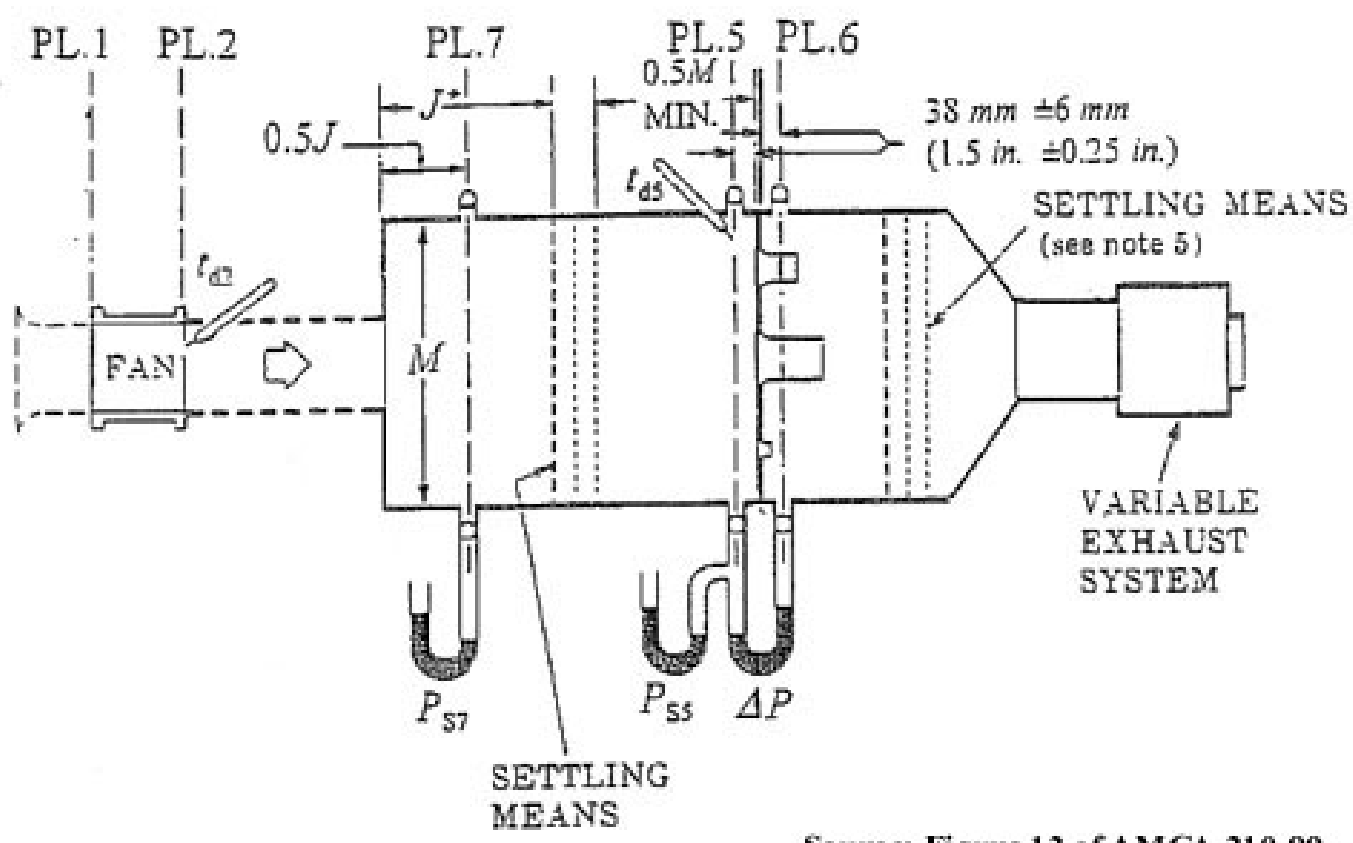

Figure 1 Schematic of airflow apparatus 
Figure 2 is a photograph of the apparatus used for the test. Note that the photograph is in the opposite orientation from the schematic shown in Figure 1. The inlet, where the furnace or blower would be mounted, is on the right side of the photograph. The airflow exit and variablespeed blower that sets the static pressure are on the left.

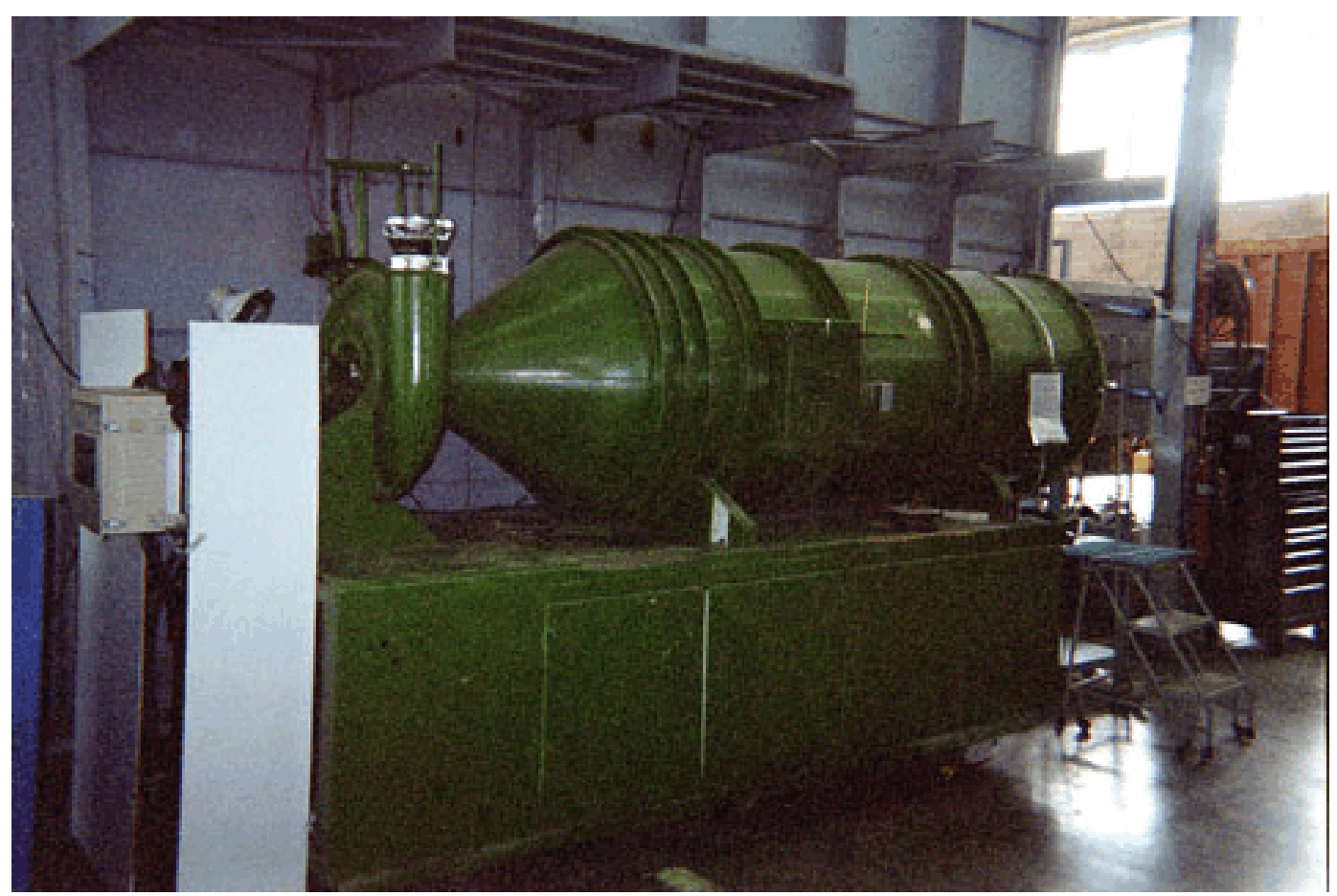

Figure 2 Airflow measurement apparatus at Energy System Laboratory - air exit at left - furnace or blower to be tested mounts on the right 
Figure 3 shows how ESL attached the furnace to the airflow apparatus. ESL mounted the furnace over an opening the size of the furnace outlet cut in the plywood. ESL then taped the furnace to the plywood and strapped it in place. The front of the furnace was facing upward.

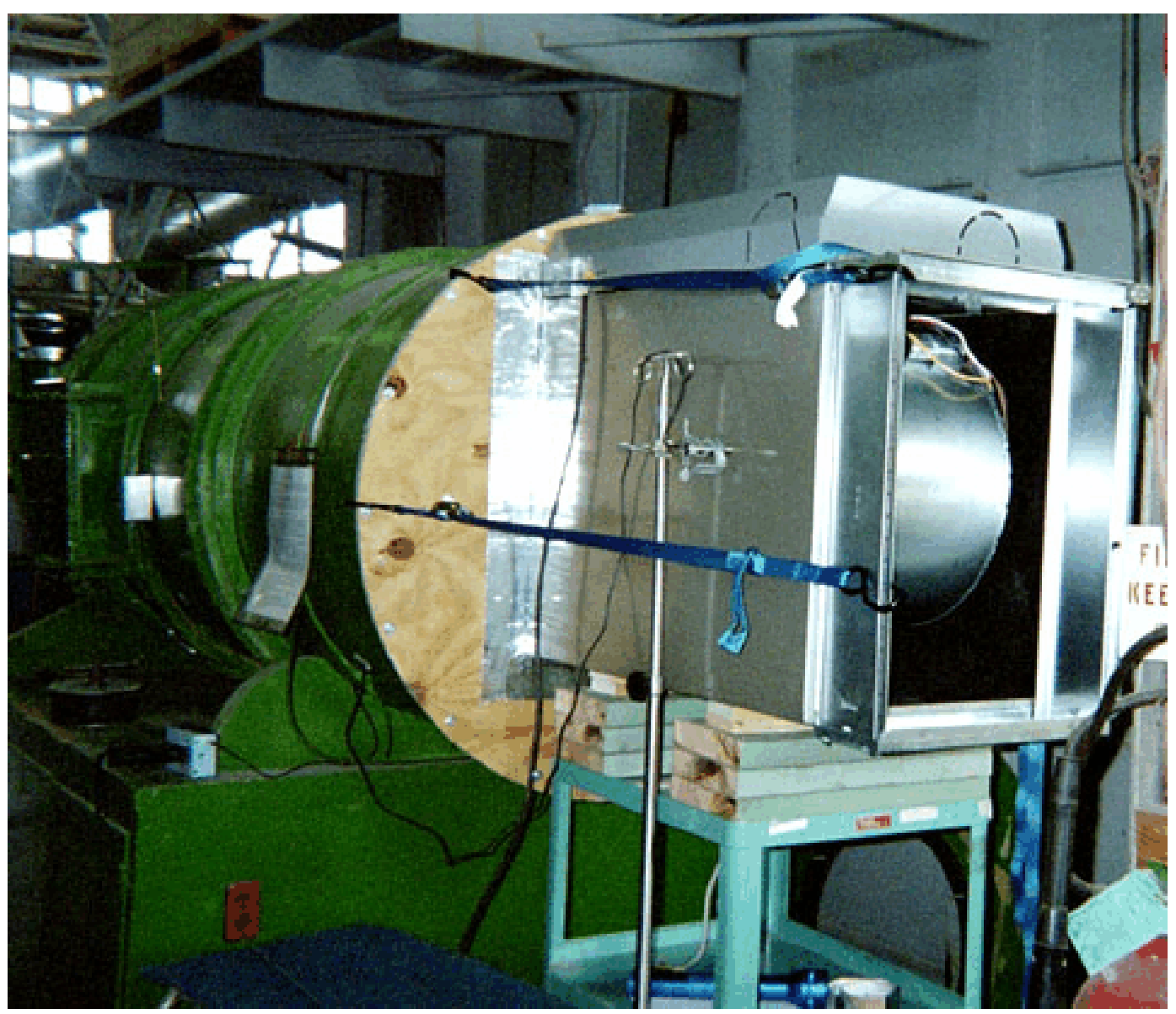

Figure 3 Furnace mounted to inlet of the airflow apparatus 
Figure 4 shows the PSC blower by itself attached to the airflow measuring apparatus for testing. The blower wheel and scroll of the blower are pointed out.

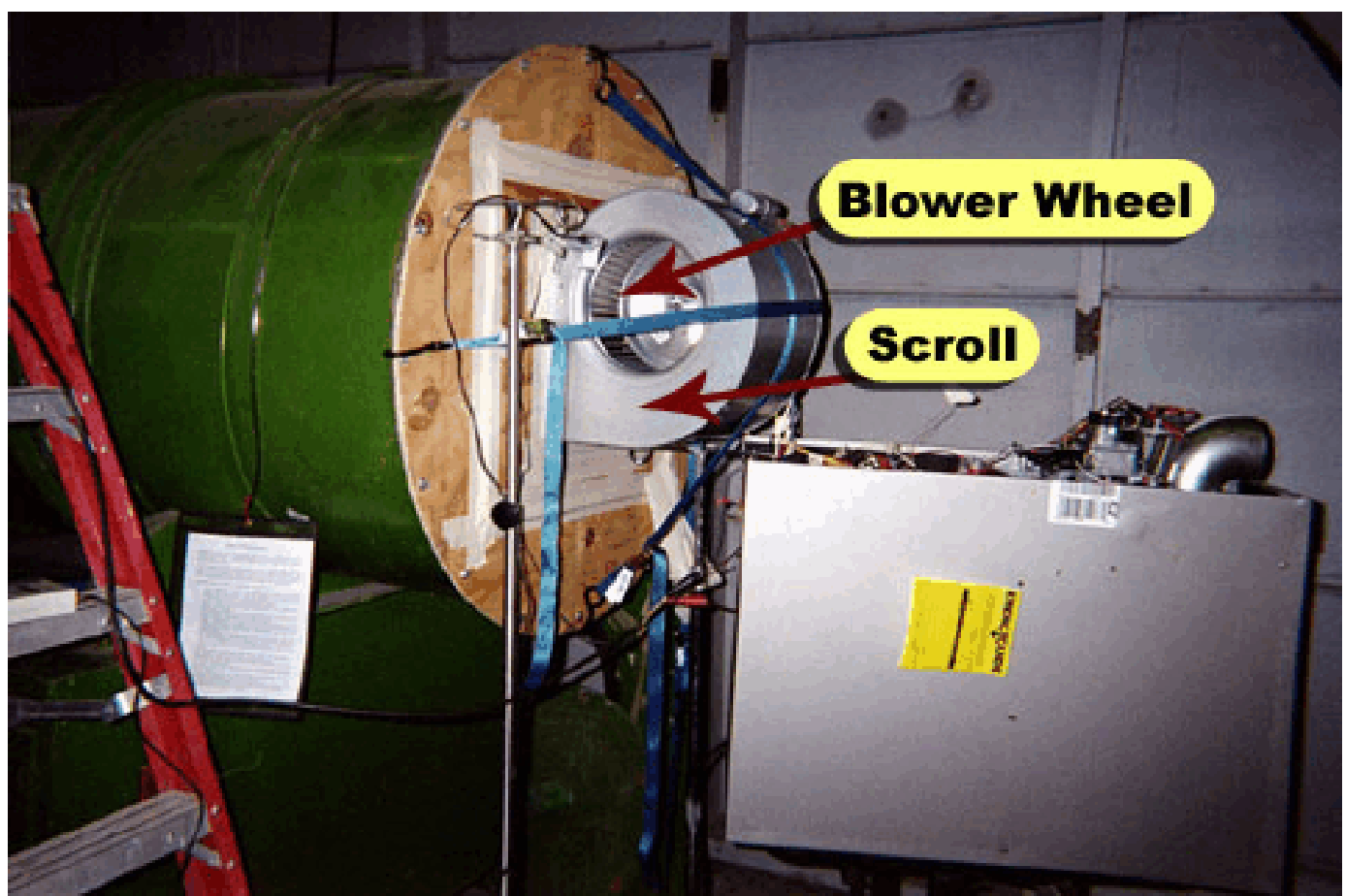

Figure 4 Testing a stand alone blower 
Figure 5 shows the downstream side of the airflow measurement nozzles. Depending on the airflow, some of the nozzles are capped off, as shown in the photograph. The data acquisition program gives three choices for nozzle selections; the operator chooses the nozzle combination that requires the fewest changes in opening and blocking off nozzles.

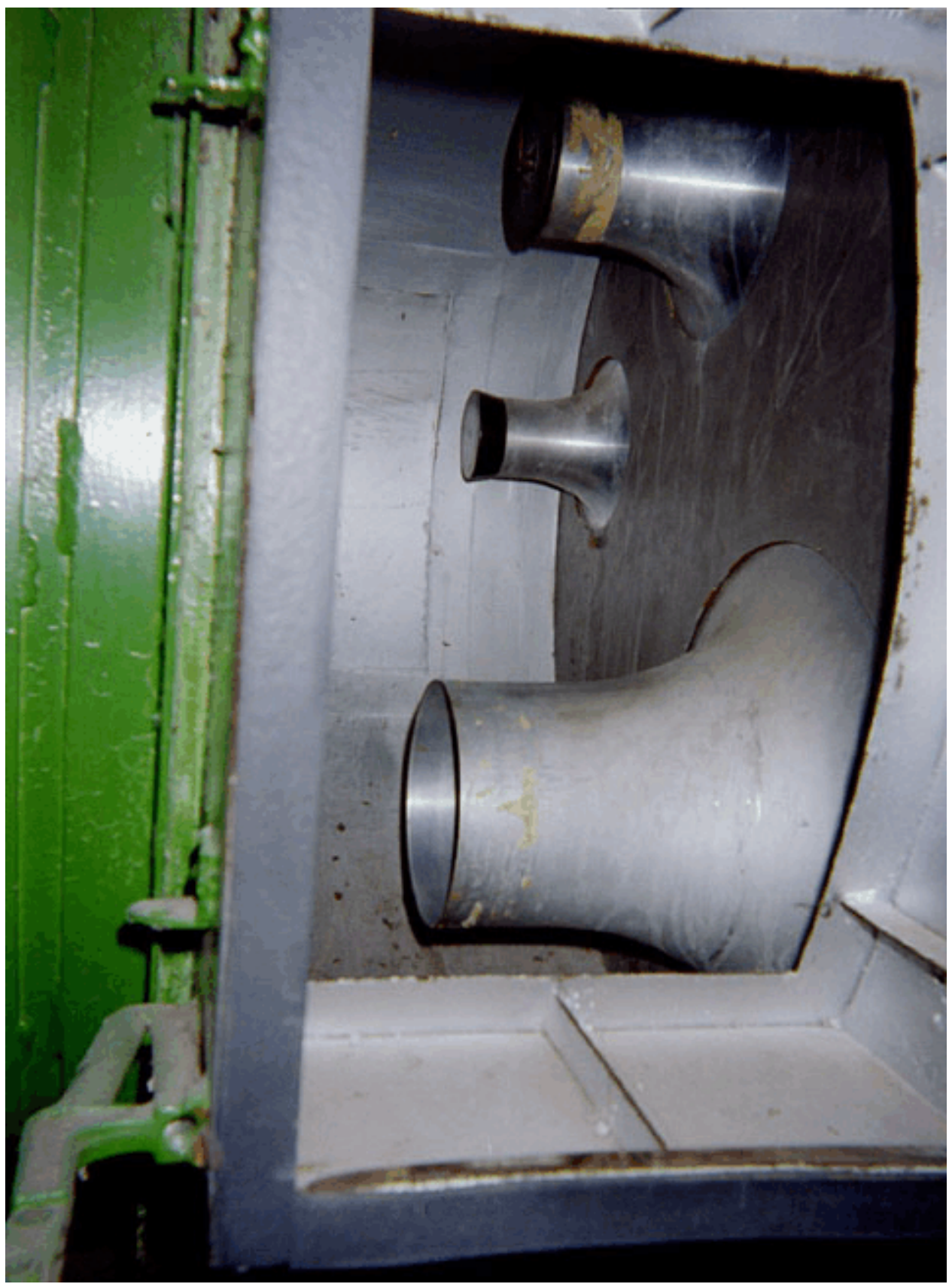

Figure 5 Airflow nozzles in airflow apparatus 
Figure 6 shows the data acquisition setup for the airflow tester. A computer collects all of the data (except for rpm). The pressure transducers (electronic pressure measuring instruments) are located on the wall behind the computer. The data acquisition computer is programmed to use equations in the AMCA 210 test procedure and is set up to produce a typical fan curve.

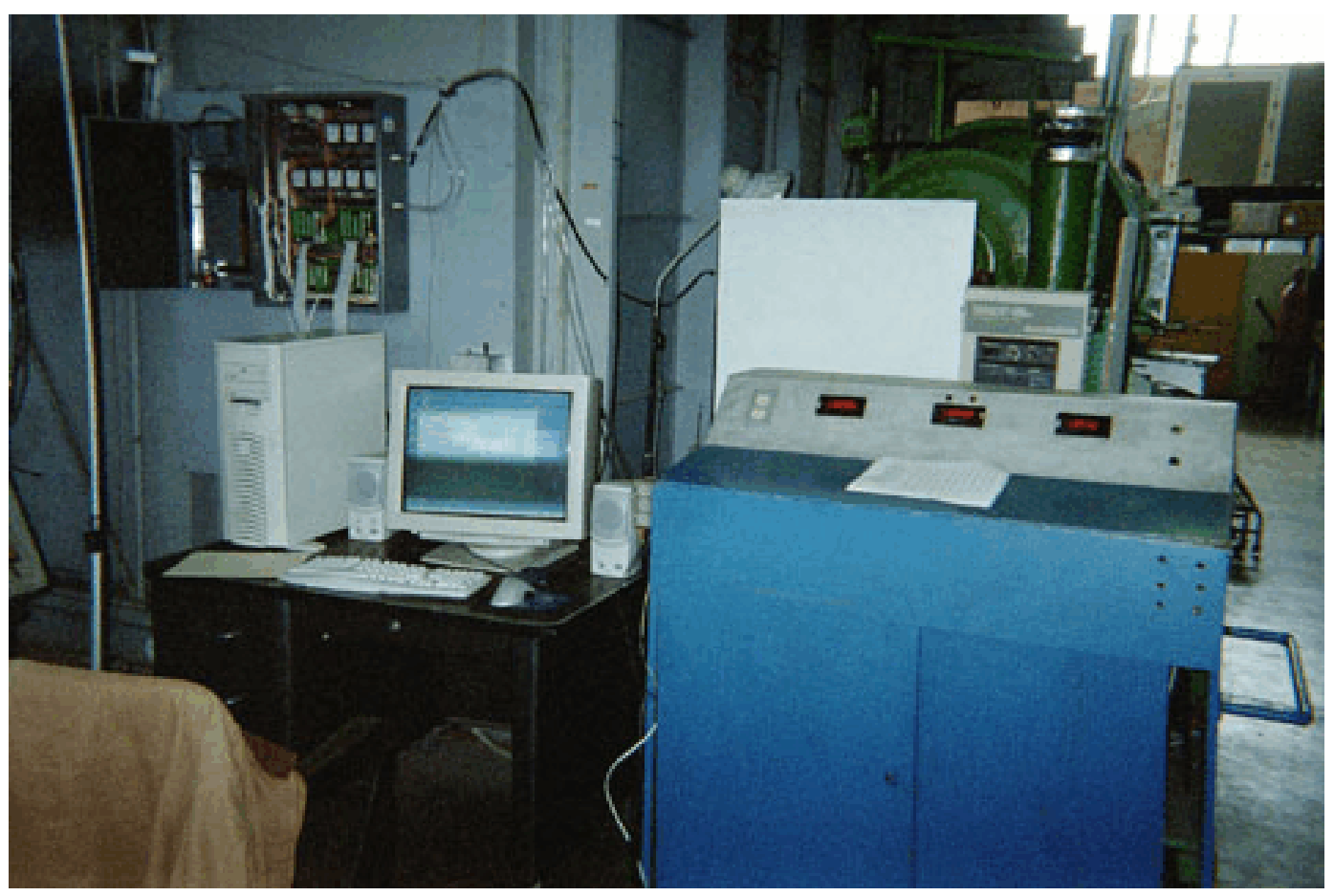

Figure 6 Data acquisition for airflow apparatus

See Appendix D for additional instrumentation and testing details. 


\subsection{RESULTS}

\subsection{Results of using AMCA 210 to Measure Airflow of Furnaces}

ESL measured airflow against various static pressures to determine if there are any problems with using the AMCA 210 test methods for measuring the airflow of furnaces, especially at $0.5 \mathrm{in}$. wg ESP, which is used as a reference point by manufacturers, for furnaces that also have a cooling coil. Figure 7 shows static-pressure-versus-airflow results for PSC, ECM 2.3, and ECM 4.0 motor types at high speed.

As expected, Figure 7 also shows less variation in airflow with changes in static pressure for the ECM motor blowers. Also as expected, as the ESP is decreased, the airflow increases for all of the blowers.

Figure 8 compares ESL test data with data published by the manufacturer in the product literature for static pressure versus airflow, at the highest airflow setting. Note that, for the case of the PSC motor, the tested airflow was up to about $40 \%$ greater than the manufacturer's reported airflow, whereas for the ECM 2.3 motor, the tested airflow was up to about $10 \%$ lower than what the manufacturer reported. Additional research is needed to explain the differences between the manufacturer's results and ESL's test results. A minor difference in test conditions was that the manufacturer's data indicated that a filter was included as part of the furnace; ESL did not include a filter as part of its testing. 


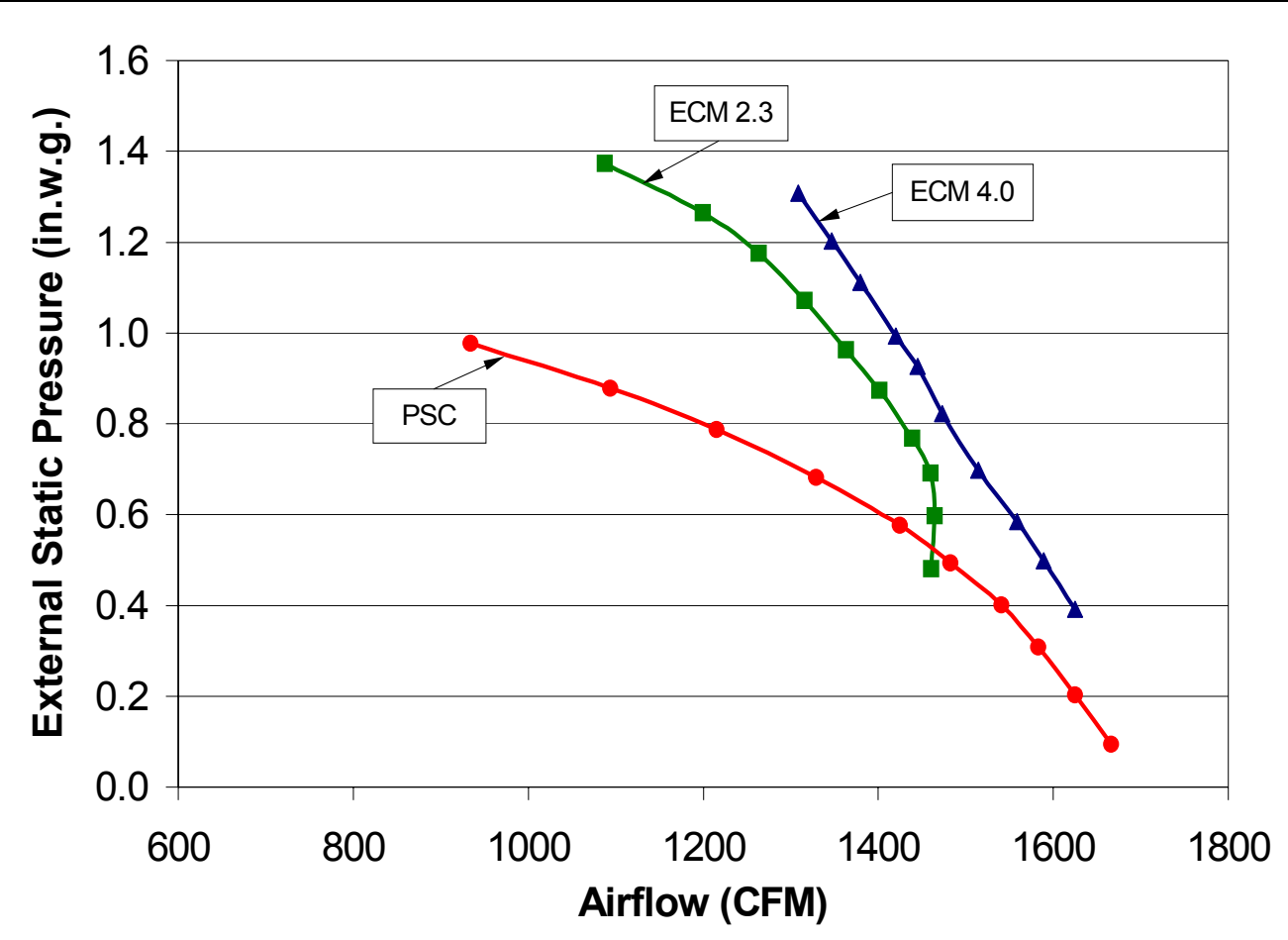

Figure 7 Airflow versus Static Pressure for Three Motor/Blower Combinations at Highest Speed

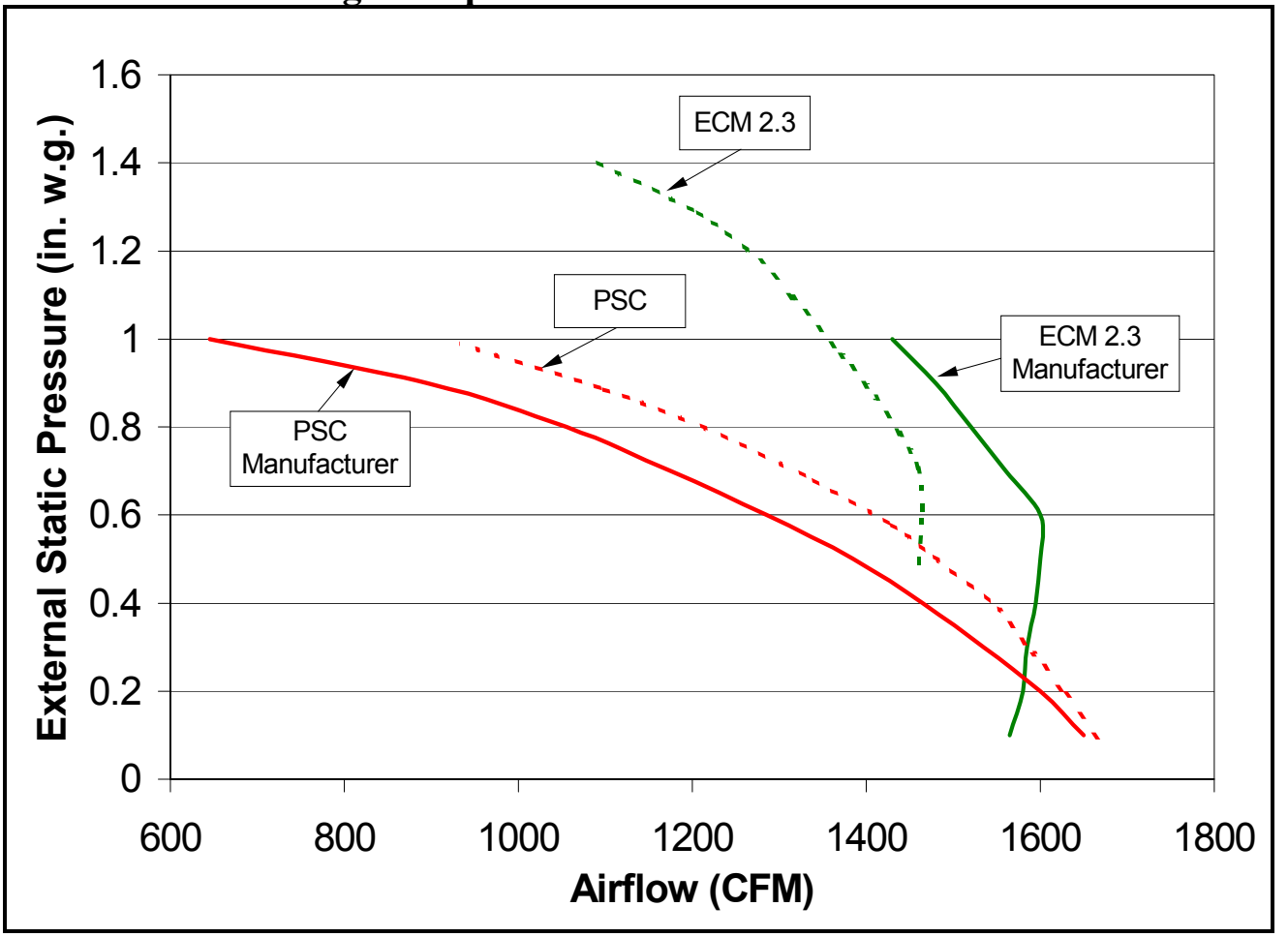

Figure 8 Comparison with Manufacturer's Reported Airflow Versus Static Pressure Data at the Highest Blower Speed 


\subsection{Airflow Measurement Issues}

While it was possible to measure airflow at $0.1 \mathrm{in.}$ wg for the PSC blower, $0.5 \mathrm{in.} \mathrm{wg}$ pressure was the lowest ESP at which ESL could obtain results for blowers with ECM motors. It is not clear why this was a problem, since manufacturer literature reports airflow measurements down to 0.1 in. wg. The ESL airflow testing with the ECM motors/blowers showed that, when the static pressure was decreased below about $0.5 \mathrm{in}$. wg, the blower speed would also decrease. If the ESP was further lowered, the blower would slow down to a stop until the rotation changed direction. This was an even greater problem when the blower was tested outside of the furnace.

The results clearly indicate that the AMCA 210 approach cannot be used for measuring the airflow of ECM motor/blower combinations at static pressure below about $0.5 \mathrm{in}$. wg and therefore there is a discrepancy between the ESL test results and the manufacturer reported data. Although these results reflect tests performed only at this facility, we concluded that the AMCA 210 test procedure can not be used for testing blowers with ECM motors, unless it were modified and further detailed instructions are given. It is possible that the manufacturer bypassed or adjusted the control algorithm to get data at the lower static pressures.

\section{Possible Remedies to Airflow Measurement problems with ECM motors.}

Discussions with General Electric (GE) provided additional insight into problems we had with testing. ${ }^{8}$ The ECM does not inherently regulate airflow, it has to be "taught" to do so. The ECM contains a microcomputer and a memory chip which the original equipment manufacturer (OEM) can choose to enable airflow regulation. GE's estimate is that greater than $95 \%$ of the ECM applications use constant airflow control. The airflow control is a full time, active control loop in the motor. It compensates for changes in ESP by measuring and controlling the speed and torque driving the blower wheel. Changes are corrected in seconds. When this airflow regulating system is in place in an active environment (where static pressure may change dynamically with airflow) there is a possibility to set up an unstable system. GE has never seen any way for this to happen in the real world, but it can happen in active airflow tests.

GE suggested some possible solutions to this problem. The stability issue is fundamentally caused by two blowers connected in series and each one is claiming to "own" the airflow. The ECM is programmed to do so, and the test setup blower does so "accidentally" because of where it operates on the CFM-ESP plane. To have a stable system, one of the two airflow regulators must yield. Every OEM that GE is aware of has been able to solve this problem by using a variable speed blower in the airflow tester. Secondly, the airflow restrictor nozzles should be opened as much as possible, particularly at the low ESP levels. The intent is to get rid of the turbulence caused by the restrictors. It appears the turbulence is sensed by the ECM as pressure modulation, which it then tries to compensate. GE believes this process will work well down to approximately 0.2 inches W.C. Below that, some have gone to actual static tests (without the external blower). Additionally, the ECM can be reprogrammed to operate in torque mode rather than airflow mode and the problem totally goes away. For agency work this is usually not acceptable because the system has been "altered". 
Additionally GE commented that the issue may be that the exhaust blower is not providing the regulation required to maintain stability in the test chamber. Problems may occur if the exhaust blower is constant speed controlled by a damper or the blower is controlled by a field weakening DC motor (soft speed control). The recommendation here is a variable speed blower. The other factor that may contribute to stability may be the size of the nozzle. ${ }^{9}$

A variable speed motor was used at ESL, nevertheless this points out problems that may occur at other testing facilities.

\subsection{Power Measurement Issues}

Data collected by ESL included both the power consumption [W] as well as the voltage $[\mathrm{V}]$ and current $[\mathrm{A}]$. Dividing the watts by the product of volts and amps, gives the true power factor. Doing this for ECM motor, the ESL test data showed power factors (PF) close to 1 and sometimes more than one. Something was amiss in the measurements as power factors of greater than 1 are not possible and the power factor reported by GE is approximately 0.6 at full load. For ECM motors, the current waveform is discontinuous, and contains harmonics and although the power input was measured upstream of the ECM motor controller, the power quality could still be affected.

GE provided further insight into power measurement issues regarding ECM motors. ${ }^{10}$ The GE ECM uses a diode rectified, capacitor-input filter. This technology is widely used in power electronic equipment. As such, the AC line current into the ECM is discontinuous and contains harmonic currents in addition to the fundamental $60 \mathrm{~Hz}$ component. It is mandatory that the line current (and/or watts ) be measured with a true-rms reading meter with a band width of at least $5 \mathrm{kHz}$. When the current is properly measured you will find that the PF for the ECM will run in the $55-60 \%$ range at full power. This PF is created by the higher frequency harmonic currents and is different than the so called "displacement" power factor for a standard PSC motor.

In addition GE suggested taking long averages when measuring power. ${ }^{11}$ The reason is that the ECM2.3 has energy storage components in it. These components take energy from the line when the voltage is high and use that energy when the voltage is low. The exchange of power could affect the measurements if the data is captured within one or a few cycles.

Investigation of the instrumentation used by ESL showed that the power transducer used (Ohio Semitronics, GW4-02E) while accurate and a true power measurement may not be the best choice of power meter for cases when there is a possibility of discontinuous voltage and current and with harmonic frequencies being present. ${ }^{12}$ According to Ohio Semitronics, for conditions where harmonic distortion is present (e.g., with the ECM motor), any watt transducer will handle the harmonics and provide an output proportional to true power, however, a true RMS measuring transducer is needed to measure the voltage and the current. Because the calculated power factor, is simply the watts divided by the product of the volts and amps, perhaps the values for 
the volts and amps were the source of error leading to an overly high power factor for the ECM.

Therefore, we conclude that these possible issues in testing furnace air-flow with blowers having an ECM motor (or perhaps other types of variable speed blowers) need to be researched and incorporated into a standard or at minimum a best practices guideline for conducting tests.

\subsection{Possible Energy Savings for Furnace Blowers}

As discussed in the previous paragraph, a caveat on power consumption must be given due to some possible inaccuracies in the power measurement. Although the power was measured with a true RMS meter on the mains side of the line feeding the ECM motor control, it is possible that some discontinuities in the power would still show up in the power entering the ECM motor. The power meter used may not account for all discontinuities or harmonics in the current and voltage and this may be the reason for the unrealistic power factors measured for the case of the ECM motors. With this caution the trends recorded should still be valid. There is no problem for any power data with the PSC motor.

Figure 9 shows that, at a given static pressure, the airflow per unit of power consumption (cfm per Watt) is higher for the ECM motors than for the PSC motor; this was expected. However, the results contradicted LBNL's expectations that the ECM 4.0 motor with the backward-inclined blower wheel blades would use less energy than the ECM 2.3 motor. Because the ECM 4.0 motor was installed in a standard blower scroll in an un-optimized prototype assembly, its performance may be less than could normally be achieved. One factor decreasing performance could be the larger prototype motor potentially blocking off more of the airflow at the blower inlet. Also, the outlet area of the prototype blower may have been restricted more than it needed to be for a backward-inclined blower wheel. Adjusting the furnace so the blower outlet area is not blocked off (as it needs to be for forward- inclined blowers) should increase the blower efficiency. All of the design parameters including the scroll size, scroll outlet area, and blower inlet area and mounting inside the furnace could be optimized before a furnace with this motor/blower was put into production. 


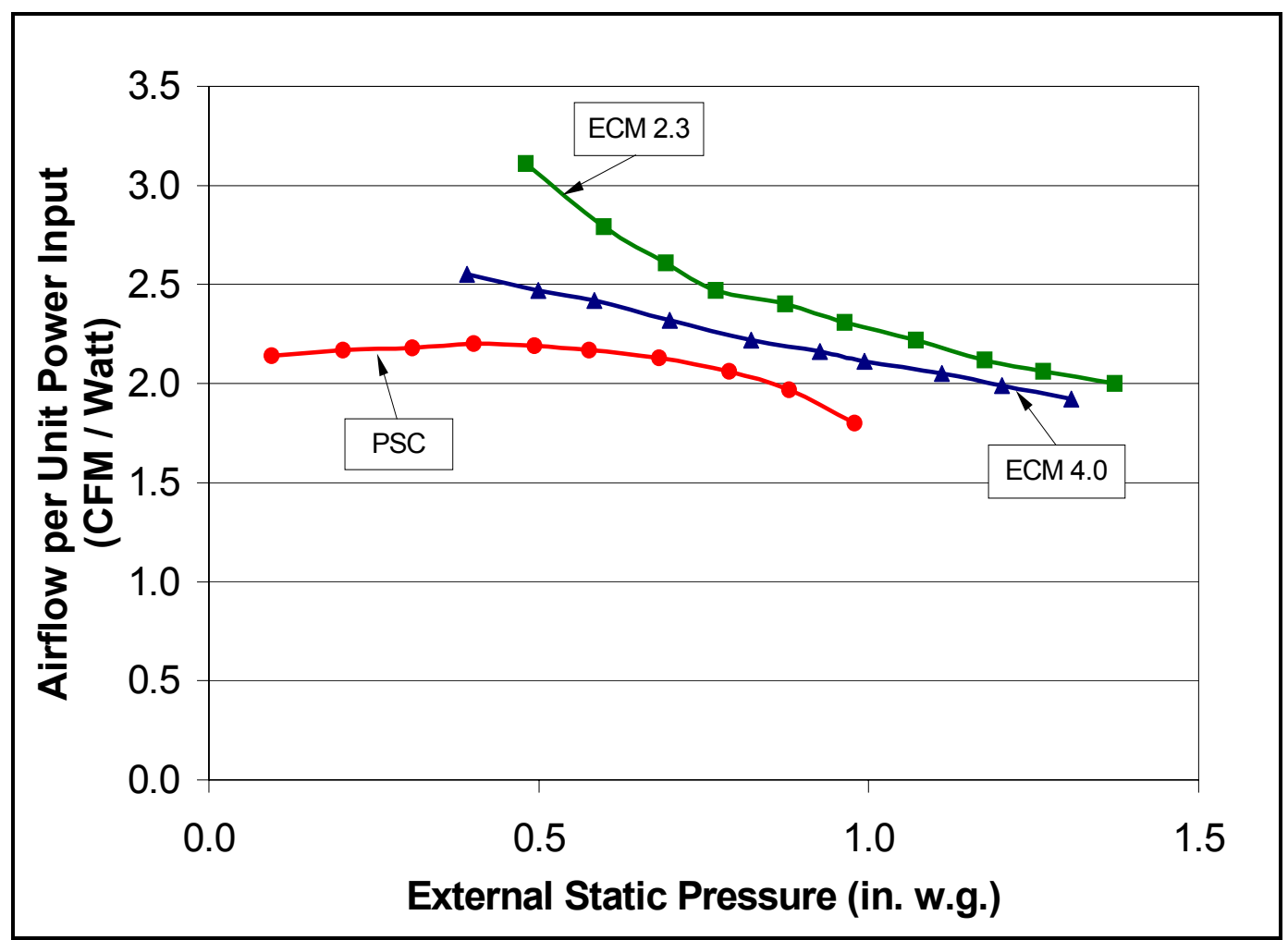

Figure 9

Airflow Efficiency versus Static Pressure at Highest Blower Speed Setting 


\subsection{Blower Speed and Airflow}

The ECM motor/blowers can be set to a specific airflow by controlling the blower speed. Figure 10 demonstrates blower speed versus airflow for all three tested blower/motor combinations. The speed and torque are controlled by an electronic control board. ECM blowers are designed to keep the airflow constant, regardless of the external static pressure. Note that the ECM 4.0 speed is much higher than the speed for ECM 2.3 and PSC motor/blowers. The higher speed is a requirement of using backward-inclined blades, instead of forward-curved blades, on a blower.

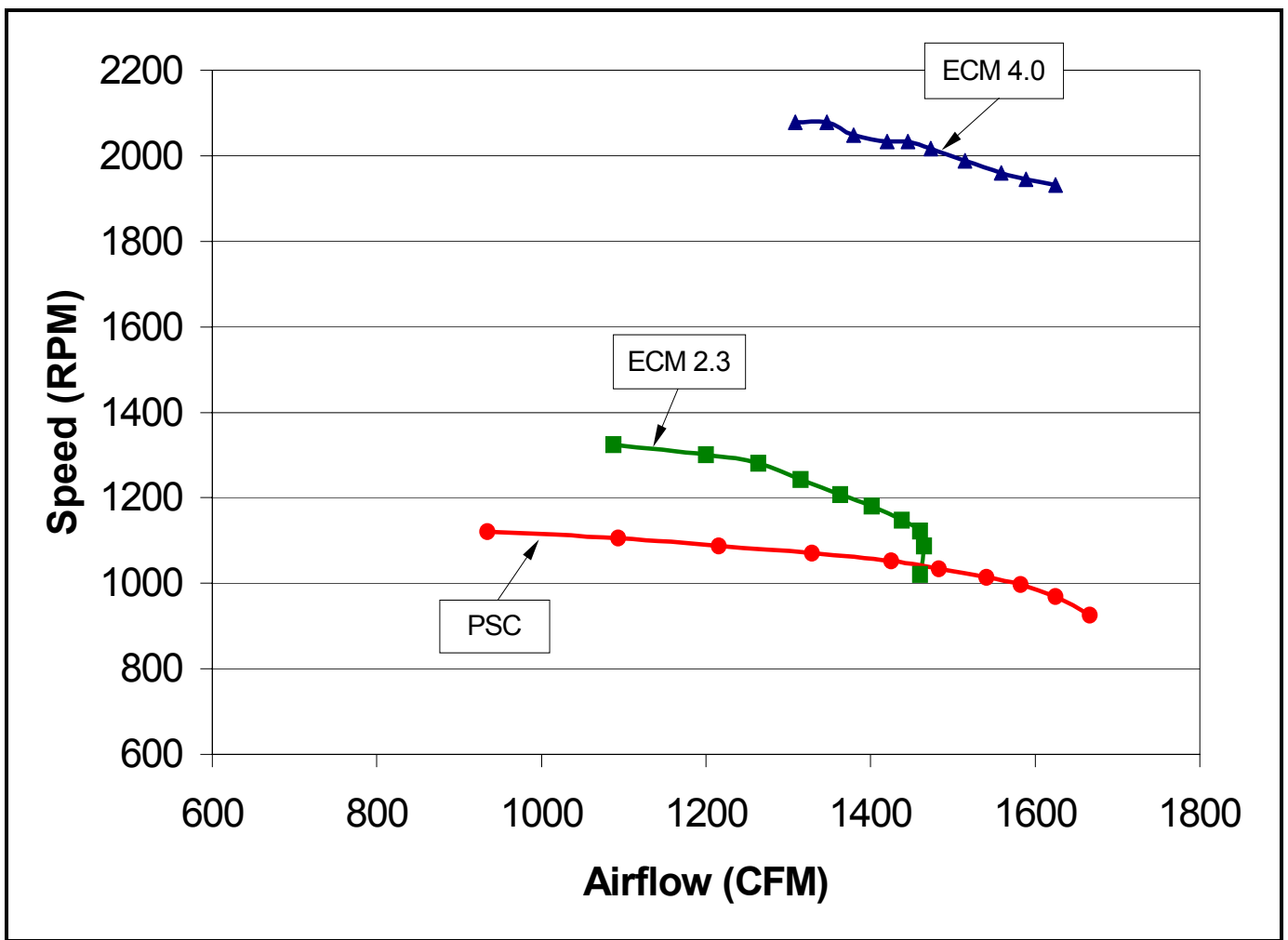

Figure $10 \quad$ Blower Speed vs. Airflow 


\subsection{Blower Curve Characteristics at Multiple Blower Speeds}

Figure 11 shows the fan curves for the PSC motor at three blower speeds. Note that the difference in airflow is greatest at the lower static pressures, i.e., the air flows at each speed converge at the higher static pressures and lower air flows.

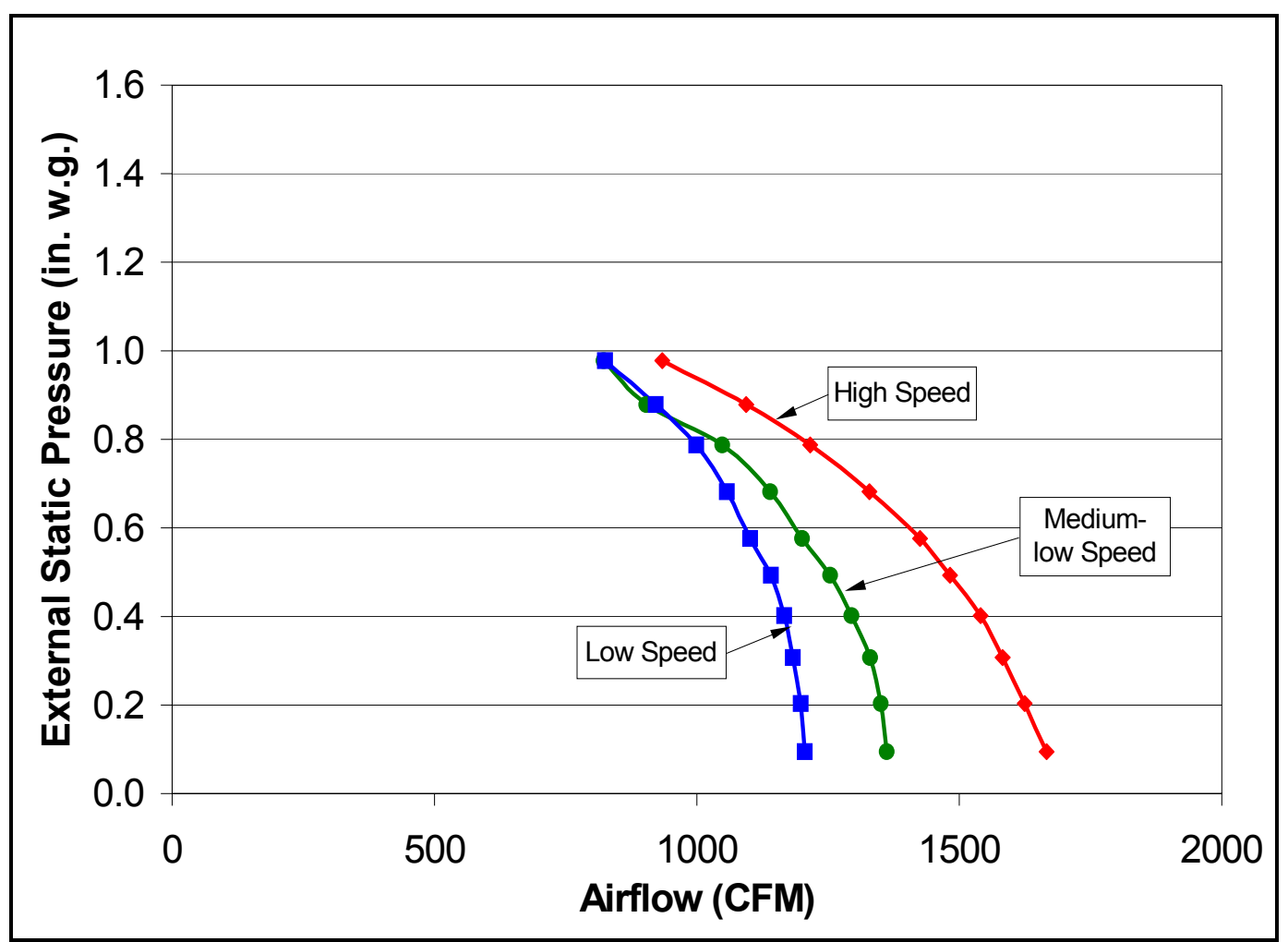

Figure 11 PSC airflow at three speeds 
Compared to Figure 11, Figure 12 shows that the fan curve is more vertical for the ECM 2.3 blower than for the PSC blower, especially for the low and medium-low blower speeds. This is one of the promoted characteristics of ECM motors. The stated advantage is that, because the airflow stays constant at the set point selected, regardless of the resistance of the ductwork, less balancing is needed.

Note that data could not be recorded at static pressures below 0.5 in. wg., even at the lowest selected blower speed.

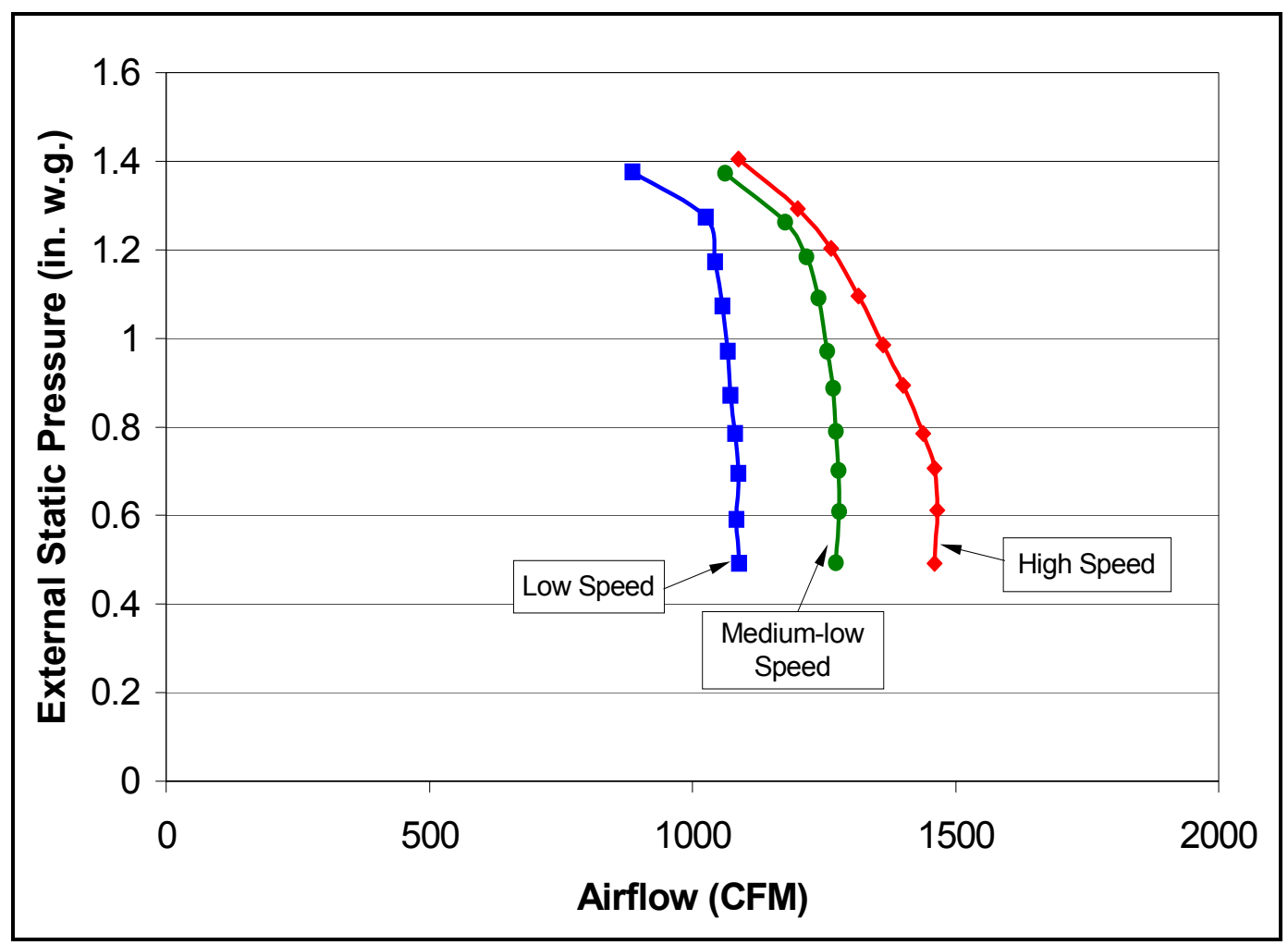

Figure 12 ECM 2.3 airflow at three speeds

\subsection{PSC Blower Curves with and without the Blower Installed in the Furnace}

Figure 14 compares the performance of a PSC, forward-curved blower, installed in the furnace and as a stand-alone blower. The right side of the curve is limited by the minimum ESP at which the test could be run. The left side of the curve was dictated by the total number of data points recorded. As expected, with the blower in the furnace, the blower ran at lower ESPs because the furnace itself contributed to the ESP across the blower. These data could be used to convert the stand-alone blower data to reflect their performance in a furnace. However, the 
absolute effects may be different for different furnaces.

For the stand-alone blower test, when the static pressure at the blower outlet was brought down to 0.7 inches wg., the speed (rpm) and the airflow (cfm) of the furnace blower started to decrease. If the static pressure at the blower outlet was lowered further, the blower speed decreased even more, until the blower wheel stopped and ran backwards.

Note that the two curves appear to converge at the lower air flows. This seems to verify the system-effect factor (the effect on blower performance by external restrictions), which is reduced at lower air flows.

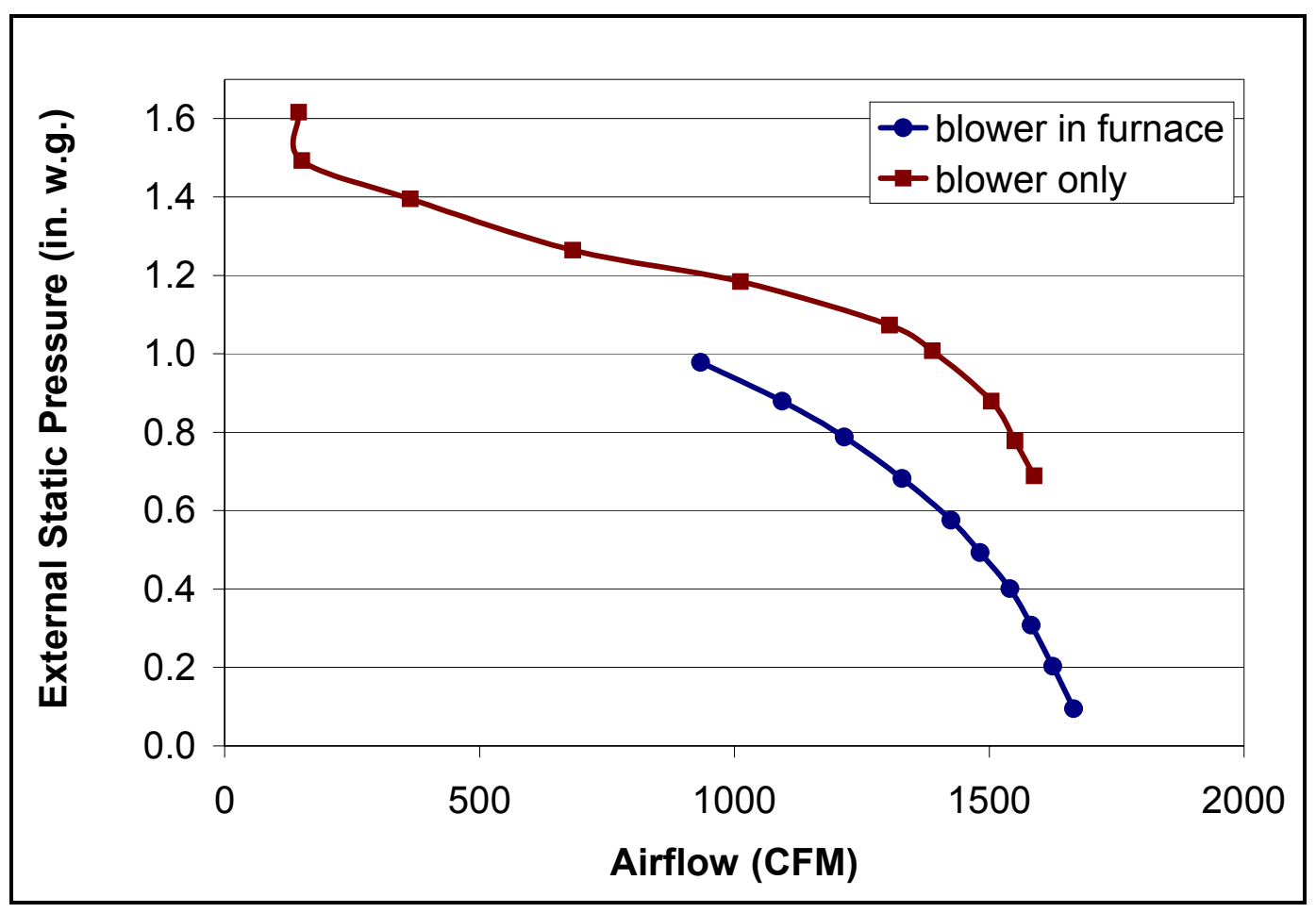

Figure 13 Comparison of PSC Blower with and without the Furnace 


\subsection{CONCLUSIONS}

\subsection{What Was Learned?}

The ESL tests for furnaces with ECM motors do not report measurements below $0.5 \mathrm{in}$. wg ESP. During the testing of the three furnace blower/motor combinations, as the static pressure was decreased, the ECM motors would slow down and start to rotate in the opposite direction. The test operator would attempt to set the static pressure on the supply side of the furnace under test by manually adjusting the speed of the air flow apparatus blower. However, in some cases a steady state condition could not be reached. In some cases, if the furnace was set at a lower-than-maximum blower speed, it was impossible to measure the airflow at static pressures as low as $0.5 \mathrm{in} . \mathrm{wg}$. This means that, for some furnace designs that utilize ECM motors, it may not be possible to test airflow at 0.5 in. wg static pressure with the current AMCA 210 protocol. Possible solutions to this issue should be examined.

Testing has determined that simply referencing the AMCA 210 test procedure to measure furnace blower airflow at $0.5 \mathrm{in}$. wg ESP is insufficient. LBNL found significant differences (at some static pressures) between the AMCA 210 test results and the manufacturer's reported data. For the PSC motor differences in air flow were up to $40 \%$ higher at the lower static pressures and for the ECM blower the air flow was up to $10 \%$ lower. These may be due to differences in the test setup or in the testing methods. One difference is that ESL tested the furnaces without the air filter in place, while manufacturers tested with the air filter in place. Measurement of airflow in furnaces using ECM motors requires further investigation. A test procedure needs to be developed such that a furnace can be tested without modification of its controls (other then testing at different speeds) and results would replicate airflow behavior in the field.

\subsection{What Needs to be Done to Resolve Issues?}

- Discuss test procedures with manufacturers and trade associations to determine the causes of variation between the ESL test results reported in manufacturers' literature;

- Work with AMCA and ASHRAE to develop a standard method to compare the performance and efficiency of competing furnace blower and motor technologies and their effect on furnace energy use and power consumption;

- $\quad$ Perform additional testing to resolve problems discovered in airflow and power measurements;

- Do additional testing to characterize energy usage of blowers for use in future energy consumption analysis in actual installations.

\subsection{Additional Directions for Further Research}

- $\quad$ Test other variable-speed motors with less-costly technologies;

- Analyze options for a test method for furnace circulating-air. Include the method of blower control in the test procedure. This step would include addressing the following 
questions:

- Which equations and procedures can be adapted from AMCA 210?

- What methods are the individual manufacturers using now?

- Which test parameters are important?

- What is the most appropriate method to test blowers with ECM motors?

- $\quad$ Measure the energy efficiencies of motors which could then be combined with blower curves to determine an overall blower/motor performance;

- Develop furnace test methods that realistically predict the electrical energy consumption of furnaces in the field.;

- $\quad$ Perform measurements to evaluate the impact of standby power consumption;

- Determine the transient effects of soft-start ECM motors on total furnace efficiency. Upon the start of the furnace the blower comes on at less than full speed and gradually increases its speed as the furnace heats up. This eliminates a blast of cold air at the start of a furnace on cycle.

\subsection{Benefits of Additional Research and Analysis}

- Manufacturers of efficient motor/blower combinations would benefit from a consistent method to compare and specify the efficiency or energy consumption of motor/blower in air handlers or furnaces.

- A common method to compare and specify the efficiency or energy consumption of motor/blowers in air handlers or blowers in furnaces, could provide a basis for giving credit for more efficient technologies

\subsection{ACKNOWLEDGMENTS}

The authors wish to thank Mohammed Khan (DOE). We also want to thank our reviewers, Ian Walker (LBNL) and James McMahon (LBNL). This work was supported by the Office of Building Research and Standards of the U.S. Department of Energy under Contract No. DE-AC03-76SF00098. 


\section{APPENDIX A: Collected data}

This appendix provides the raw and calculated data for each airflow test. It is organized in the following manner:

- Specifications identifying the furnace and blower as entered into the computer by the operator running the test

- Raw data as recorded by instrumentation

- Data corrected to standard density (calculations are automatically performed by the computer program)

- $\quad$ Key data is repeated in a summary table

- $\quad$ A plot of airflow (Cfm) versus fan pressure (in. wg.) and power (Watts) 


\section{PSC furnace at high speed}

Table A1 Test Information for PSC furnace at high speed

\begin{tabular}{|l|l||l|l|}
\hline Contract Number & $03-153 \mathrm{G}$ & Motor Volts & 120 \\
\hline Test Date & 5-Feb-03 & Wheel Diameter (in) & 10 \\
\hline Fan Model Number & 58CTA090---10114 & Outlet Diameter (in) & 18.4 \\
\hline Motor Model Number & Carrier & Outlet Area (sq ft) & 1.847 \\
\hline Number of Motors & 1 & Motor Notes & \\
\hline Number of Blades & 0 & Operator(s) & Michael \\
\hline Blade Material & Tluminum & \\
\hline
\end{tabular}

Table A2 Report for PSC furnace at high speed

\begin{tabular}{|c|c|c|c|c|c|c|c|c|c|c|c|}
\hline 1. & Test Point Number & 1 & 2 & 3 & 4 & 5 & 6 & 7 & 8 & 9 & 10 \\
\hline 2. & Fan Static Pressure & 0.096 & 0.205 & 0.311 & 0.405 & 0.498 & 0.581 & 0.689 & 0.796 & 0.889 & 0.988 \\
\hline 3. & $\begin{array}{l}\text { Nozzle Differential } \\
\text { Pressure }\end{array}$ & 1.120 & 1.066 & 1.012 & 0.960 & 0.889 & 0.822 & 0.716 & 0.600 & 0.487 & 0.356 \\
\hline 4. & Nozzle Key (ID) & 10 & 10 & 10 & 10 & 10 & 10 & 10 & 10 & 10 & 10 \\
\hline 5. & Nozzle Static Pressure & -1.040 & -0.879 & -0.716 & -0.564 & -0.397 & -0.248 & -0.035 & 0.198 & 0.402 & 0.631 \\
\hline 6. & $\begin{array}{l}\text { Barometric Pressure } \\
\text { (in } \mathrm{Hg} \text { ) }\end{array}$ & 30.05 & 30.06 & 30.06 & 30.05 & 30.05 & 30.05 & 30.05 & 30.04 & 30.05 & 30.05 \\
\hline 7. & \begin{tabular}{|l} 
Fan Inlet Dry Bulb \\
Temperature $(\mathrm{F})$ \\
\end{tabular} & 67.0 & 67.1 & 67.1 & 67.3 & 67.0 & 67.0 & 66.9 & 66.9 & 67.1 & 66.7 \\
\hline 8. & $\begin{array}{l}\text { Fan Inlet Wet Bulb } \\
\text { Temperature }(\mathrm{F})\end{array}$ & 54.6 & 54.7 & 54.6 & 54.8 & 54.7 & 54.7 & 54.6 & 54.5 & 54.7 & 54.7 \\
\hline 9. & $\begin{array}{l}\text { Chamber Dry Bulb } \\
\text { Temperature (F) }\end{array}$ & 65.1 & 65.2 & 65.1 & 65.2 & 65.3 & 65.3 & 65.2 & 65.1 & 64.9 & 65.1 \\
\hline 10. & Fan Motor Amperage & 7.63 & 7.15 & 6.97 & 6.73 & 6.44 & 6.25 & 6.10 & 5.80 & 5.52 & 5.33 \\
\hline 11. & Fan Motor Voltage & 120.3 & 121.3 & 122.3 & 121.2 & 120.8 & 121.5 & 121.4 & 122.6 & 122.7 & 122.6 \\
\hline 12. & Fan Motor Wattage & 784.1 & 752.0 & 730.3 & 704.0 & 682.5 & 660.5 & 630.2 & 594.1 & 560.1 & 524.1 \\
\hline 13. & Fan Motor RPM & 926 & 969 & 997 & 1014 & 1033 & 1052 & 1071 & 1088 & 1105 & 1120 \\
\hline 14. & Fan Motor \#2 RPM & 0 & 0 & 0 & 0 & 0 & 0 & 0 & 0 & 0 & 0 \\
\hline 15. & $\begin{array}{l}\text { Air Density at Fan } \\
\text { Inlet (lb/ft3) }\end{array}$ & 0.07537 & 0.07536 & 0.07537 & 0.07534 & 0.07536 & 0.07536 & 0.07537 & 0.07537 & 0.07535 & 0.07539 \\
\hline 16. & $\begin{array}{l}\text { Air Density at Fan } \\
\text { Outlet }(\mathrm{lb} / \mathrm{ft} 3)\end{array}$ & 0.07545 & 0.07547 & 0.07552 & 0.07553 & 0.07553 & 0.07556 & 0.07561 & 0.07566 & 0.07574 & 0.07573 \\
\hline 17. & $\begin{array}{l}\text { Air Density at Nozzle } \\
\text { Inlet }(\mathrm{lb} / \mathrm{ft} 3)\end{array}$ & 0.07566 & 0.07567 & 0.07571 & 0.07570 & 0.07570 & 0.07571 & 0.07574 & 0.07577 & 0.07583 & 0.07580 \\
\hline 18. & CFM at Nozzle Inlet & 1665.9 & 1624.9 & 1582.4 & 1541.0 & 1482.5 & 1425.0 & 1329.0 & 1215.5 & 1093.6 & 933.9 \\
\hline 19. & CFM at Fan Outlet & 1661.3 & 1620.6 & 1578.5 & 1537.4 & 1479.3 & 1422.1 & 1326.6 & 1213.7 & 1092.3 & 933.1 \\
\hline 20. & Fan Outlet Static Pres. & 0.096 & 0.205 & 0.311 & 0.405 & 0.498 & 0.581 & 0.689 & 0.796 & 0.889 & 0.988 \\
\hline 21. & $\begin{array}{l}\text { Fan Outlet Velocity } \\
\text { Pressure }\end{array}$ & 0.051 & 0.048 & 0.046 & 0.044 & 0.040 & 0.037 & 0.033 & 0.027 & 0.022 & 0.016 \\
\hline 22. & Fan Outlet Total Pres. & 0.147 & 0.253 & 0.357 & 0.449 & 0.538 & 0.618 & 0.722 & 0.823 & 0.911 & 1.004 \\
\hline \multicolumn{12}{|c|}{ Values Corrected for Standard Air Density } \\
\hline 23. & CFM at Nozzle Inlet & 1665.9 & 1624.9 & 1582.4 & 1541.0 & 1482.5 & 1425.0 & 1329.0 & 1215.5 & 1093.6 & 933.9 \\
\hline 24. & Static Pressure & 0.095 & 0.203 & 0.308 & 0.401 & 0.493 & 0.576 & 0.682 & 0.788 & 0.879 & 0.978 \\
\hline 25. & Velocity Pressure & 0.051 & 0.048 & 0.046 & 0.043 & 0.040 & 0.037 & 0.032 & 0.027 & 0.022 & 0.016 \\
\hline 26. & Total Pressure of Fan & 0.146 & 0.251 & 0.354 & 0.444 & 0.533 & 0.613 & 0.714 & 0.815 & 0.901 & 0.994 \\
\hline 27. & Motor Amperage & 7.56 & 7.08 & 6.90 & 6.67 & 6.38 & 6.19 & 6.04 & 5.74 & 5.46 & 5.27 \\
\hline 28. & Motor Wattage & 777.3 & 745.3 & 723.4 & 697.5 & 676.2 & 654.3 & 624.1 & 588.0 & 554.0 & 518.6 \\
\hline 29. & CFM per Watt & 2.14 & 2.17 & 2.18 & 2.20 & 2.19 & 2.17 & 2.13 & 2.06 & 1.97 & 1.80 \\
\hline
\end{tabular}

Note: All pressures are in inches of water unless otherwise stated. 
Table A3 Summary data for PSC furnace at high speed

\begin{tabular}{|c|c|c|c|c|c|c|c|c|c|c|}
\hline Point & 1 & 2 & 3 & 4 & 5 & 6 & 7 & 8 & 9 & 10 \\
\hline $\begin{array}{l}\text { Fan Static Pressure } \\
\text { (in/water) }\end{array}$ & 0.096 & 0.205 & 0.311 & 0.405 & 0.498 & 0.581 & 0.689 & 0.796 & 0.889 & 0.988 \\
\hline $\begin{array}{l}\text { Nozzle Diff. Pressure } \\
\text { (in/water) }\end{array}$ & 1.12 & 1.066 & 1.012 & 0.96 & 0.889 & 0.822 & 0.716 & $\overline{0.6}$ & 0.487 & 0.356 \\
\hline Nozzle Key (ID) & $3+4+5$ & $3+4+5$ & $3+4+5$ & $3+4+5$ & $3+4+5$ & $3+4+5$ & $3+4+5$ & $3+4+5$ & $3+4+5$ & $3+4+5$ \\
\hline $\begin{array}{l}\text { Nozzle Static Pressure } \\
\text { (in/H2O) }\end{array}$ & $\begin{array}{l}-1.04 \\
\end{array}$ & -0.879 & -0.716 & -0.564 & -0.397 & -0.248 & -0.035 & 0.198 & 0.402 & 0.631 \\
\hline $\begin{array}{l}\text { Fan Inlet Dry Bulb } \\
\text { Temp (F) }\end{array}$ & 66.994 & 67.129 & 67.114 & 67.281 & 67.03 & 67 & 66.891 & 66.895 & 67.072 & 66.732 \\
\hline $\begin{array}{l}\text { Fan Inlet Wet Bulb } \\
\text { Temp (F) }\end{array}$ & 54.603 & 54.668 & 54.629 & 54.754 & 54.706 & 54.733 & 54.606 & 54.522 & 54.652 & 54.691 \\
\hline $\begin{array}{l}\text { Chamber Dry Bulb } \\
\text { Temp (F) }\end{array}$ & 65.088 & 65.245 & 65.12 & 65.234 & 65.301 & 65.269 & 65.214 & 65.12 & 64.864 & 65.146 \\
\hline Barometric Pressure & 30.05 & 30.055 & 30.056 & 30.054 & 30.049 & 30.047 & 30.047 & 30.044 & 30.047 & 30.045 \\
\hline Fan Motor Volts & 120.344 & 121.284 & 122.301 & 121.191 & 120.792 & 121.545 & 121.36 & 122.646 & 122.694 & 122.639 \\
\hline Fan Motor Amps & 7.627 & 7.146 & 6.966 & 6.734 & 6.441 & 6.245 & 6.101 & 5.801 & 5.519 & 5.327 \\
\hline Fan Motor Watts & 784.088 & 751.984 & 730.255 & 704.01 & 682.526 & 660.492 & 630.249 & 594.055 & 560.089 & 524.078 \\
\hline Fan Motor RPM & 926 & 969 & 997 & $\overline{1014}$ & 1033 & 1052 & 1071 & 1088 & 1105 & 1120 \\
\hline
\end{tabular}

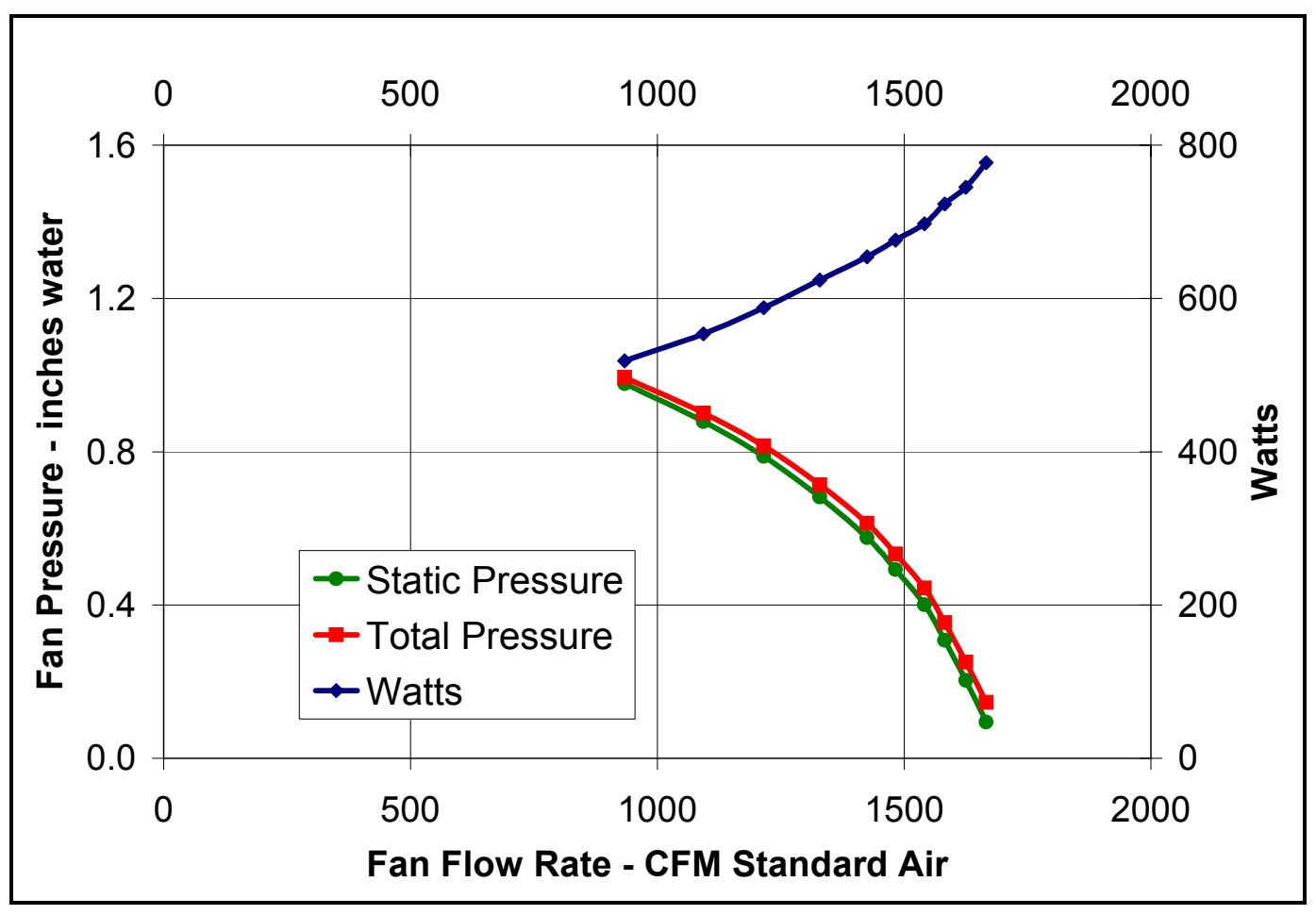

Figure 14 Airflow versus Pressure and Power for PSC furnace at high speed 


\section{PSC furnace at medium speed}

Table A4 Test Information for PSC furnace at medium speed

\begin{tabular}{|l|l||l|l|}
\hline Contract Number & $03-153 \mathrm{~F}$ & Motor Volts & 120 \\
\hline Test Date & February & Wheel Diameter (in) & 10 \\
\hline Fan Model Number & 58CTA090---10114 & Outlet Diameter (in) & 18.4 \\
\hline Motor Model Number & Carrier & Outlet Area (sq ft) & 1.847 \\
\hline Number of Motors & 1 & Motor Notes & \\
\hline Number of Blades & 0 & Operator(s) & Michael \\
\hline Blade Material & Aluminum & Test Notes: & Medium Speed \\
\hline
\end{tabular}

Table A5 Report for PSC furnace at medium speed

\begin{tabular}{|c|c|c|c|c|c|c|c|c|c|c|c|}
\hline 1. & Test Point Number & 1 & 2 & 3 & 4 & 5 & 6 & 7 & 8 & 9 & 10 \\
\hline 2. & Fan Static Pressure & 0.102 & 0.201 & 0.285 & 0.398 & 0.495 & 0.594 & 0.684 & 0.785 & 0.908 & 0.971 \\
\hline 3. & $\begin{array}{l}\text { Nozzle Differential } \\
\text { Pressure }\end{array}$ & 0.996 & 0.981 & 0.951 & 0.902 & 0.846 & 0.777 & 0.700 & 0.594 & 0.442 & 0.367 \\
\hline 4. & Nozzle Key (ID) & 9 & 9 & 9 & 9 & 9 & 9 & 9 & 9 & & 9 \\
\hline 5. & Nozzle Static Pressure & -0.891 & -0.781 & -0.674 & -0.513 & -0.360 & -0.191 & -0.026 & 0.196 & 0.466 & 0.601 \\
\hline 6. & $\begin{array}{l}\text { Barometric Pressure } \\
\text { (in } \mathrm{Hg} \text { ) }\end{array}$ & 30.08 & 30.08 & 30.07 & 30.07 & 30.07 & 30.07 & 30.07 & 30.07 & 30.07 & 30.07 \\
\hline 7. & \begin{tabular}{|l|} 
Fan Inlet Dry Bulb \\
Temperature $(\mathrm{F})$ \\
\end{tabular} & 66.9 & 67.0 & 66.8 & 67.3 & 67.2 & 67.0 & 66.7 & 66.9 & 66.9 & 67.1 \\
\hline 8. & $\begin{array}{l}\text { Fan Inlet Wet Bulb } \\
\text { Temperature }(\mathrm{F}) \\
\end{array}$ & 54.2 & 54.1 & 54.2 & 54.3 & 54.4 & 54.1 & 54.3 & 54.3 & 54.3 & 54.2 \\
\hline 9. & $\begin{array}{l}\text { Chamber Dry Bulb } \\
\text { Temperature }(\mathrm{F}) \\
\end{array}$ & 64.9 & 64.7 & 64.9 & 64.8 & 64.7 & 65.0 & 64.9 & 65.1 & 65.2 & 65.1 \\
\hline 10. & Fan Motor Amperage & 5.83 & 5.59 & 5.36 & 5.08 & 4.91 & 4.66 & 4.41 & 4.19 & 3.69 & 3.53 \\
\hline 11. & Fan Motor Voltage & 119.3 & 119.1 & 120.1 & 120.7 & 120.2 & 121.6 & 120.5 & 120.6 & 121.4 & 122.6 \\
\hline 12. & Fan Motor Wattage & 599.7 & 575.5 & 549.9 & 531.8 & 513.6 & 488.8 & 469.8 & 436.2 & 403.4 & 385.2 \\
\hline 13. & Fan Motor RPM & 789 & 840 & 876 & 925 & 960 & 992 & 1021 & 1049 & 1080 & 1095 \\
\hline 14. & Fan Motor \#2 RPM & 0 & 0 & 0 & 0 & 0 & 0 & 0 & 0 & 0 & 0 \\
\hline 15. & $\begin{array}{l}\text { Air Density at Fan } \\
\text { Inlet (lb/ft3) } \\
\end{array}$ & 0.07546 & 0.07545 & 0.07546 & 0.07539 & 0.07540 & 0.07544 & 0.07547 & 0.07544 & 0.07544 & 0.07542 \\
\hline 16. & \begin{tabular}{|l|} 
Air Density at Fan \\
Outlet $(\mathrm{lb} / \mathrm{ft} 3)$ \\
\end{tabular} & 0.07559 & 0.07564 & 0.07560 & 0.07566 & 0.07569 & 0.07570 & 0.07573 & 0.07574 & 0.07577 & 0.07581 \\
\hline 17. & $\begin{array}{l}\text { Air Density at Nozzle } \\
\text { Inlet }(\mathrm{lb} / \mathrm{ft} 3)\end{array}$ & 0.07577 & 0.07582 & 0.07578 & 0.07582 & 0.07585 & 0.07584 & 0.07586 & 0.07585 & 0.07586 & 0.07588 \\
\hline 18. & CFM at Nozzle Inlet & 1361.2 & 1350.5 & 1329.9 & 1294.5 & 1253.2 & 1200.7 & 1139.1 & 1048.6 & 903.4 & 822.4 \\
\hline 19. & CFM at Fan Outlet & 1357.9 & 1347.2 & 1326.8 & 1291.7 & 1250.6 & 1198.4 & 1137.1 & 1047.1 & 902.4 & 821.7 \\
\hline 20. & Fan Outlet Static Pres. & 0.102 & 0.201 & 0.285 & 0.398 & 0.495 & 0.594 & 0.684 & 0.785 & 0.908 & 0.971 \\
\hline 21. & \begin{tabular}{|l|} 
Fan Outlet Velocity \\
Pressure
\end{tabular} & 0.034 & 0.034 & 0.033 & 0.031 & 0.029 & 0.027 & 0.024 & 0.020 & 0.015 & 0.013 \\
\hline 22. & Fan Outlet Total Pres. & 0.136 & 0.235 & 0.318 & 0.429 & 0.524 & 0.621 & 0.708 & 0.805 & 0.923 & 0.984 \\
\hline \multicolumn{12}{|c|}{ Values Corrected for Standard Air Density } \\
\hline 23. & CFM at Nozzle Inlet & 1361.2 & 1350.5 & 1329.9 & 1294.5 & 1253.2 & 1200.7 & 1139.1 & 1048.6 & 903.4 & 822.4 \\
\hline 24. & Static Pressure & 0.101 & 0.199 & 0.282 & 0.394 & 0.489 & 0.587 & 0.676 & 0.776 & 0.898 & 0.960 \\
\hline 25. & Velocity Pressure & 0.034 & 0.033 & 0.032 & 0.031 & 0.029 & 0.026 & 0.024 & 0.020 & 0.015 & 0.012 \\
\hline 26. & Total Pressure of Fan & 0.135 & 0.232 & 0.314 & 0.424 & 0.518 & 0.614 & 0.700 & 0.796 & 0.913 & 0.972 \\
\hline 27. & Motor Amperage & 5.77 & 5.53 & 5.31 & 5.02 & 4.85 & 4.61 & 4.36 & 4.14 & 3.65 & 3.49 \\
\hline 28. & Motor Wattage & 593.5 & 569.2 & 544.2 & 526.0 & 507.8 & 483.4 & 464.5 & 431.3 & 398.9 & 380.7 \\
\hline 29.1 & CFM per Watt & 2.29 & 2.37 & 2.44 & 2.46 & 2.46 & 2.48 & 2.45 & 2.43 & 2.26 & 2.16 \\
\hline
\end{tabular}

Note: All pressures are in inches of water unless otherwise stated. 
Table A6 Summary Data for PSC furnace at medium speed

\begin{tabular}{|c|c|c|c|c|c|c|c|c|c|c|}
\hline Point & 1 & 2 & 3 & 4 & 5 & 6 & 7 & 8 & 9 & 10 \\
\hline $\begin{array}{l}\text { Fan Static Pressure } \\
\text { (in/water) }\end{array}$ & 0.102 & 0.201 & 0.285 & 0.398 & 0.495 & 0.594 & 0.684 & 0.785 & 0.908 & 0.971 \\
\hline $\begin{array}{l}\text { Nozzle Diff. Pressure } \\
\text { (in/water) }\end{array}$ & 0.996 & 0.981 & 0.951 & 0.902 & 0.846 & 0.777 & 0.7 & 0.594 & 0.442 & 0.367 \\
\hline Nozzle Key (ID) & $4+5$ & $4+5$ & $4+5$ & $\overline{4+5}$ & $4+5$ & $4+5$ & $4+5$ & $4+5$ & $4+5$ & $4+5$ \\
\hline $\begin{array}{l}\text { Nozzle Static Pressure } \\
(\mathrm{in} / \mathrm{H} 2 \mathrm{O})\end{array}$ & -0.891 & -0.781 & -0.674 & -0.513 & -0.36 & -0.191 & -0.026 & 0.196 & 0.466 & 0.601 \\
\hline $\begin{array}{l}\text { Fan Inlet Dry Bulb } \\
\text { Temp (F) }\end{array}$ & 66.893 & 67.004 & 66.817 & 67.306 & 67.18 & 67.015 & 66.714 & 66.913 & 66.902 & 67.078 \\
\hline $\begin{array}{l}\text { Fan Inlet Wet Bulb } \\
\text { Temp (F) }\end{array}$ & 54.24 & 54.065 & 54.153 & $\overline{54.331}$ & 54.401 & 54.092 & 54.309 & 54.32 & 54.339 & 54.239 \\
\hline $\begin{array}{l}\text { Chamber Dry Bulb } \\
\text { Temp (F) }\end{array}$ & 64.852 & 64.709 & 64.933 & 64.808 & 64.721 & 64.955 & 64.91 & 65.084 & 65.157 & 65.125 \\
\hline Barometric Pressure & 30.078 & 30.079 & 30.071 & 30.073 & 30.071 & 30.073 & 30.074 & 30.072 & 30.07 & 30.072 \\
\hline Fan Motor Volts & 119.268 & 119.055 & 120.097 & 120.667 & 120.165 & 121.644 & 120.513 & 120.609 & 121.408 & 122.557 \\
\hline Fan Motor Amps & 5.834 & 5.588 & 5.361 & $\overline{5.08}$ & 4.909 & 4.664 & 4.414 & 4.189 & 3.689 & 3.533 \\
\hline Fan Motor Watts & 599.67 & 575.47 & 549.866 & 531.83 & 513.55 & 488.8 & 469.788 & 436.188 & 403.442 & 385.162 \\
\hline Fan Motor RPM & 789 & 840 & 876 & $\overline{925}$ & 960 & 992 & 1021 & 1049 & 1080 & 1095 \\
\hline
\end{tabular}

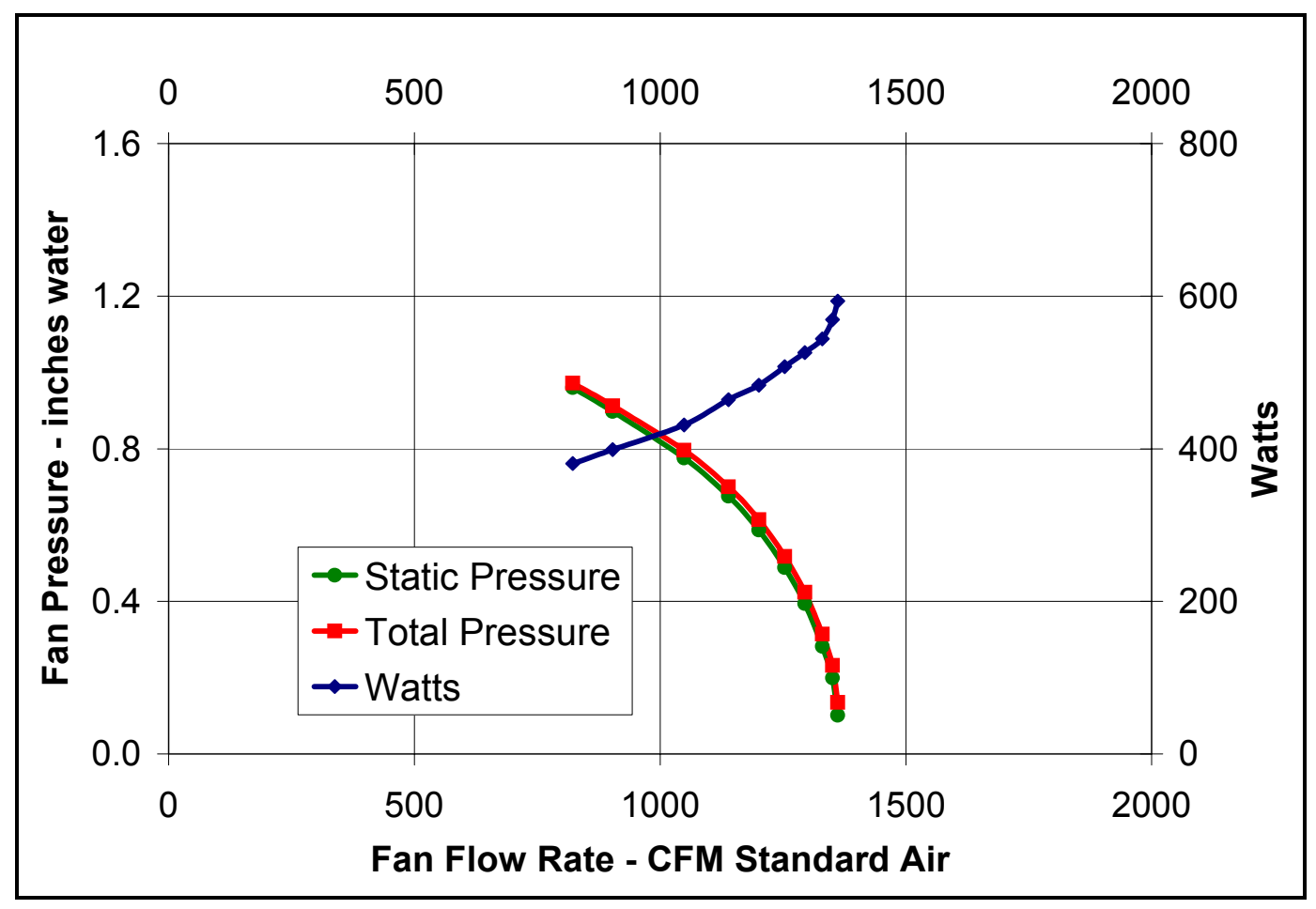

Figure 15 Airflow versus Pressure and Power 


\section{PSC furnace at low speed}

Table A7 Test Information for PSC furnace at low speed

\begin{tabular}{|l|l||l|l|}
\hline Contract Number & 03-154B & Motor Volts & 120 \\
\hline Test Date & 4-Feb-03 & Wheel Diameter (in) & 12 \\
\hline Fan Model Number & 8000TS & Outlet Diameter (in) & 18.4 \\
\hline Motor Model Number & Carrier Blower & Outlet Area (sq ft) & 1.847 \\
\hline Number of Motors & 1 & Motor Notes & \\
\hline Number of Blades & 0 & Operator(s) & Michael \\
\hline Blade Material & Aluminum & Test Notes: & \\
\hline
\end{tabular}

Table A8 Report for PSC furnace at low speed

\begin{tabular}{|c|c|c|c|c|c|c|c|c|c|c|c|}
\hline 1. & Test Point Number & 1 & 2 & 3 & 4 & 5 & 6 & 7 & 8 & 9 & 10 \\
\hline 2. & Fan Static Pressure & -0.005 & 0.092 & 0.214 & 0.308 & 0.386 & 0.512 & 0.603 & 0.697 & 0.805 & 0.899 \\
\hline 3. & $\begin{array}{l}\text { Nozzle Differential } \\
\text { Pressure }\end{array}$ & 1.539 & 1.520 & 1.481 & 1.439 & 1.380 & 1.286 & 1.185 & 1.060 & 0.903 & 0.724 \\
\hline 4. & Nozzle Key (ID) & 5 & 5 & 5 & 5 & 5 & 5 & 5 & 5 & 5 & 5 \\
\hline 5 . & Nozzle Static Pressure & -1.564 & -1.446 & -1.286 & -1.147 & -1.010 & -0.792 & -0.600 & -0.379 & -0.113 & 0.171 \\
\hline 6. & $\begin{array}{l}\text { Barometric Pressure } \\
\text { (in } \mathrm{Hg} \text { ) }\end{array}$ & 30.27 & 30.27 & 30.27 & 30.27 & 30.27 & 30.27 & 30.27 & 30.27 & 30.27 & 30.27 \\
\hline 7. & $\begin{array}{l}\text { Fan Inlet Dry Bulb } \\
\text { Temperature }(\mathrm{F})\end{array}$ & 67.1 & 67.2 & 67.7 & 67.4 & 67.6 & 67.9 & 67.8 & 67.4 & 68.1 & 67.6 \\
\hline 8 . & $\begin{array}{l}\text { Fan Inlet Wet Bulb } \\
\text { Temperature (F) }\end{array}$ & 54.0 & 53.8 & 54.1 & 53.8 & 54.1 & 53.8 & 54.1 & 53.7 & 54.2 & 54.0 \\
\hline 9 . & $\begin{array}{l}\text { Chamber Dry Bulb } \\
\text { Temperature (F) }\end{array}$ & 63.6 & 63.5 & 64.0 & 64.1 & 63.9 & 64.0 & 64.4 & 64.2 & 64.0 & 64.1 \\
\hline 10. & Fan Motor Amperage & 5.08 & 4.99 & 4.68 & 4.59 & 4.43 & 4.19 & 3.97 & 3.74 & 3.57 & 3.28 \\
\hline 11. & Fan Motor Voltage & 121.2 & 121.0 & 119.8 & 119.9 & 120.9 & 120.8 & 120.7 & 121.2 & 122.3 & 121.0 \\
\hline 12. & Fan Motor Wattage & 495.7 & 488.2 & 474.0 & 461.2 & 452.0 & 433.9 & 416.9 & 398.4 & 376.4 & 350.8 \\
\hline 13. & Fan Motor RPM & 668 & 700 & 782 & 823 & 869 & 915 & 953 & 989 & 1025 & 1055 \\
\hline 14. & Fan Motor \#2 RPM & 0 & 0 & 0 & 0 & 0 & 0 & 0 & 0 & 0 & 0 \\
\hline 15 . & $\begin{array}{l}\text { Air Density at Fan } \\
\text { Inlet (lb/ft3) }\end{array}$ & 0.07593 & 0.07592 & 0.07584 & 0.07588 & 0.07586 & 0.07583 & 0.07583 & 0.07589 & 0.07578 & 0.07585 \\
\hline 16. & $\begin{array}{l}\text { Air Density at Fan } \\
\text { Outlet (lb/ft } 3)\end{array}$ & 0.07614 & 0.07619 & 0.07613 & 0.07615 & 0.07621 & 0.07625 & 0.07621 & 0.07628 & 0.07635 & 0.07638 \\
\hline 17. & $\begin{array}{l}\text { Air Density at Nozzle } \\
\text { Inlet }(\mathrm{lb} / \mathrm{ft} 3)\end{array}$ & 0.07643 & 0.07647 & 0.07641 & 0.07642 & 0.07647 & 0.07649 & 0.07644 & 0.07648 & 0.07652 & 0.07652 \\
\hline 18. & CFM at Nozzle Inlet & 1205.7 & 1197.9 & 1182.8 & 1165.7 & 1141.1 & 1101.1 & 1057.1 & 999.2 & 921.5 & 824.5 \\
\hline 19. & CFM at Fan Outlet & 1201.1 & 1193.4 & 1178.5 & 1161.6 & 1137.2 & 1097.7 & 1054.0 & 996.6 & 919.4 & 823.0 \\
\hline 20. & Fan Outlet Static Pres. & -0.005 & 0.092 & 0.214 & 0.308 & 0.386 & 0.512 & 0.603 & 0.697 & 0.805 & 0.899 \\
\hline 21. & $\begin{array}{l}\text { Fan Outlet Velocity } \\
\text { Pressure }\end{array}$ & 0.027 & 0.027 & 0.026 & 0.025 & 0.024 & 0.022 & 0.021 & 0.019 & 0.016 & 0.013 \\
\hline 22. & Fan Outlet Total Pres. & 0.022 & 0.119 & 0.240 & 0.333 & 0.410 & 0.534 & 0.624 & 0.716 & 0.821 & 0.912 \\
\hline \multicolumn{12}{|c|}{ Values Corrected for Standard Air Density } \\
\hline 23. & CFM at Nozzle Inlet & 1205.7 & 1197.9 & 1182.8 & 1165.7 & 1141.1 & 1101.1 & 1057.1 & 999.2 & 921.5 & 824.5 \\
\hline 24. & Static Pressure & -0.005 & 0.090 & 0.210 & 0.302 & 0.379 & 0.502 & 0.592 & 0.684 & 0.789 & 0.881 \\
\hline 25. & Velocity Pressure & 0.026 & 0.026 & 0.025 & 0.025 & 0.024 & 0.022 & 0.020 & 0.018 & 0.015 & 0.012 \\
\hline 26. & Total Pressure of Fan & 0.021 & 0.116 & 0.235 & 0.327 & 0.402 & 0.524 & 0.612 & 0.702 & 0.805 & 0.894 \\
\hline 27. & Motor Amperage & 4.98 & 4.89 & 4.59 & 4.50 & 4.34 & 4.10 & 3.90 & 3.66 & 3.50 & 3.22 \\
\hline 28. & Motor Wattage & 486.4 & 478.8 & 465.3 & 452.7 & 443.3 & 425.5 & 409.0 & 390.7 & 368.9 & 343.9 \\
\hline 29. & CFM per Watt & 2.47 & 2.49 & 2.53 & 2.57 & 2.57 & 2.58 & 2.58 & 2.55 & 2.49 & 2.39 \\
\hline
\end{tabular}

Note: All pressures are in inches of water unless otherwise stated. 
Table A9 Summary Data for PSC furnace at low speed

\begin{tabular}{|c|c|c|c|c|c|c|c|c|c|c|}
\hline Point & 1 & 2 & 3 & 4 & 5 & 6 & 7 & 8 & 9 & 10 \\
\hline $\begin{array}{l}\text { Fan Static Pressure } \\
\text { (in/water) }\end{array}$ & -0.005 & 0.092 & 0.214 & 0.308 & 0.386 & 0.512 & 0.603 & 0.697 & 0.805 & 0.899 \\
\hline $\begin{array}{l}\text { Nozzle Diff. Pressure } \\
\text { (in/water) }\end{array}$ & 1.539 & 1.52 & 1.481 & 1.439 & 1.38 & 1.286 & 1.185 & 1.06 & 0.903 & 0.724 \\
\hline Nozzle Key (ID) & 5 & 5 & 5 & 5 & 5 & 5 & 5 & 5 & 5 & 5 \\
\hline $\begin{array}{l}\text { Nozzle Static Pressure } \\
(\mathrm{in} / \mathrm{H} 2 \mathrm{O})\end{array}$ & -1.564 & -1.446 & -1.286 & -1.147 & -1.01 & -0.792 & -0.6 & -0.379 & -0.113 & 0.171 \\
\hline $\begin{array}{l}\text { Fan Inlet Dry Bulb } \\
\text { Temp (F) }\end{array}$ & 67.082 & 67.155 & 67.718 & 67.43 & 67.59 & 67.879 & 67.75 & 67.398 & 68.091 & 67.572 \\
\hline $\begin{array}{l}\text { Fan Inlet Wet Bulb } \\
\text { Temp (F) }\end{array}$ & 53.971 & 53.752 & 54.083 & 53.842 & 54.07 & 53.837 & 54.056 & 53.699 & 54.245 & 54.044 \\
\hline $\begin{array}{l}\text { Chamber Dry Bulb } \\
\text { Temp (F) }\end{array}$ & 63.646 & 63.466 & 64.021 & 64.116 & 63.869 & 63.992 & 64.353 & 64.215 & 64.013 & 64.131 \\
\hline Barometric Pressure & 30.272 & 30.269 & 30.269 & 30.269 & 30.27 & 30.272 & 30.269 & 30.269 & 30.267 & 30.267 \\
\hline Fan Motor Volts & 121.193 & 121.001 & 119.847 & 119.948 & 120.905 & 120.781 & 120.735 & 121.248 & 122.289 & 120.957 \\
\hline Fan Motor Amps & 5.078 & 4.988 & 4.681 & 4.588 & 4.43 & 4.186 & 3.97 & 3.737 & 3.571 & 3.282 \\
\hline Fan Motor Watts & 495.703 & 488.228 & 474.041 & 461.226 & 451.992 & 433.892 & 416.858 & 398.384 & 376.36 & 350.837 \\
\hline Fan Motor RPM & 668 & 700 & 782 & $\overline{823}$ & 869 & 915 & 953 & $\overline{989}$ & 1025 & 1055 \\
\hline
\end{tabular}

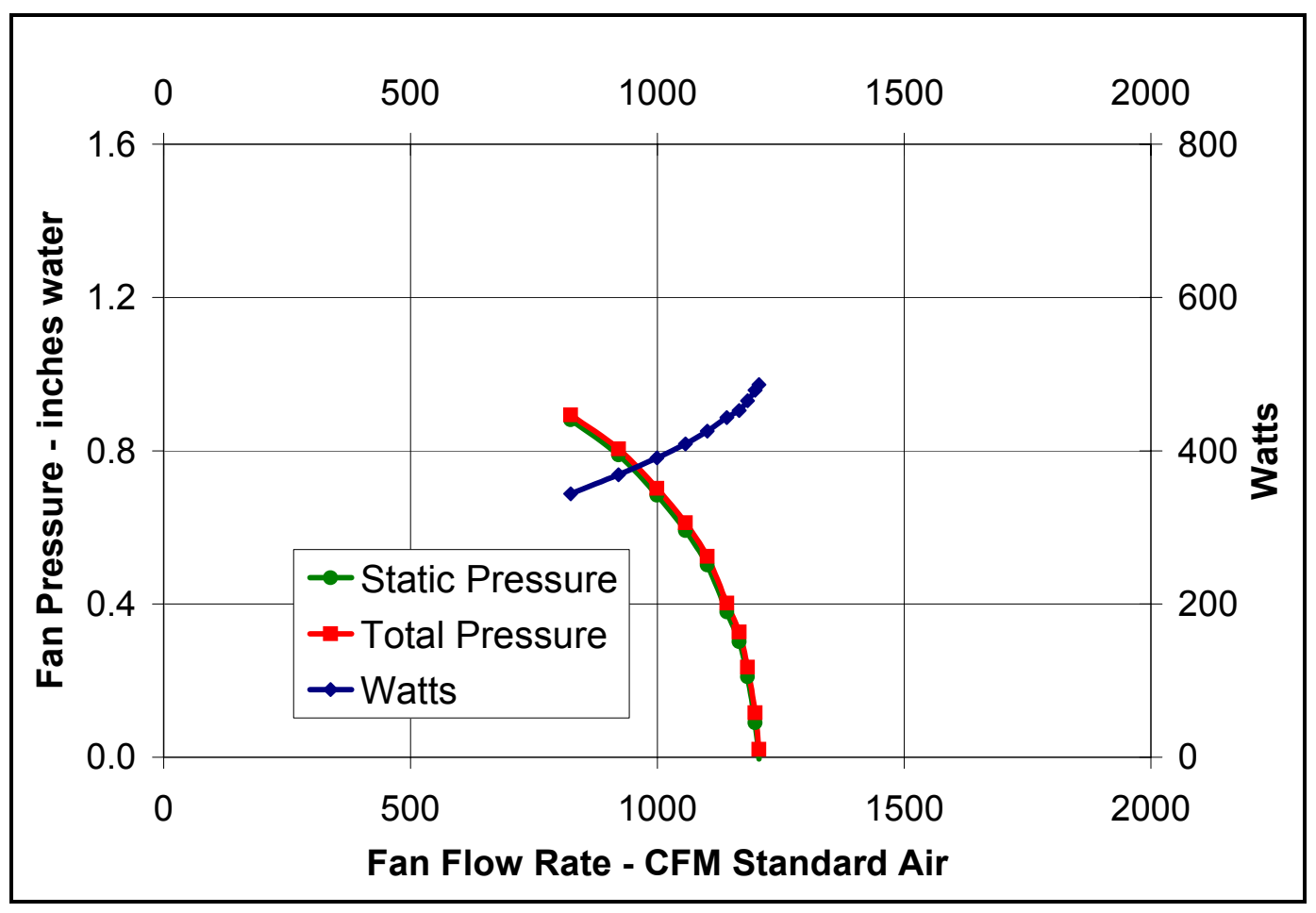

Figure 16 Airflow versus Pressure and Power for PSC furnace at low speed 
PSC blower only at high speed

Table A10 Test Information for PSC blower only at high speed

\begin{tabular}{|l|l||l|l|}
\hline Contract Number & 03-153J & Motor Volts & 120 \\
\hline Test Date & 6-Feb-03 & Wheel Diameter (in) & 10 \\
\hline Fan Model Number & 58CTA090---10114 & Outlet Diameter (in) & 10.86523 \\
\hline Motor Model Number & PSC & Outlet Area (sq ft) & 0.644 \\
\hline Number of Motors & 1 & Motor Notes & \\
\hline Number of Blades & 0 & Operator(s) & Michael \\
\hline Blade Material & Aluminum & Test Notes: & $\begin{array}{l}\text { Blower only, 10.75"x } \\
8.625 " \text { outlet, High Speed }\end{array}$ \\
\hline
\end{tabular}

Table A11 Report for PSC blower only at high speed

\begin{tabular}{|c|c|c|c|c|c|c|c|c|c|c|c|}
\hline 1. & Test Point Number & 1 & 2 & 3 & 4 & 5 & 6 & 7 & 8 & 9 & 10 \\
\hline 2. & Fan Static Pressure & 0.695 & 0.783 & 0.885 & 1.015 & 1.081 & 1.194 & 1.275 & 1.406 & 1.504 & 1.629 \\
\hline 3. & $\begin{array}{l}\text { Nozzle Differential } \\
\text { Pressure }\end{array}$ & 1.351 & 1.286 & 1.211 & 1.033 & $\overline{0.913}$ & $\overline{0.552}$ & 0.253 & 0.073 & 0.025 & $\overline{0.023}$ \\
\hline 4. & Nozzle Key (ID) & 9 & 9 & 9 & 9 & 9 & & & & & \\
\hline 5. & Nozzle Static Pressure & -0.668 & -0.506 & -0.330 & -0.036 & 0.169 & 0.630 & 1.000 & 1.312 & 1.467 & 1.608 \\
\hline 6. & $\begin{array}{l}\text { Barometric Pressure } \\
\text { (in } \mathrm{Hg} \text { ) }\end{array}$ & 30.00 & 30.00 & 30.00 & 30.00 & 30.00 & 30.00 & 30.00 & 30.00 & 30.00 & 30.00 \\
\hline 7. & \begin{tabular}{|l|} 
Fan Inlet Dry Bulb \\
Temperature $(F)$
\end{tabular} & 65.7 & 65.6 & 65.7 & 65.6 & 65.6 & 65.6 & 65.6 & 65.8 & 65.8 & 65.6 \\
\hline 8. & $\begin{array}{l}\text { Fan Inlet Wet Bulb } \\
\text { Temperature (F) }\end{array}$ & 55.6 & 59.2 & 59.2 & 59.4 & 59.4 & 59.4 & 59.2 & 59.4 & 59.5 & 55.5 \\
\hline 9. & $\begin{array}{l}\text { Chamber Dry Bulb } \\
\text { Temperature }(F)\end{array}$ & 64.6 & 65.1 & 65.1 & 65.2 & 65.1 & 64.9 & 65.0 & 65.4 & 65.9 & 66.3 \\
\hline 10. & Fan Motor Amperage & 7.54 & 7.08 & 6.71 & 6.17 & 5.93 & 5.28 & 5.05 & 5.11 & 5.15 & 5.13 \\
\hline 11. & Fan Motor Voltage & 118.1 & 121.0 & 120.0 & 120.7 & 121.4 & 123.3 & 123.6 & 124.9 & 124.9 & 124.6 \\
\hline 12. & Fan Motor Wattage & 777.3 & 738.9 & 712.5 & 662.2 & 625.9 & 542.2 & 463.0 & 412.3 & 399.3 & 397.9 \\
\hline 13. & Fan Motor RPM & 937 & 979 & 1007 & 1048 & 1069 & 1112 & 1141 & 1165 & 1169 & 1170 \\
\hline 14. & Fan Motor \#2 RPM & 0 & 0 & 0 & 0 & 0 & 0 & 0 & 0 & 0 & \\
\hline 15. & $\begin{array}{l}\text { Air Density at Fan } \\
\text { Inlet (lb/ft3) }\end{array}$ & 0.07539 & 0.07530 & 0.07528 & 0.07530 & 0.07530 & 0.07530 & 0.07531 & 0.07528 & 0.07527 & $\overline{0.07540}$ \\
\hline 16. & $\begin{array}{l}\text { Air Density at Fan } \\
\text { Outlet (lb/ft3) }\end{array}$ & 0.07541 & 0.07527 & 0.07530 & 0.07536 & 0.07541 & 0.07551 & 0.07558 & 0.07558 & 0.07553 & 0.07560 \\
\hline 17. & $\begin{array}{l}\text { Air Density at Nozzle } \\
\text { Inlet (lb/ft3) }\end{array}$ & 0.07566 & 0.07551 & 0.07553 & 0.07555 & 0.07557 & 0.07561 & 0.07563 & 0.07559 & 0.07554 & 0.07560 \\
\hline 18. & CFM at Nozzle Inlet & 88.2 & 50.8 & 04.4 & 88.5 & 04.6 & 2.2 & 682.8 & 364.2 & 151.3 & 145.0 \\
\hline 19. & CFM at Fan Outlet & 1582.9 & 1546.0 & 1500.0 & 1384.9 & 1301.7 & 1010.8 & 682.3 & $\overline{364.1}$ & 151.3 & 145.0 \\
\hline 20. & Fan Outlet Static Pres. & 0.695 & 0.783 & 0.885 & 1.015 & 1.081 & 1.194 & 1.275 & 1.406 & 1.504 & 1.629 \\
\hline 21. & Fan Outlet Vel. Pres. & 0.381 & 0.362 & 0.341 & 0.291 & 0.257 & 0.155 & 0.071 & 0.020 & 0.003 & 0.003 \\
\hline 22. & Fan Outlet Total Pres. & 1.076 & 1.145 & 1.226 & 1.306 & 1.338 & 1.349 & 1.346 & 1.426 & 1.507 & 1.632 \\
\hline \multicolumn{12}{|c|}{ Values Corrected for Standard Air Density } \\
\hline 23. & Jozzle Inlet & 1588.2 & 1550.8 & 1504.4 & 1388.5 & 1304.6 & 1012.2 & 682.8 & 364.2 & 151.3 & 145.0 \\
\hline 24. & Static P & 0.689 & 0.778 & 0.879 & 1.008 & 1.073 & 1.184 & 1.26 & 1.3 & 1.493 & 1.616 \\
\hline 25. & Velocity Pressure & 0.377 & 0.360 & 0.339 & 0.289 & 0.255 & 0.154 & 0.070 & 0.020 & 0.003 & 0.003 \\
\hline 26. & Total Pressure of Fan & 1.066 & 1.138 & 1.218 & 1.296 & 1.328 & 1.338 & 1.334 & 1.415 & 1.497 & 1.619 \\
\hline 27. & Motor Amperage & 7.48 & 7.03 & 6.67 & 6.13 & 5.89 & 5.24 & 5.01 & 5.07 & 5.11 & 5.09 \\
\hline 28. & Motor Wattage & 770.4 & 733.9 & 707.5 & 657.3 & 621.2 & 537.8 & 459.2 & 409.1 & 396.4 & 394.8 \\
\hline 29. & CFM per Watt & 2.05 & 2.11 & 2.12 & 2.11 & 2.10 & 1.88 & 1.49 & 0.89 & 0.38 & 0.37 \\
\hline
\end{tabular}

Note: All pressures are in inches of water unless otherwise stated. 
Table A12 Summary data for PSC blower only at high speed

\begin{tabular}{|c|c|c|c|c|c|c|c|c|c|c|}
\hline Point & 1 & 2 & 3 & 4 & 5 & 6 & 7 & 8 & 9 & 10 \\
\hline $\begin{array}{l}\text { Fan Static Pressure } \\
\text { (in/water) }\end{array}$ & 0.695 & 0.783 & 0.885 & 1.015 & 1.081 & 1.194 & 1.275 & 1.406 & 1.504 & 1.629 \\
\hline $\begin{array}{l}\text { Nozzle Diff. Pressure } \\
\text { (in/water) }\end{array}$ & 1.351 & 1.286 & 1.211 & 1.033 & 0.913 & 0.552 & 0.253 & 0.073 & 0.025 & 0.023 \\
\hline Nozzle Key (ID) & $4+5$ & $4+5$ & $4+5$ & $\overline{4+5}$ & $4+5$ & $4+5$ & $4+5$ & $\overline{4+5}$ & 5 & 5 \\
\hline $\begin{array}{l}\text { Nozzle Static Pressure } \\
(\mathrm{in} / \mathrm{H} 2 \mathrm{O})\end{array}$ & -0.668 & -0.506 & -0.33 & -0.036 & 0.169 & 0.63 & 1 & 1.312 & 1.467 & 1.608 \\
\hline $\begin{array}{l}\text { Fan Inlet Dry Bulb } \\
\text { Temp (F) }\end{array}$ & 65.65 & 65.593 & 65.748 & 65.641 & 65.604 & 65.585 & 65.614 & 65.783 & 65.776 & 65.61 \\
\hline $\begin{array}{l}\text { Fan Inlet Wet Bulb } \\
\text { Temp (F) }\end{array}$ & 55.642 & 59.191 & 59.197 & 59.36 & 59.375 & 59.399 & 59.227 & 59.356 & 59.526 & 55.518 \\
\hline $\begin{array}{l}\text { Chamber Dry Bulb } \\
\text { Temp (F) }\end{array}$ & 64.629 & 65.128 & 65.136 & 65.159 & 65.1 & 64.943 & 64.999 & 65.393 & 65.875 & 66.334 \\
\hline Barometric Pressure & 29.998 & 29.998 & 29.998 & 30.003 & 30.003 & 30.001 & 30.003 & 30.003 & 30.002 & 30.001 \\
\hline Fan Motor Volts & 118.137 & 120.962 & 120.016 & 120.699 & 121.381 & 123.251 & 123.573 & 124.883 & 124.873 & 124.622 \\
\hline Fan Motor Amps & 7.542 & 7.081 & 6.713 & 6.174 & 5.932 & 5.278 & 5.048 & 5.106 & 5.151 & 5.127 \\
\hline Fan Motor Watts & 777.252 & 738.892 & 712.494 & 662.17 & 625.916 & 542.206 & 463.043 & 412.292 & 399.261 & 397.949 \\
\hline Fan Motor RPM & 937 & 979 & 1007 & 1048 & 1069 & 1112 & 1141 & 1165 & 1169 & 1170 \\
\hline
\end{tabular}

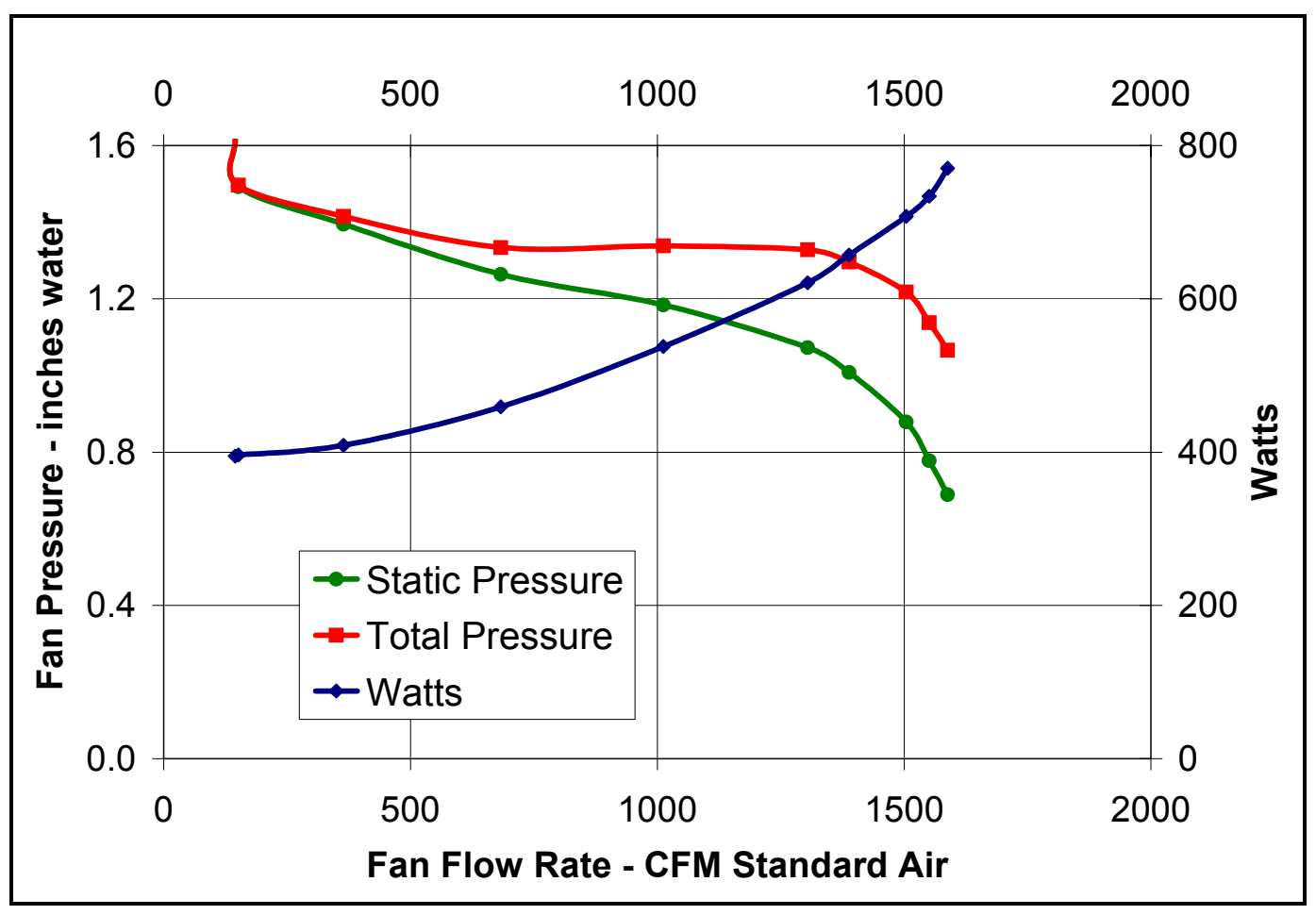

Figure 17 Airflow versus Pressure and Power for PSC blower only at high speed 


\section{PSC blower only at medium speed}

Table 13 Test Information for PSC blower only at medium speed

\begin{tabular}{|l|l||l|l|}
\hline Contract Number & 03-153J & Motor Volts & 120 \\
\hline Test Date & 6-Feb-03 & Wheel Diameter (in) & 10 \\
\hline Fan Model Number & 58CTA090---10114 & Outlet Diameter (in) & 10.86523 \\
\hline Motor Model Number & PSC & 0.644 \\
\hline Number of Motors & 1 & Outlet Area (sq ft) & \\
\hline Number of Blades & 0 & Motor Notes & Michael \\
\hline Blade Material & Operator(s) & $\begin{array}{l}\text { Blower only, 10.75" x 8.625" } \\
\text { outlet, Med-Low Speed }\end{array}$ \\
\hline
\end{tabular}

Table 14 Report for PSC blower only at medium speed

\begin{tabular}{|c|c|c|c|c|c|c|c|c|c|c|c|}
\hline 1. & Test Point Number & 1 & 2 & 3 & 4 & 5 & 6 & 7 & 8 & 9 & 10 \\
\hline 2. & Fan Static Pressure & 0.587 & 0.691 & 0.791 & 0.904 & 0.989 & 1.095 & 1.192 & 1.324 & 1.508 & 1.583 \\
\hline 3. & $\begin{array}{l}\text { Nozzle Differential } \\
\text { Pressure }\end{array}$ & 0.936 & 0.902 & 0.848 & 0.762 & 0.650 & 0.502 & 0.289 & 0.055 & 0.009 & 0.006 \\
\hline 4. & Nozzle Key (ID) & 9 & 9 & 9 & 9 & 9 & 9 & 9 & 9 & 9 & 9 \\
\hline 5. & Nozzle Static Pressure & -0.339 & -0.204 & -0.055 & 0.154 & 0.348 & 0.589 & 0.888 & 1.250 & 1.485 & 1.566 \\
\hline 6. & $\begin{array}{l}\text { Barometric Pressure } \\
\text { (in } \mathrm{Hg} \text { ) }\end{array}$ & 30.00 & 30.00 & 30.00 & 29.99 & 29.99 & 29.99 & 29.99 & 29.99 & 29.99 & 30.00 \\
\hline 7. & $\begin{array}{l}\text { Fan Inlet Dry Bulb } \\
\text { Temperature }(F)\end{array}$ & 67.3 & 67.7 & 68.1 & 68.0 & 67.8 & 67.7 & 67.4 & 67.8 & 68.1 & 67.9 \\
\hline 8. & $\begin{array}{l}\text { Fan Inlet Wet Bulb } \\
\text { Temperature }(F)\end{array}$ & 56.8 & 56.9 & 56.9 & 57.0 & 56.8 & 56.9 & 56.8 & 56.9 & 57.0 & 57.0 \\
\hline 9. & $\begin{array}{l}\text { Chamber Dry Bulb } \\
\text { Temperature }(\mathrm{F})\end{array}$ & 67.4 & 67.8 & 67.8 & 67.7 & 67.4 & 67.6 & 68.1 & 67.9 & 68.0 & 68.1 \\
\hline 10. & Fan Motor Amperage & 5.59 & 5.29 & 4.98 & 4.58 & 4.23 & 3.64 & 3.10 & 2.48 & 2.38 & 2.40 \\
\hline 11. & Fan Motor Voltage & 121.7 & 120.0 & 120.6 & 120.5 & 120.4 & 121.6 & 123.9 & 123.2 & 124.7 & 124.6 \\
\hline 12. & Fan Motor Wattage & 568.9 & 550.4 & 519.1 & 488.0 & 459.1 & 414.2 & 345.7 & 269.0 & 265.1 & 254.3 \\
\hline 13. & Fan Motor RPM & 851 & 898 & 937 & 986 & 1025 & 1070 & 1110 & 1149 & 1158 & 1159 \\
\hline 14. & Fan Motor \#2 RPM & 0 & 0 & 0 & 0 & 0 & 0 & 0 & 0 & 0 & 0 \\
\hline 15. & $\begin{array}{l}\text { Air Density at Fan } \\
\text { Inlet }(\mathrm{lb} / \mathrm{ft} 3)\end{array}$ & 0.07514 & 0.07507 & 0.07503 & 0.07503 & 0.07506 & 0.07507 & 0.07511 & 0.07506 & 0.07502 & 0.07506 \\
\hline 16. & $\begin{array}{l}\text { Air Density at Fan } \\
\text { Outlet }(\mathrm{lb} / \mathrm{ft} 3)\end{array}$ & 0.07506 & 0.07503 & 0.07505 & 0.07509 & 0.07518 & 0.07519 & 0.07518 & 0.07528 & 0.07531 & 0.07531 \\
\hline 17. & $\begin{array}{l}\text { Air Density at Nozzle } \\
\text { Inlet }(\mathrm{lb} / \mathrm{ft} 3)\end{array}$ & 0.07523 & 0.07519 & 0.07521 & 0.07523 & 0.07529 & 0.07528 & 0.07524 & 0.07529 & 0.07531 & 0.07532 \\
\hline 18. & CFM at Nozzle Inlet & 1324.0 & 1299.9 & 1260.0 & 1193.7 & 1101.3 & 966.9 & 732.0 & 316.1 & 125.9 & 102.4 \\
\hline 19. & CFM at Fan Outlet & 1321.0 & 1297.0 & 1257.4 & 1191.5 & 1099.6 & 965.7 & 731.5 & 316.1 & 125.9 & 102.4 \\
\hline 20. & Fan Outlet Static Pres. & 0.587 & 0.691 & 0.791 & 0.904 & 0.989 & 1.095 & 1.192 & 1.324 & 1.508 & 1.583 \\
\hline 21. & Fan Outlet Vel. Pres. & 0.264 & 0.254 & 0.239 & 0.214 & 0.183 & 0.141 & 0.081 & 0.015 & 0.002 & 0.002 \\
\hline 22. & Fan Outlet Total Pres. & 0.851 & 0.945 & 1.030 & 1.118 & 1.172 & 1.236 & 1.273 & 1.339 & 1.510 & 1.585 \\
\hline \multicolumn{12}{|c|}{ Values Corrected for Standard Air Density } \\
\hline 23. & CFM at Nozzle Inlet & 1324.0 & 1299.9 & 1260.0 & 1193.7 & 1101.3 & 966.9 & 732.0 & 316.1 & 125.9 & 102.4 \\
\hline 24. & Static Pressure & 0.585 & 0.689 & 0.789 & 0.901 & 0.985 & 1.091 & 1.188 & 1.319 & 1.502 & 1.576 \\
\hline 25. & Velocity Pressure & 0.263 & 0.253 & 0.238 & 0.214 & 0.182 & 0.140 & 0.081 & 0.015 & 0.002 & 0.002 \\
\hline 26. & Total Pressure of Fan & 0.848 & 0.943 & 1.027 & 1.115 & 1.167 & 1.231 & 1.269 & 1.334 & 1.504 & 1.578 \\
\hline 27. & Motor Amperage & 5.57 & 5.28 & 4.96 & 4.57 & 4.21 & 3.62 & 3.09 & 2.47 & 2.37 & 2.39 \\
\hline 28. & Motor Wattage & 567.2 & 549.1 & 517.7 & 486.5 & 457.3 & 412.6 & 344.6 & 267.9 & 264.0 & 253.2 \\
\hline 29. & CFM per Watt & 2.33 & 2.36 & 2.43 & 2.45 & 2.40 & 2.34 & 2.12 & 1.18 & 0.48 & 0.40 \\
\hline
\end{tabular}

Note: All pressures are in inches of water unless otherwise stated. 
Table 15 Summary data for PSC blower only at medium speed

\begin{tabular}{|c|c|c|c|c|c|c|c|c|c|c|}
\hline Point & 1 & 2 & 3 & 4 & 5 & 6 & 7 & 8 & 9 & 10 \\
\hline $\begin{array}{l}\text { Fan Static Pressure } \\
\text { (in/water) }\end{array}$ & 0.587 & 0.691 & 0.791 & 0.904 & 0.989 & 1.095 & 1.192 & 1.324 & 1.508 & 1.583 \\
\hline $\begin{array}{l}\text { Nozzle Diff. Pressure } \\
\text { (in/water) }\end{array}$ & 0.936 & 0.902 & 0.848 & 0.762 & 0.65 & 0.502 & 0.289 & 0.055 & 0.009 & 0.006 \\
\hline Nozzle Key (ID) & $4+5$ & $4+5$ & $4+5$ & $\overline{4+5}$ & $4+5$ & $4+5$ & $4+5$ & $4+5$ & $4+5$ & $4+5$ \\
\hline $\begin{array}{l}\text { Nozzle Static Pressure } \\
\text { (in/H2O) }\end{array}$ & -0.339 & -0.204 & -0.055 & 0.154 & 0.348 & 0.589 & 0.888 & 1.25 & 1.485 & 1.566 \\
\hline $\begin{array}{l}\text { Fan Inlet Dry Bulb } \\
\text { Temp (F) }\end{array}$ & 67.307 & 67.744 & 68.063 & 67.998 & 67.776 & 67.682 & 67.408 & 67.817 & 68.052 & 67.866 \\
\hline $\begin{array}{l}\text { Fan Inlet Wet Bulb } \\
\text { Temp (F) }\end{array}$ & 56.828 & 56.928 & 56.91 & $\overline{56.998}$ & 56.809 & 56.876 & 56.818 & 56.891 & 57.024 & 57.004 \\
\hline $\begin{array}{l}\text { Chamber Dry Bulb } \\
\text { Temp (F) }\end{array}$ & 67.446 & 67.793 & 67.843 & 67.745 & 67.435 & 67.611 & 68.086 & 67.88 & 67.954 & 68.093 \\
\hline Barometric Pressure & 30 & 29.996 & 29.996 & 29.993 & 29.994 & 29.992 & 29.994 & 29.994 & 29.994 & 29.998 \\
\hline Fan Motor Volts & 121.678 & 120.012 & 120.554 & 120.481 & 120.353 & 121.582 & 123.88 & 123.232 & 124.677 & 124.567 \\
\hline Fan Motor Amps & 5.586 & 5.292 & 4.977 & 4.582 & 4.229 & 3.635 & 3.098 & 2.481 & 2.38 & 2.403 \\
\hline Fan Motor Watts & 568.909 & 550.446 & 519.135 & 487.976 & 459.137 & 414.154 & 345.673 & 268.951 & 265.076 & 254.272 \\
\hline Fan Motor RPM & 851 & 898 & 937 & 986 & 1025 & 1070 & 1110 & 1149 & 1158 & 1159 \\
\hline
\end{tabular}

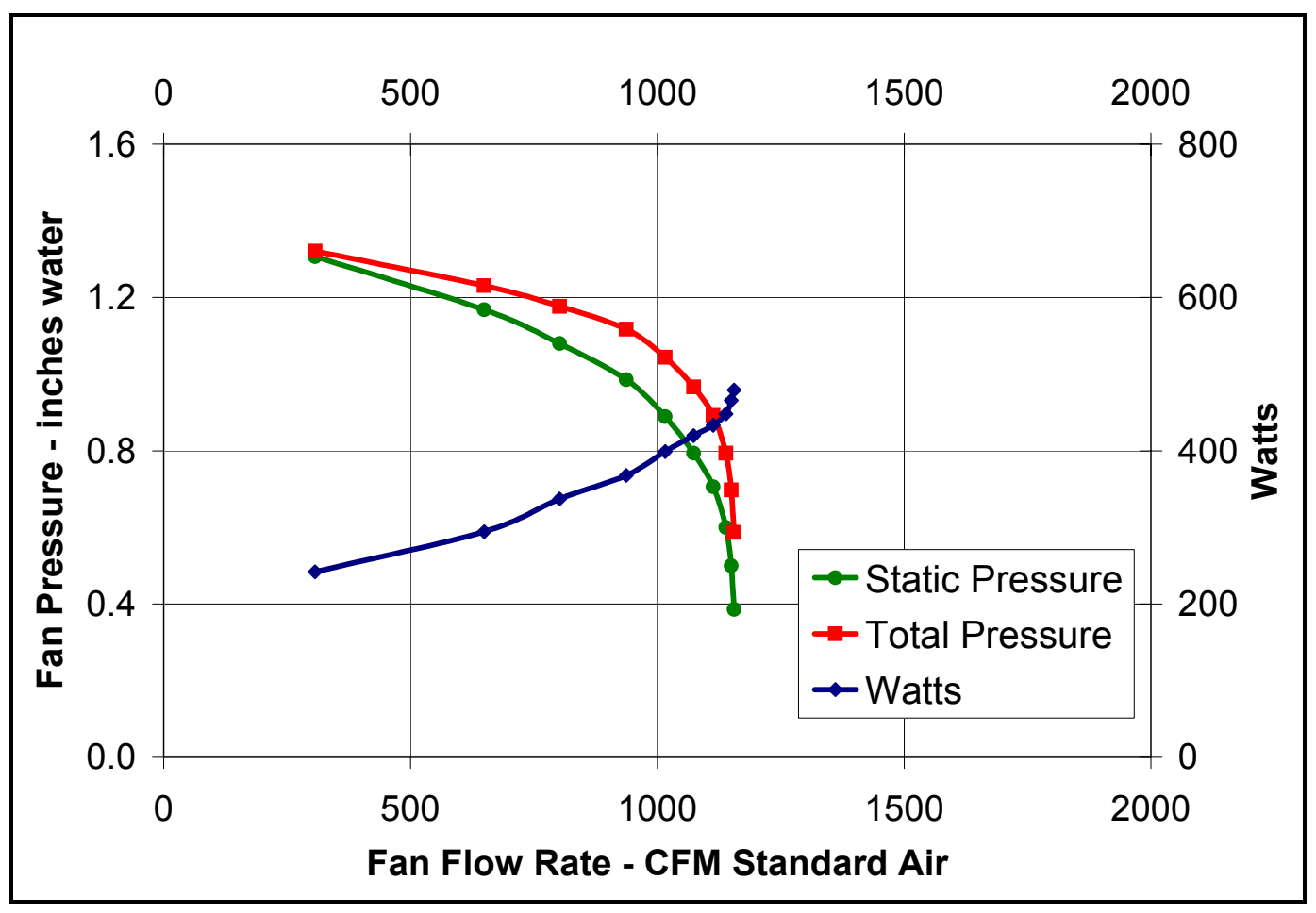

Figure 18 Airflow versus Pressure and Power for PSC blower only at medium speed 


\section{PSC blower only at low speed}

Table A16 Test Information for PSC blower only at low speed

\begin{tabular}{|l|l||l|l|}
\hline Contract Number & 03-153J & Motor Volts & 120 \\
\hline Test Date & 6-Feb-03 & Wheel Diameter (in) & 10 \\
\hline Fan Model Number & 58CTA090--10114 & Outlet Diameter (in) & 10.86523 \\
\hline Motor Model Number & PSC & Outlet Area (sq ft) & 0.644 \\
\hline Number of Motors & 1 & Motor Notes & \\
\hline Number of Blades & 0 & Operator(s) & Michael \\
\hline Blade Material & Aluminum & Test Notes: & $\begin{array}{l}\text { Blower only, 10.75" } \mathrm{x} \\
8.625^{\prime \prime} \text { outlet, Low Speed }\end{array}$ \\
\hline
\end{tabular}

Table A17 Report for PSC blower only at low speed

\begin{tabular}{|c|c|c|c|c|c|c|c|c|c|c|c|}
\hline 1. & Test Point Number & $\mathbf{1}$ & 2 & 3 & 4 & 5 & 6 & 7 & 8 & 9 & 10 \\
\hline 2. & Fan Static Pressure & 0.389 & 0.503 & 0.604 & 0.711 & 0.800 & 0.897 & 0.994 & 1.090 & 1.178 & 1.318 \\
\hline 3. & $\begin{array}{l}\text { Nozzle Differential } \\
\text { Pressure }\end{array}$ & 0.717 & 0.710 & 0.697 & 0.666 & 0.620 & 0.556 & 0.474 & 0.348 & 0.229 & 0.052 \\
\hline 4. & Nozzle Key (ID) & 9 & 9 & 9 & 9 & 9 & 9 & 9 & 9 & 9 & 9 \\
\hline 5 . & Nozzle Static Pressure & -0.327 & -0.206 & -0.093 & 0.055 & 0.189 & 0.347 & 0.520 & 0.728 & 0.933 & 1.245 \\
\hline 6. & $\begin{array}{l}\text { Barometric Pressure } \\
\text { (in } \mathrm{Hg} \text { ) }\end{array}$ & 29.99 & 29.99 & 29.99 & 30.00 & 30.00 & 30.00 & 30.00 & 30.00 & 30.00 & 30.00 \\
\hline 7. & $\begin{array}{l}\text { Fan Inlet Dry Bulb } \\
\text { Temperature }(\mathrm{F})\end{array}$ & 66.0 & 66.4 & 66.2 & 66.1 & 66.3 & 66.2 & 65.9 & 66.0 & 66.3 & 66.2 \\
\hline 8. & $\begin{array}{l}\text { Fan Inlet Wet Bulb } \\
\text { Temperature }(F)\end{array}$ & 55.8 & 56.0 & 56.0 & 55.9 & 55.9 & 55.8 & 55.8 & 55.8 & 55.8 & 56.1 \\
\hline 9. & $\begin{array}{l}\text { Chamber Dry Bulb } \\
\text { Temperature }(\mathrm{F})\end{array}$ & 65.2 & 65.3 & 65.4 & 65.4 & 65.3 & 65.1 & 65.1 & 65.1 & 65.2 & 65.6 \\
\hline 10. & Fan Motor Amperage & 4.83 & 4.61 & 4.43 & 4.20 & 4.06 & 3.70 & 3.42 & 2.97 & 2.65 & 2.05 \\
\hline 11. & Fan Motor Voltage & 121.7 & 121.0 & 120.1 & 120.4 & 121.4 & 123.6 & 122.7 & 121.0 & 122.5 & 122.6 \\
\hline 12. & Fan Motor Wattage & 482.4 & 468.8 & 451.4 & 436.3 & 423.0 & 402.3 & 371.1 & 339.9 & 296.9 & 243.9 \\
\hline 13. & Fan Motor RPM & 705 & 771 & 820 & 879 & 927 & 973 & 1018 & 1063 & 1095 & 1138 \\
\hline 14. & Fan Motor \#2 RPM & 0 & 0 & 0 & 0 & 0 & 0 & 0 & 0 & 0 & 0 \\
\hline 15 . & $\begin{array}{l}\text { Air Density at Fan } \\
\text { Inlet }(\mathrm{lb} / \mathrm{ft} 3)\end{array}$ & 0.07532 & 0.07527 & 0.07529 & 0.07531 & 0.07529 & 0.07531 & 0.07535 & 0.07533 & 0.07530 & 0.07530 \\
\hline 16. & $\begin{array}{l}\text { Air Density at Fan } \\
\text { Outlet }(1 \mathrm{lb} / \mathrm{ft} 3)\end{array}$ & 0.07537 & 0.07538 & 0.07540 & 0.07542 & 0.07547 & 0.07553 & 0.07555 & 0.07560 & 0.07562 & 0.07561 \\
\hline 17. & $\begin{array}{l}\text { Air Density at Nozzle } \\
\text { Inlet }(\mathrm{lb} / \mathrm{ft} 3)\end{array}$ & 0.07551 & 0.07551 & 0.07553 & 0.07554 & 0.07558 & 0.07563 & 0.07564 & 0.07566 & 0.07567 & 0.07563 \\
\hline 18. & CFM at Nozzle Inlet & 1155.6 & 1149.8 & 1139.1 & 1113.1 & 1073.4 & 1015.7 & 937.1 & 801.8 & 649.1 & 306.6 \\
\hline 19. & CFM at Fan Outlet & 1153.5 & 1147.8 & 1137.1 & 1111.4 & 1071.8 & 1014.3 & 936.1 & 801.1 & 648.7 & 306.5 \\
\hline 20. & Fan Outlet Static Pres. & 0.389 & 0.503 & 0.604 & 0.711 & 0.800 & 0.897 & 0.994 & 1.090 & 1.178 & 1.318 \\
\hline 21. & Fan Outlet Vel. Pres. & 0.202 & 0.200 & 0.196 & 0.187 & 0.174 & 0.156 & 0.133 & 0.097 & 0.064 & 0.014 \\
\hline 22. & Fan Outlet Total Pres. & 0.591 & 0.703 & 0.800 & 0.898 & 0.974 & 1.053 & 1.127 & 1.187 & 1.242 & 1.332 \\
\hline \multicolumn{12}{|c|}{ Values Corrected for Standard Air Density } \\
\hline 23. & CFM at Nozzle Inlet & 1155.6 & 1149.8 & 1139.1 & 1113.1 & 1073.4 & 1015.7 & 937.1 & 801.8 & 649.1 & 306.6 \\
\hline 24. & Static Pressure & 0.386 & 0.500 & 0.600 & 0.706 & 0.794 & 0.889 & 0.986 & 1.080 & 1.168 & 1.307 \\
\hline 25. & Velocity Pressure & 0.200 & 0.198 & 0.195 & 0.186 & 0.173 & 0.155 & 0.132 & 0.097 & 0.063 & 0.014 \\
\hline 26. & Total Pressure of Fan & 0.587 & 0.698 & 0.794 & 0.892 & 0.967 & 1.044 & 1.117 & 1.177 & 1.231 & 1.321 \\
\hline 27. & Motor Amperage & 4.80 & 4.58 & 4.40 & 4.17 & 4.03 & 3.67 & 3.39 & 2.94 & 2.62 & 2.03 \\
\hline 28. & Motor Wattage & 479.1 & 465.6 & 448.2 & 433.2 & 419.8 & 399.0 & 368.0 & 337.0 & 294.3 & 241.9 \\
\hline 29. & CFM per Watt & 2.41 & 2.47 & 2.54 & 2.57 & 2.55 & 2.54 & 2.54 & 2.38 & 2.20 & 1.27 \\
\hline
\end{tabular}

Note: All pressures are in inches of water unless otherwise stated. 
Table A18 Summary data for PSC blower only at low speed

\begin{tabular}{|c|c|c|c|c|c|c|c|c|c|c|}
\hline Point & 1 & 2 & 3 & 4 & 5 & 6 & 7 & 8 & 9 & 10 \\
\hline $\begin{array}{l}\text { Fan Static Pressure } \\
\text { (in/water) }\end{array}$ & 0.389 & 0.503 & 0.604 & 0.711 & $\overline{0.8}$ & 0.897 & 0.994 & 1.09 & 1.178 & 1.318 \\
\hline $\begin{array}{l}\text { Nozzle Diff. Pressure } \\
\text { (in/water) }\end{array}$ & 0.717 & 0.71 & 0.697 & 0.666 & 0.62 & 0.556 & 0.474 & 0.348 & 0.229 & 0.052 \\
\hline Nozzle Key (ID) & $4+5$ & $4+5$ & $4+5$ & $4+5$ & $4+5$ & $4+5$ & $4+5$ & $4+5$ & $4+5$ & $4+5$ \\
\hline $\begin{array}{l}\text { Nozzle Static Pressure } \\
\text { (in/H2O) }\end{array}$ & -0.327 & -0.206 & -0.093 & 0.055 & 0.189 & 0.347 & 0.52 & 0.728 & 0.933 & 1.245 \\
\hline $\begin{array}{l}\text { Fan Inlet Dry Bulb } \\
\text { Temp (F) }\end{array}$ & 66 & 66.371 & 66.222 & 66.11 & 66.276 & 66.217 & 65.853 & 66.016 & 66.259 & 66.235 \\
\hline $\begin{array}{l}\text { Fan Inlet Wet Bulb } \\
\text { Temp (F) }\end{array}$ & 55.805 & 56.017 & 55.997 & 55.871 & 55.882 & 55.794 & 55.807 & 55.82 & 55.779 & 56.133 \\
\hline $\begin{array}{l}\text { Chamber Dry Bulb } \\
\text { Temp (F) }\end{array}$ & 65.208 & 65.328 & 65.372 & 65.44 & 65.301 & 65.099 & 65.125 & 65.124 & 65.224 & 65.621 \\
\hline Barometric Pressure & 29.992 & 29.993 & 29.994 & 29.995 & 29.995 & 29.998 & 29.997 & 29.998 & 29.997 & 29.998 \\
\hline Fan Motor Volts & 121.71 & 120.994 & 120.106 & 120.406 & 121.381 & 123.644 & 122.706 & 121.003 & 122.488 & 122.619 \\
\hline Fan Motor Amps & 4.829 & $\overline{4.614}$ & 4.434 & $\overline{4.2}$ & 4.058 & 3.7 & 3.42 & 2.97 & 2.647 & 2.051 \\
\hline Fan Motor Watts & 482.361 & 468.75 & 451.385 & 436.34 & 423.035 & 402.344 & 371.124 & 339.935 & 296.906 & 243.896 \\
\hline Fan Motor RPM & 705 & 771 & 820 & 879 & 927 & 973 & 1018 & 1063 & 1095 & 1138 \\
\hline
\end{tabular}

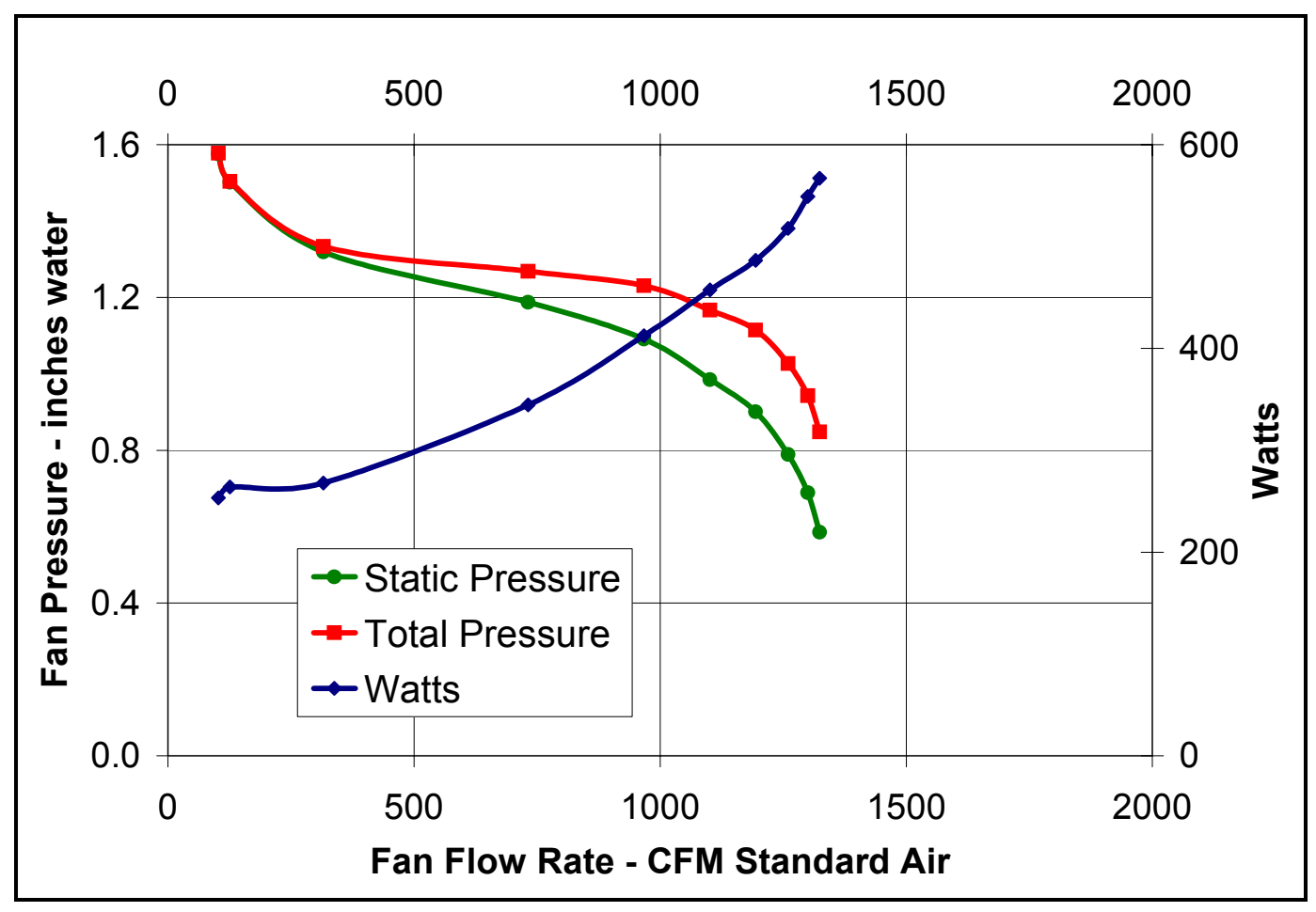

Figure 19 Airflow versus Pressure and Power for PSC blower only at low speed 


\section{ECM 2.3 furnace at high speed}

Table A19 Test Information for ECM 2.3 furnace at high speed

\begin{tabular}{|l|l||l|l|}
\hline Contract Number & $03-153 \mathrm{~K}$ & Motor Volts & 120 \\
\hline Test Date & $2 / 7 / 2003$ & Wheel Diameter (in) & 10 \\
\hline Fan Model Number & 58 CVA090---10116 & Outlet Diameter (in) & 18.4 \\
\hline Motor Model Number & ECM2.3 & Outlet Area (sq ft) & 1.847 \\
\hline Number of Motors & 1 & Motor Notes & \\
\hline Number of Blades & 0 & Operator(s) & Stephen \\
\hline Blade Material & Aluminum & Test Notes: & $\begin{array}{l}\text { Furnace and Blower - } \\
\text { High Speed Constant Fan }\end{array}$ \\
\hline
\end{tabular}

Table A20 Report for ECM 2.3 furnace at high speed

\begin{tabular}{|c|c|c|c|c|c|c|c|c|c|c|c|}
\hline 1. & Test Point Number & 1 & 2 & 3 & 4 & 5 & 6 & 7 & 8 & 9 & 10 \\
\hline 2. & Fan Static Pressure & 0.491 & 0.612 & 0.707 & 0.785 & 0.893 & 0.985 & 1.095 & 1.203 & 1.293 & 1.404 \\
\hline 3. & $\begin{array}{l}\text { Nozzle Differential } \\
\text { Pressure }\end{array}$ & 0.874 & 0.879 & 0.873 & 0.848 & 0.805 & 0.762 & 0.710 & 0.656 & 0.592 & 0.487 \\
\hline 4. & Nozzle Key (ID) & 10 & 10 & 10 & 10 & 10 & 10 & 10 & 10 & 10 & 10 \\
\hline 5. & Nozzle Static Pressure & -0.395 & -0.280 & -0.177 & -0.075 & 0.074 & 0.210 & 0.362 & 0.526 & 0.674 & 0.889 \\
\hline 6. & $\begin{array}{l}\text { Barometric Pressure } \\
\text { (in } \mathrm{Hg} \text { ) }\end{array}$ & 30.47 & 30.47 & 30.47 & 30.48 & 30.48 & 30.47 & 30.47 & 30.47 & 30.47 & 30.46 \\
\hline 7. & $\begin{array}{l}\text { Fan Inlet Dry Bulb } \\
\text { Temperature }(\mathrm{F})\end{array}$ & 66.7 & 66.9 & 66.9 & 66.3 & 66.8 & 66.9 & 66.9 & 67.4 & 66.7 & 67.1 \\
\hline 8. & \begin{tabular}{|l|} 
Fan Inlet Wet Bulb \\
Temperature $(\mathrm{F})$ \\
\end{tabular} & 53.5 & 53.7 & 53.8 & 53.6 & 53.6 & 53.7 & 53.7 & 53.7 & 53.6 & 53.8 \\
\hline 9. & $\begin{array}{l}\text { Chamber Dry Bulb } \\
\text { Temperature }(\mathrm{F})\end{array}$ & 65.8 & 66.1 & 66.6 & 66.5 & 66.6 & 66.5 & 66.8 & 66.8 & 66.5 & 66.9 \\
\hline 10. & Fan Motor Amperage & 3.68 & 4.09 & 4.51 & 4.61 & 4.68 & 4.68 & 4.85 & 4.75 & 4.69 & 4.33 \\
\hline 11. & Fan Motor Voltage & 120.4 & 120.2 & 119.2 & 119.3 & 119.8 & 120.5 & 119.2 & 118.0 & 119.7 & 119.7 \\
\hline 12. & Fan Motor Wattage & 478.6 & 534.9 & 571.5 & 593.7 & 595.2 & 602.1 & 605.7 & 609.1 & 594.1 & 556.0 \\
\hline 13. & Fan Motor RPM & 1020 & 1087 & 1122 & 1147 & 1180 & 1207 & 1242 & 1281 & 1300 & 1324 \\
\hline 14. & Fan Motor \#2 RPM & 0 & 0 & 0 & 0 & 0 & 0 & 0 & 0 & 0 & 0 \\
\hline 15. & $\begin{array}{l}\text { Air Density at Fan } \\
\text { Inlet (lb/ft3) }\end{array}$ & 0.07650 & 0.07647 & 0.07647 & 0.07656 & 0.07649 & 0.07647 & 0.07646 & 0.07639 & 0.07648 & 0.07641 \\
\hline 16. & \begin{tabular}{|l} 
Air Density at Fan \\
Outlet $(\mathrm{lb} / \mathrm{ft} 3)$ \\
\end{tabular} & 0.07655 & 0.07653 & 0.07648 & 0.07653 & 0.07654 & 0.07655 & 0.07655 & 0.07657 & 0.07663 & 0.07659 \\
\hline 17. & $\begin{array}{l}\text { Air Density at Nozzle } \\
\text { Inlet }(\mathrm{lb} / \mathrm{ft} 3)\end{array}$ & 0.07671 & 0.07670 & 0.07664 & 0.07669 & 0.07669 & 0.07669 & 0.07668 & 0.07669 & 0.07674 & 0.07669 \\
\hline 18. & CFM at Nozzle Inlet & 1460.3 & 1464.6 & 1460.0 & 1438.4 & 1401.1 & 1362.9 & 1315.3 & 1263.8 & 1199.7 & 1087.5 \\
\hline 19. & CFM at Fan Outlet & 1457.1 & 1461.4 & 1456.9 & 1435.4 & 1398.4 & 1360.3 & 1313.0 & 1261.7 & 1197.9 & 1086.2 \\
\hline 20. & Fan Outlet Static Pres. & 0.491 & 0.612 & 0.707 & 0.785 & 0.893 & 0.985 & 1.095 & 1.203 & 1.293 & 1.404 \\
\hline 21. & Fan Outlet Vel. Pres. & 0.040 & 0.040 & 0.040 & 0.039 & 0.037 & 0.035 & 0.032 & 0.030 & 0.027 & 0.022 \\
\hline 22. & Fan Outlet Total Pres. & 0.531 & 0.652 & 0.747 & 0.824 & 0.930 & 1.020 & 1.127 & 1.233 & 1.320 & 1.426 \\
\hline \multicolumn{12}{|c|}{ Values Corrected for Standard Air Density } \\
\hline 23. & CFM at Nozzle Inlet & 1460.3 & 1464.6 & 1460.0 & 1438.4 & 1401.1 & 1362.9 & 1315.3 & 1263.8 & 1199.7 & 1087.5 \\
\hline 24. & Static Pressure & 0.480 & 0.598 & 0.692 & 0.768 & 0.873 & 0.963 & 1.071 & 1.176 & 1.264 & 1.373 \\
\hline 25. & Velocity Pressure & 0.039 & 0.039 & 0.039 & 0.038 & 0.036 & 0.034 & 0.032 & 0.029 & 0.026 & 0.022 \\
\hline 26. & Total Pressure of Fan & 0.519 & 0.638 & 0.731 & 0.805 & 0.909 & 0.997 & 1.103 & 1.206 & 1.290 & 1.395 \\
\hline 27. & Motor Amperage & 3.60 & 4.00 & 4.42 & 4.51 & 4.58 & 4.58 & 4.74 & 4.65 & 4.58 & 4.23 \\
\hline 28. & Motor Wattage & 467.9 & 523.1 & 559.2 & 580.6 & 582.1 & 588.8 & 592.4 & 595.6 & 580.6 & 543.7 \\
\hline 29. & CFM per Watt & 3.11 & 2.79 & 2.61 & 2.47 & 2.40 & 2.31 & 2.22 & 2.12 & 2.06 & 2.00 \\
\hline
\end{tabular}

Note: All pressures are in inches of water unless otherwise stated. 
Table A21 Summary data for ECM 2.3 furnace at high speed

\begin{tabular}{|c|c|c|c|c|c|c|c|c|c|c|}
\hline Point & 1 & 2 & 3 & 4 & 5 & 6 & 7 & 8 & 9 & 10 \\
\hline $\begin{array}{l}\text { Fan Static Pressure } \\
\text { (in/water) }\end{array}$ & 0.491 & 0.612 & 0.707 & 0.785 & 0.893 & 0.985 & 1.095 & 1.203 & 1.293 & 1.404 \\
\hline $\begin{array}{l}\text { Nozzle Diff. Pressure } \\
\text { (in/water) }\end{array}$ & 0.874 & 0.879 & 0.873 & 0.848 & 0.805 & 0.762 & 0.71 & 0.656 & 0.592 & 0.487 \\
\hline Nozzle Key (ID) & $3+4+5$ & $3+4+5$ & $3+4+5$ & $3+4+5$ & $3+4+5$ & $3+4+5$ & $3+4+5$ & $3+4+5$ & $3+4+5$ & $3+4+5$ \\
\hline $\begin{array}{l}\text { Nozzle Static Pressure } \\
(\mathrm{in} / \mathrm{H} 2 \mathrm{O})\end{array}$ & -0.395 & -0.28 & -0.177 & -0.075 & 0.074 & 0.21 & 0.362 & 0.526 & 0.674 & 0.889 \\
\hline $\begin{array}{l}\text { Fan Inlet Dry Bulb } \\
\text { Temp (F) }\end{array}$ & 66.66 & 66.888 & 66.88 & 66.325 & 66.801 & 66.86 & 66.939 & 67.35 & 66.714 & 67.105 \\
\hline $\begin{array}{l}\text { Fan Inlet Wet Bulb } \\
\text { Temp (F) }\end{array}$ & 53.521 & 53.716 & 53.757 & $\overline{53.606}$ & 53.616 & 53.672 & 53.712 & 53.745 & 53.58 & 53.83 \\
\hline $\begin{array}{l}\text { Chamber Dry Bulb } \\
\text { Temp (F) }\end{array}$ & 65.813 & 66.124 & 66.596 & 66.456 & 66.574 & 66.545 & 66.787 & 66.79 & 66.547 & 66.943 \\
\hline Barometric Pressure & 30.468 & 30.474 & 30.473 & 30.478 & 30.476 & 30.469 & 30.471 & 30.466 & 30.465 & 30.46 \\
\hline Fan Motor Volts & 120.385 & 120.174 & 119.158 & 119.307 & 119.836 & 120.515 & 119.151 & 117.954 & 119.653 & 119.705 \\
\hline Fan Motor Amps & 3.683 & 4.089 & 4.514 & 4.612 & 4.68 & 4.681 & 4.849 & 4.752 & 4.685 & 4.327 \\
\hline Fan Motor Watts & 478.577 & 534.943 & 571.503 & 593.658 & 595.184 & 602.142 & 605.682 & 609.1 & 594.055 & 555.969 \\
\hline Fan Motor RPM & 1020 & 1087 & 1122 & $\overline{1147}$ & 1180 & 1207 & 1242 & 1281 & 1300 & 1324 \\
\hline
\end{tabular}

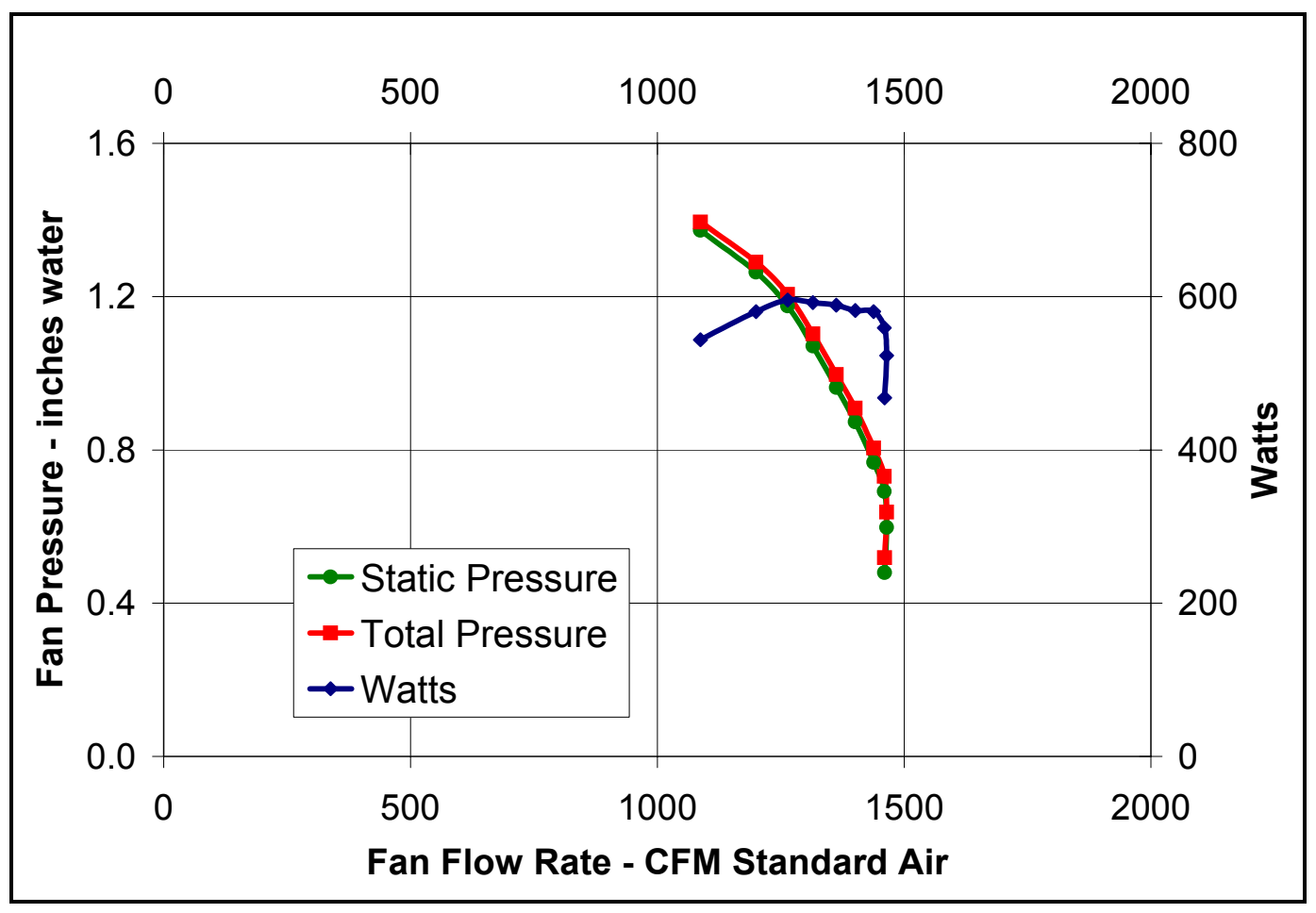

Figure 20 Airflow versus Pressure and Power for ECM 2.3 furnace at high speed 


\section{ECM 2.3 furnace at medium speed}

Table A22 Test Information for ECM 2.3 furnace at medium speed

\begin{tabular}{|l|l||l|l|}
\hline Contract Number & $03-153 \mathrm{~L}$ & Motor Volts & 120 \\
\hline Test Date & $2 / 7 / 2003$ & Wheel Diameter (in) & 10 \\
\hline Fan Model Number & $58 \mathrm{CVA} 090---10116$ & Outlet Diameter (in) & 18.4 \\
\hline Motor Model Number & ECM2.3 & Outlet Area (sq ft) & 1.847 \\
\hline Number of Motors & 1 & Motor Notes & \\
\hline Number of Blades & 0 & Operator(s) & Stephen \\
\hline Blade Material & Aluminum & Test Notes: & $\begin{array}{l}\text { Furnace and Blower - } \\
\text { Medium-Low Speed } \\
\text { Constant Fan }\end{array}$ \\
\hline
\end{tabular}

Table 23 Report for ECM 2.3 furnace at medium speed

\begin{tabular}{|c|c|c|c|c|c|c|c|c|c|c|c|}
\hline 1. & Test Point Number & 1 & 2 & 3 & 4 & 5 & 6 & 7 & 8 & 9 & 10 \\
\hline 2. & Fan Static Pressure & 0.504 & 0.619 & 0.715 & 0.806 & 0.904 & 0.989 & 1.112 & 1.207 & 1.286 & 1.399 \\
\hline 3. & $\begin{array}{l}\text { Nozzle Differential } \\
\text { Pressure }\end{array}$ & 0.663 & 0.669 & 0.669 & 0.663 & 0.657 & 0.646 & 0.630 & 0.606 & 0.567 & 0.463 \\
\hline 4. & Nozzle Key (ID) & 10 & 10 & 10 & 10 & 10 & 10 & 10 & 10 & 10 & 10 \\
\hline 5. & Nozzle Static Pressure & -0.169 & -0.061 & 0.036 & 0.130 & 0.234 & 0.330 & 0.460 & 0.578 & 0.695 & 0.911 \\
\hline 6. & Barometric P. (in Hg) & 30.44 & 30.43 & 30.43 & 30.43 & 30.43 & 30.42 & 30.42 & 30.42 & 30.42 & 30.42 \\
\hline 7. & $\begin{array}{l}\text { Fan Inlet Dry Bulb } \\
\text { Temperature }(\mathrm{F})\end{array}$ & 67.2 & 67.6 & 67.6 & 67.4 & 67.7 & 67.8 & 67.9 & 67.7 & 68.1 & 67.5 \\
\hline 8. & $\begin{array}{l}\text { Fan Inlet Wet Bulb } \\
\text { Temperature }(\mathrm{F})\end{array}$ & 53.8 & 54.2 & 54.1 & 53.8 & 54.1 & 54.2 & 54.2 & 54.1 & 54.5 & $\overline{54.1}$ \\
\hline 9. & $\begin{array}{l}\text { Chamber Dry Bulb } \\
\text { Temperature }(\mathrm{F})\end{array}$ & 66.7 & 67.6 & 66.9 & 66.9 & 67.6 & 67.3 & 67.2 & 67.7 & 67.8 & 67.9 \\
\hline 10. & Fan Motor Amperage & 2.76 & 3.06 & 3.33 & 3.56 & 3.85 & 4.13 & 4.37 & 4.62 & 4.68 & 4.35 \\
\hline 11. & Fan Motor Voltage & 121.4 & 120.8 & 119.1 & 119.2 & 119.2 & 118.9 & 118.0 & 117.7 & 117.1 & 118.1 \\
\hline 12. & Fan Motor Wattage & 361.8 & 405.4 & 433.2 & 459.4 & 495.5 & 520.9 & 555.4 & 573.3 & 575.1 & 543.9 \\
\hline 13. & Fan Motor RPM & 965 & 1028 & 1075 & 1113 & 1156 & 1187 & 1232 & 1266 & 1293 & 1322 \\
\hline 14. & Fan Motor \#2 RPM & 0 & 0 & 0 & 0 & 0 & 0 & 0 & 0 & 0 & 0 \\
\hline 15. & $\begin{array}{l}\text { Air Density at Fan } \\
\text { Inlet }(\mathrm{lb} / \mathrm{ft} 3)\end{array}$ & 0.07634 & 0.07626 & 0.07624 & 0.07629 & 0.07624 & 0.07620 & 0.07619 & 0.07622 & 0.07616 & 0.07624 \\
\hline 16. & $\begin{array}{l}\text { Air Density at Fan } \\
\text { Outlet (lb/ft3) }\end{array}$ & 0.07638 & 0.07626 & 0.07635 & 0.07639 & 0.07629 & 0.07634 & 0.07638 & 0.07633 & 0.07634 & 0.07635 \\
\hline 17. & $\begin{array}{l}\text { Air Density at Nozzle } \\
\text { Inlet }(\mathrm{lb} / \mathrm{ft} 3)\end{array}$ & 0.07650 & 0.07639 & 0.07648 & 0.07651 & 0.07641 & 0.07646 & 0.07650 & 0.07645 & 0.07645 & 0.07644 \\
\hline 18. & CFM at Nozzle Inlet & 1272.1 & 1278.9 & 1278.1 & 1272.0 & 1267.0 & 1255.9 & 1239.8 & 1216.2 & 1176.1 & 1061.9 \\
\hline 19. & CFM at Fan Outlet & 1270.1 & 1276.8 & 1276.0 & 1270.0 & 1265.0 & 1253.9 & 1237.9 & 1214.4 & 1174.4 & 1060.6 \\
\hline 20. & Fan Outlet Static Pres. & 0.504 & 0.619 & 0.715 & 0.806 & 0.904 & 0.989 & 1.112 & 1.207 & 1.286 & 1.399 \\
\hline 21. & Fan Outlet Velocity P. & 0.030 & 0.030 & 0.030 & 0.030 & 0.030 & 0.029 & 0.029 & 0.028 & 0.026 & 0.021 \\
\hline 22. & Fan Outlet Total Pres. & 0.534 & 0.649 & 0.745 & 0.836 & 0.934 & 1.018 & 1.141 & 1.235 & 1.312 & 1.420 \\
\hline \multicolumn{12}{|c|}{ Values Corrected for Standard Air Density } \\
\hline 23. & CFM at Nozzle Inlet & 1272.1 & 1278.9 & 1278.1 & 1272.0 & 1267.0 & 1255.9 & 1239.8 & 1216.2 & 1176.1 & 1061.9 \\
\hline 24. & Static Pressure & 0.494 & 0.608 & 0.701 & 0.790 & 0.887 & 0.970 & 1.090 & 1.184 & 1.262 & 1.373 \\
\hline 25. & Velocity Pressure & 0.030 & 0.030 & 0.030 & 0.030 & 0.029 & 0.029 & 0.028 & 0.027 & 0.025 & 0.021 \\
\hline 26. & Total Pressure of Fan & 0.524 & 0.638 & 0.731 & 0.820 & 0.917 & 0.999 & 1.118 & 1.211 & 1.287 & 1.393 \\
\hline 27. & Motor Amperage & 2.71 & 3.00 & 3.27 & 3.49 & 3.78 & 4.05 & 4.28 & 4.53 & 4.59 & 4.27 \\
\hline 28. & Motor Wattage & 354.7 & 398.0 & 424.8 & 450.3 & 486.3 & 511.0 & 544.5 & 562.5 & 564.2 & 533.7 \\
\hline 29. & CFM per Watt & 3.58 & 3.21 & 3.00 & 2.82 & 2.60 & 2.45 & 2.27 & 2.16 & 2.08 & 1.99 \\
\hline
\end{tabular}

Note: All pressures are in inches of water unless otherwise stated. 
Table A24 Summary data for ECM 2.3 furnace at medium speed

\begin{tabular}{|c|c|c|c|c|c|c|c|c|c|c|}
\hline Point & 1 & 2 & 3 & 4 & 5 & 6 & 7 & 8 & 9 & 10 \\
\hline $\begin{array}{l}\text { Fan Static Pressure } \\
\text { (in/water) }\end{array}$ & 0.504 & 0.619 & 0.715 & 0.806 & 0.904 & 0.989 & 1.112 & 1.207 & 1.286 & 1.399 \\
\hline $\begin{array}{l}\text { Nozzle Diff. Pressure } \\
\text { (in/water) }\end{array}$ & 0.663 & 0.669 & 0.669 & 0.663 & 0.657 & 0.646 & 0.63 & 0.606 & 0.567 & 0.463 \\
\hline Nozzle Key (ID) & $3+4+5$ & $3+4+5$ & $3+4+5$ & $3+4+5$ & $3+4+5$ & $3+4+5$ & $3+4+5$ & $3+4+5$ & $3+4+5$ & $3+4+5$ \\
\hline $\begin{array}{l}\text { Nozzle Static Pressure } \\
\text { (in/H2O) }\end{array}$ & -0.169 & -0.061 & 0.036 & 0.13 & 0.234 & 0.33 & 0.46 & 0.578 & 0.695 & 0.911 \\
\hline $\begin{array}{l}\text { Fan Inlet Dry Bulb } \\
\text { Temp (F) }\end{array}$ & 67.214 & 67.614 & 67.645 & 67.375 & 67.652 & 67.839 & 67.927 & 67.723 & 68.115 & 67.538 \\
\hline $\begin{array}{l}\text { Fan Inlet Wet Bulb } \\
\text { Temp (F) }\end{array}$ & 53.796 & 54.199 & 54.094 & 53.757 & 54.132 & 54.247 & 54.225 & 54.147 & 54.451 & 54.089 \\
\hline $\begin{array}{l}\text { Chamber Dry Bulb } \\
\text { Temp (F) }\end{array}$ & 66.74 & 67.55 & 66.939 & 66.904 & 67.604 & 67.302 & 67.193 & 67.721 & 67.751 & 67.942 \\
\hline Barometric Pressure & 30.439 & 30.434 & 30.427 & 30.429 & 30.426 & 30.421 & 30.422 & 30.423 & 30.421 & 30.418 \\
\hline Fan Motor Volts & 121.353 & 120.84 & 119.085 & 119.172 & 119.195 & 118.9 & 117.959 & 117.684 & 117.075 & 118.117 \\
\hline Fan Motor Amps & 2.76 & 3.06 & 3.331 & 3.564 & 3.847 & 4.133 & 4.369 & 4.617 & 4.676 & 4.351 \\
\hline Fan Motor Watts & 361.755 & 405.365 & 433.197 & 459.381 & 495.483 & 520.905 & 555.359 & 573.334 & 575.073 & 543.915 \\
\hline Fan Motor RPM & 965 & 1028 & 1075 & 1113 & 1156 & 1187 & 1232 & 1266 & 1293 & 1322 \\
\hline
\end{tabular}

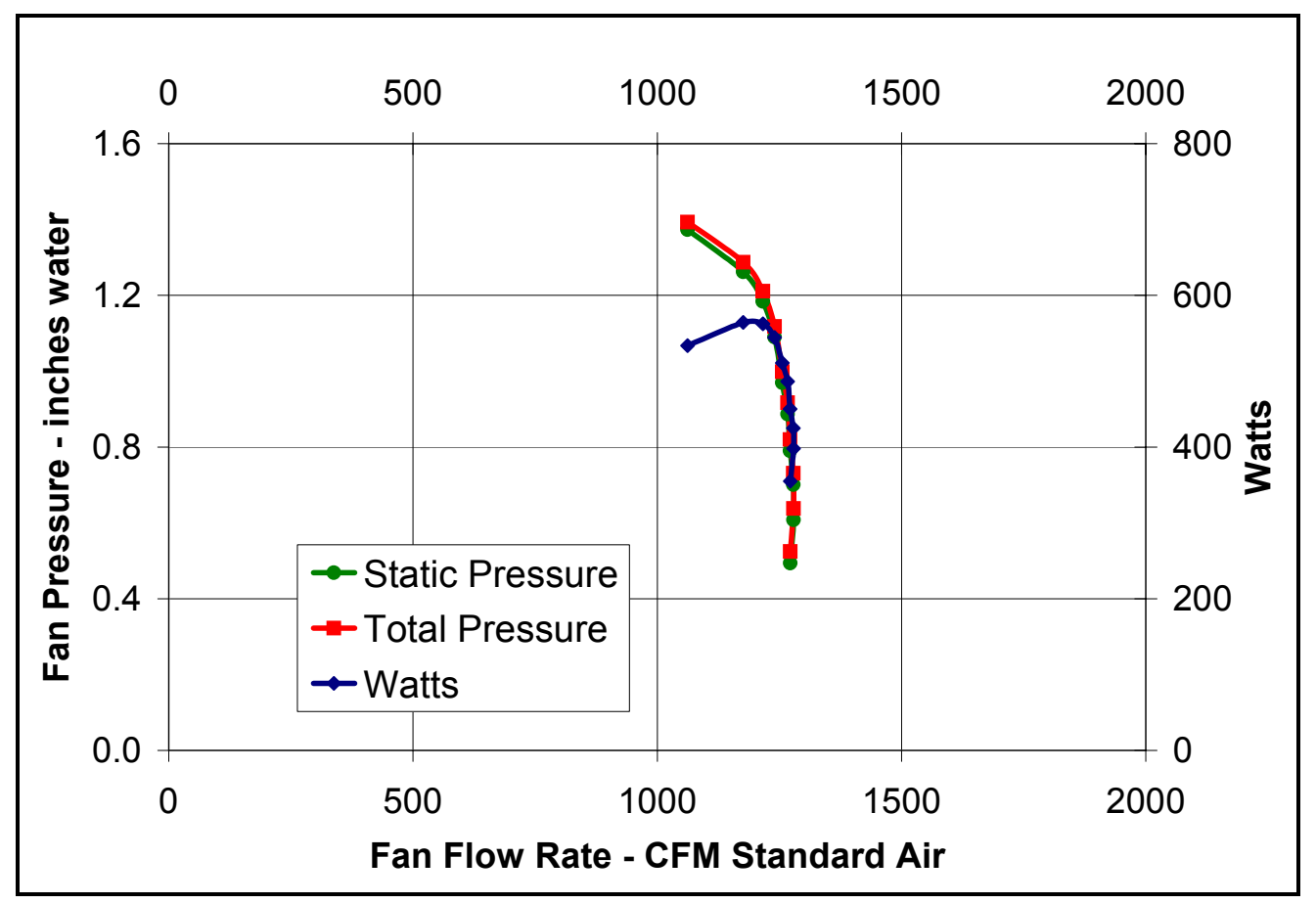

Figure 21 Airflow versus Pressure and Power ECM 2.3 furnace at medium speed 


\section{ECM 2.3 furnace at low speed}

Table A25 Test Information for ECM 2.3 furnace at low speed

\begin{tabular}{|l|l||l|l|}
\hline Contract Number & $03-153 \mathrm{M}$ & Motor Volts & 120 \\
\hline Test Date & $2 / 7 / 2003$ & Wheel Diameter (in) & 10 \\
\hline Fan Model Number & $58 \mathrm{CVA} 090---10116$ & Outlet Diameter (in) & 18.4 \\
\hline Motor Model Number & ECM2.3 & Outlet Area (sq ft) & 1.847 \\
\hline Number of Motors & 1 & Motor Notes & \\
\hline Number of Blades & 0 & Operator(s) & Michael \\
\hline Blade Material & Aluminum & Test Notes: & $\begin{array}{l}\text { Furnace and Blower - } \\
\text { Low Speed Constant Fan }\end{array}$ \\
\hline
\end{tabular}

Table A26 Report for ECM 2.3 furnace at low speed

\begin{tabular}{|c|c|c|c|c|c|c|c|c|c|c|c|}
\hline 1. & Test Point Number & 1 & 2 & 3 & 4 & 5 & 6 & 7 & 8 & 9 & 10 \\
\hline 2. & Fan Static Pressure & 0.500 & 0.601 & 0.707 & 0.799 & 0.886 & 0.987 & 1.092 & 1.194 & 1.295 & 1.4 \\
\hline 3. & $\begin{array}{l}\text { Nozzle Differential } \\
\text { Pressure }\end{array}$ & 0.485 & 0.481 & 0.484 & 0.479 & 0.471 & 0.467 & 0.458 & 0.447 & 0.431 & 0.323 \\
\hline 4. & Nozzle Key (ID) & 10 & 10 & 10 & 10 & 10 & 10 & 10 & 10 & 10 & 10 \\
\hline 5. & Nozzle Static Pressure & 0.010 & 0.109 & 0.212 & 0.308 & 0.404 & 0.505 & 0.615 & 0.725 & 0.841 & 1.052 \\
\hline 6. & $\begin{array}{l}\text { Barometric Pressure } \\
\text { (in } \mathrm{Hg} \text { ) }\end{array}$ & 30.41 & 30.41 & 30.40 & 30.41 & 30.41 & 30.41 & 30.40 & 30.41 & 30.40 & 30.4 \\
\hline 7. & $\begin{array}{l}\text { Fan Inlet Dry Bulb } \\
\text { Temperature }(F)\end{array}$ & 68.4 & 67.9 & 68.5 & 68.4 & 68.2 & 68.5 & 68.2 & 68.2 & 67.9 & 68.4 \\
\hline 8. & $\begin{array}{l}\text { Fan Inlet Wet Bulb } \\
\text { Temperature }(F)\end{array}$ & 54.7 & 54.3 & 54.6 & 54.6 & 54.5 & 54.7 & 54.7 & 54.5 & 54.3 & 54.7 \\
\hline 9. & $\begin{array}{l}\text { Chamber Dry Bulb } \\
\text { Temperature }(\mathrm{F})\end{array}$ & 67.9 & 67.5 & 68.0 & 67.9 & 68.1 & 67.9 & 68.0 & 67.8 & 68.4 & 68.5 \\
\hline 10. & Fan Motor Amperage & 2.02 & 2.14 & 2.43 & 2.72 & 2.81 & 3.11 & 3.35 & 3.51 & 3.73 & 3.55 \\
\hline 11. & Fan Motor Voltage & 121.6 & 121.6 & 122.3 & 120.2 & 120.9 & 119.9 & 119.2 & 118.2 & 118.6 & 120.3 \\
\hline 12. & Fan Motor Wattage & 268.7 & 294.7 & 326.6 & 352.1 & 377.4 & 404.1 & 431.5 & 460.8 & 486.8 & 460.8 \\
\hline 13. & Fan Motor RPM & 915 & 958 & 1020 & 1065 & 1106 & 1147 & 1194 & 1231 & 1273 & 1312 \\
\hline 14. & Fan Motor \#2 RPM & 0 & 0 & 0 & 0 & 0 & 0 & 0 & 0 & 0 & 0 \\
\hline 15. & $\begin{array}{l}\text { Air Density at Fan } \\
\text { Inlet }(\mathrm{lb} / \mathrm{ft} 3)\end{array}$ & 0.07607 & 0.07615 & 0.07606 & 0.07609 & 0.07611 & 0.07607 & 0.07609 & 0.07610 & 0.07614 & 0.07604 \\
\hline 16. & $\begin{array}{l}\text { Air Density at Fan } \\
\text { Outlet }(\mathrm{lb} / \mathrm{ft} 3)\end{array}$ & 0.07614 & 0.07623 & 0.07617 & 0.07621 & 0.07620 & 0.07625 & 0.07623 & 0.07630 & 0.07622 & 0.07623 \\
\hline 17. & $\begin{array}{l}\text { Air Density at Nozzle } \\
\text { Inlet (lb/ft3) }\end{array}$ & 0.07623 & 0.07632 & 0.07626 & 0.07630 & 0.07629 & 0.07634 & 0.07632 & 0.07639 & 0.07630 & 0.07629 \\
\hline 18. & CFM at Nozzle Inlet & 1088.4 & 1083.3 & 1087.1 & 1081.2 & 1072.1 & 1067.1 & 1056.8 & 1043.5 & 1025.1 & 886.2 \\
\hline 19. & CFM at Fan Outlet & 1087.2 & 1082.0 & 1085.8 & 1079.9 & 1070.8 & 1065.9 & 1055.6 & 1042.3 & 1024.0 & 885.5 \\
\hline 20. & Fan Outlet Static Pres. & 0.500 & 0.601 & 0.707 & 0.799 & 0.886 & 0.987 & 1.092 & 1.194 & 1.295 & 1.4 \\
\hline 21. & Fan Outlet Vel. Pres. & 0.022 & 0.022 & 0.022 & 0.022 & 0.021 & 0.021 & 0.021 & 0.020 & 0.020 & 0.015 \\
\hline 22. & Fan Outlet Total Pres. & 0.522 & 0.623 & 0.729 & 0.821 & 0.907 & 1.008 & 1.113 & 1.214 & 1.315 & 1.415 \\
\hline \multicolumn{12}{|c|}{ Values Corrected for Standard Air Density } \\
\hline 23. & CFM at Nozzle Inlet & 1088.4 & 1083.3 & 1087.1 & 1081.2 & 1072.1 & 1067.1 & 1056.8 & 1043.5 & 1025.1 & 886.2 \\
\hline 24. & Static Pressure & 0.492 & 0.591 & 0.695 & 0.785 & 0.871 & 0.970 & 1.073 & 1.172 & 1.273 & 1.376 \\
\hline 25. & Velocity Pressure & 0.022 & 0.021 & 0.022 & 0.021 & 0.021 & 0.021 & 0.020 & 0.020 & 0.019 & 0.014 \\
\hline 26. & Total Pressure of Fan & 0.514 & 0.612 & 0.717 & 0.807 & 0.892 & 0.990 & 1.093 & 1.192 & 1.292 & 1.391 \\
\hline 27. & Motor Amperage & 1.99 & 2.10 & 2.39 & 2.68 & 2.76 & 3.06 & 3.29 & 3.45 & 3.67 & 3.49 \\
\hline 28. & Motor Wattage & 264.4 & 289.6 & 321.2 & 346.2 & 371.0 & 397.0 & 424.1 & 452.5 & 478.5 & 453 \\
\hline 29. & CFM per Watt & 4.11 & 3.74 & 3.38 & 3.12 & 2.89 & 2.69 & 2.49 & 2.30 & 2.14 & 1.95 \\
\hline
\end{tabular}

Note: All pressures are in inches of water unless otherwise stated. 
Table A27 Summary Data for ECM 2.3 furnace at low speed

\begin{tabular}{|l|r|r|r|r|r|r|r|r|r|r|}
\hline Point & \multicolumn{1}{|c|}{$\mathbf{1}$} & $\mathbf{2}$ & $\mathbf{3}$ & \multicolumn{1}{c|}{$\mathbf{4}$} & $\mathbf{5}$ & \multicolumn{1}{c|}{$\mathbf{6}$} & $\mathbf{7}$ & $\mathbf{8}$ & $\mathbf{9}$ & $\mathbf{1 0}$ \\
\hline $\begin{array}{l}\text { Fan Static Pressure } \\
\text { (in/water) }\end{array}$ & 0.5 & 0.601 & 0.707 & 0.799 & 0.886 & 0.987 & 1.092 & 1.194 & 1.295 & 1.4 \\
\hline $\begin{array}{l}\text { Nozzle Diff. Pressure } \\
\text { (in/water) }\end{array}$ & 0.485 & 0.481 & 0.484 & 0.479 & 0.471 & 0.467 & 0.458 & 0.447 & 0.431 & 0.323 \\
\hline Nozzle Key (ID) & $3+4+5$ & $3+4+5$ & $3+4+5$ & $3+4+5$ & $3+4+5$ & $3+4+5$ & $3+4+5$ & $3+4+5$ & $3+4+5$ & $3+4+5$ \\
\hline $\begin{array}{l}\text { Nozzle Static Pressure } \\
\text { (in/H2O) }\end{array}$ & 0.01 & 0.109 & 0.212 & 0.308 & 0.404 & 0.505 & 0.615 & 0.725 & 0.841 & 1.052 \\
\hline $\begin{array}{l}\text { Fan Inlet Dry Bulb } \\
\text { Temp (F) }\end{array}$ & 68.431 & 67.883 & 68.454 & 68.361 & 68.156 & 68.45 & 68.214 & 68.238 & 67.88 & 68.442 \\
\hline $\begin{array}{l}\text { Fan Inlet Wet Bulb } \\
\text { Temp (F) }\end{array}$ & 54.683 & 54.262 & 54.578 & 54.577 & 54.527 & 54.679 & 54.666 & 54.464 & 54.323 & 54.685 \\
\hline $\begin{array}{l}\text { Chamber Dry Bulb } \\
\text { Temp (F) }\end{array}$ & 67.946 & 67.478 & 67.966 & 67.921 & 68.05 & 67.858 & 68.017 & 67.758 & 68.429 & 68.501 \\
\hline Barometric Pressure & 30.406 & 30.405 & 30.401 & 30.407 & 30.407 & 30.408 & 30.403 & 30.405 & 30.401 & 30.395 \\
\hline Fan Motor Volts & 121.566 & 121.598 & 122.296 & 120.227 & 120.852 & 119.911 & 119.209 & 118.233 & 118.643 & 120.33 \\
\hline Fan Motor Amps & 2.024 & 2.136 & 2.43 & 2.724 & 2.806 & 3.112 & 3.353 & 3.51 & 3.731 & 3.549 \\
\hline Fan Motor Watts & 268.738 & 294.708 & 326.599 & 352.142 & 377.38 & 404.053 & 431.549 & 460.846 & 486.816 & 460.785 \\
\hline Fan Motor RPM & 915 & 958 & 1020 & 1065 & 1106 & 1147 & 1194 & 1231 & 1273 & 1312 \\
\hline
\end{tabular}

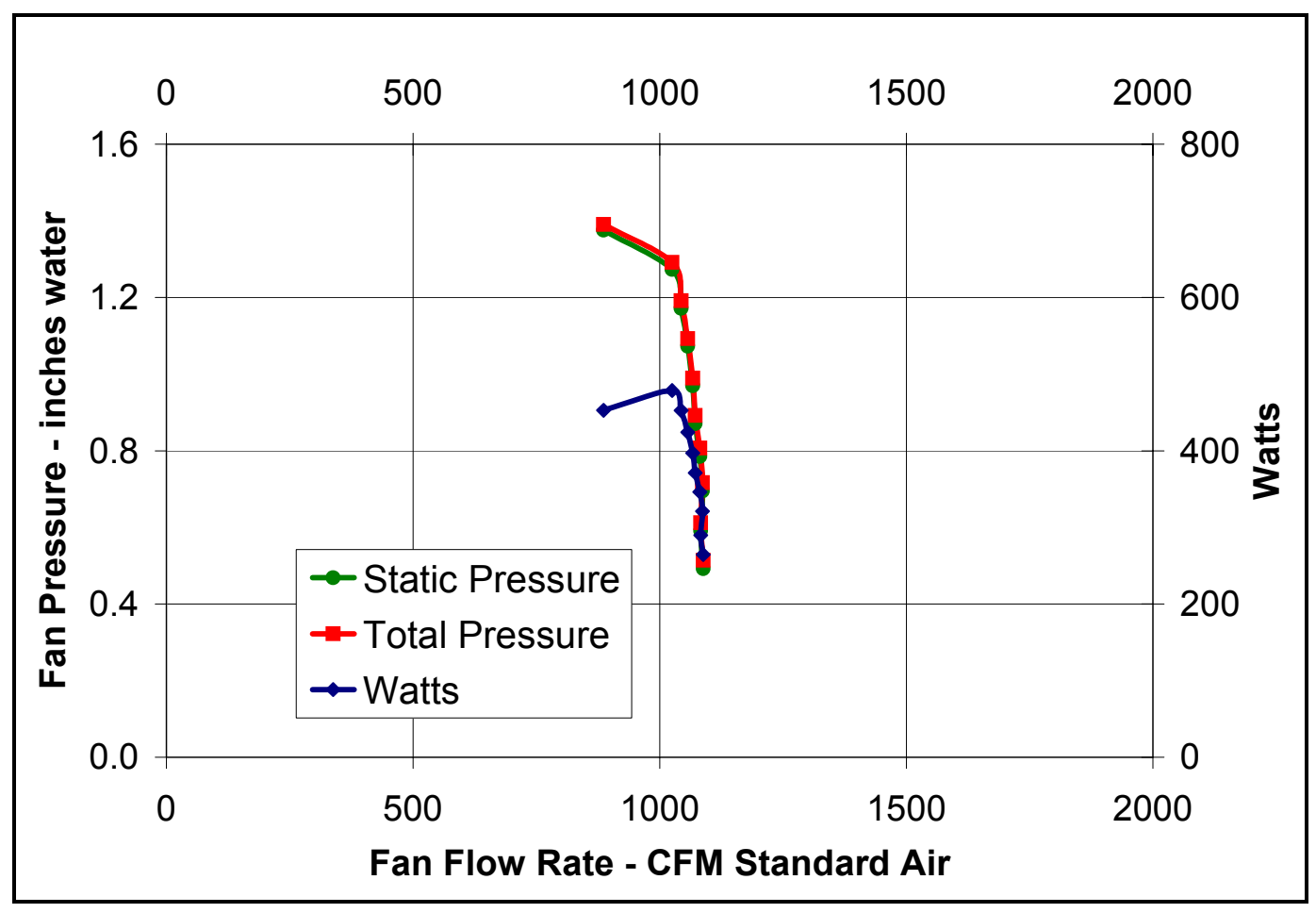

Figure 22 Airflow versus Pressure and Power for ECM 2.3 furnace at low speed 


\section{ECM 4.0 furnace at high speed}

Table A28 Test Information for ECM 4.0 furnace at high speed

\begin{tabular}{|l|l||l|l|}
\hline Contract Number & $03-153 \mathrm{~N}$ & Motor Volts & 120 \\
\hline Test Date & 25 March, 2003 & Wheel Diameter (in) & 10 \\
\hline Fan Model Number & $58 \mathrm{CVA} 090--10116$ & Outlet Diameter (in) & 18.4 \\
\hline Motor Model Number & ECM 4.0 & Outlet Area (sq ft) & 1.847 \\
\hline Number of Motors & 1 & Motor Notes & \\
\hline Number of Blades & 0 & Operator(s) & Michael \\
\hline Blade Material & Aluminum & Test Notes: & $\begin{array}{l}\text { Furnace and Blower - } \\
\text { High Speed }\end{array}$ \\
\hline
\end{tabular}

Table A29 Report for ECM 4.0 furnace at high speed

\begin{tabular}{|c|c|c|c|c|c|c|c|c|c|c|c|}
\hline 1. & Test Point Number & 1 & 2 & 3 & 4 & 5 & 6 & 7 & 8 & 9 & 10 \\
\hline 2. & Fan Static Pressure & 0.389 & 0.496 & 0.581 & 0.695 & 0.818 & 0.921 & 0.989 & 1.106 & 1.196 & 1.301 \\
\hline 3. & $\begin{array}{l}\text { Nozzle Differential } \\
\text { Pressure }\end{array}$ & 1.051 & 1.006 & 0.968 & 0.915 & 0.866 & 0.833 & 0.805 & 0.760 & 0.725 & 0.685 \\
\hline 4. & Nozzle Key (ID) & 10 & 10 & 10 & 10 & 10 & 10 & 10 & 10 & 10 & 10 \\
\hline 5. & Nozzle Static Pressure & -0.683 & -0.525 & -0.405 & -0.238 & -0.066 & 0.051 & 0.145 & 0.293 & 0.414 & 0.561 \\
\hline 6. & $\begin{array}{l}\text { Barometric Pressure } \\
\text { (in } \mathrm{Hg} \text { ) }\end{array}$ & 29.93 & 29.93 & 29.93 & 29.93 & 29.93 & 29.93 & 29.93 & 29.93 & 29.93 & 29.93 \\
\hline 7. & $\begin{array}{l}\text { Fan Inlet Dry Bulb } \\
\text { Temperature }(F)\end{array}$ & 70.9 & 70.9 & 70.9 & 71.1 & 71.2 & 71.2 & 71.3 & 71.4 & 71.2 & 71.3 \\
\hline 8. & $\begin{array}{l}\text { Fan Inlet Wet Bulb } \\
\text { Temperature }(\mathrm{F})\end{array}$ & 66.7 & 66.7 & 66.8 & 66.7 & 66.9 & 66.9 & 67.0 & 67.0 & 67.1 & 67.0 \\
\hline 9. & $\begin{array}{l}\text { Chamber Dry Bulb } \\
\text { Temperature }(\mathrm{F})\end{array}$ & 68.8 & 68.6 & 68.8 & 68.7 & 68.8 & 69.2 & 69.2 & 69.2 & 69.3 & 69.2 \\
\hline 10. & Fan Motor Amperage & 5.17 & 5.24 & 5.25 & 5.33 & 5.41 & 5.50 & 5.54 & 5.59 & 5.64 & 5.62 \\
\hline 11. & Fan Motor Voltage & 115.9 & 115.2 & 115.2 & 114.0 & 114.8 & 115.0 & 114.5 & 115.2 & 114.6 & 115.2 \\
\hline 12. & Fan Motor Wattage & 632.9 & 637.8 & 640.1 & 648.9 & 659.7 & 662.7 & 666.9 & 669.8 & 672.3 & 678.5 \\
\hline 13. & Fan Motor RPM & 1931 & 1945 & 1959 & 1988 & 2017 & 2033 & 2033 & 2048 & 2079 & 2079 \\
\hline 14. & Fan Motor \#2 RPM & 0 & 0 & 0 & 0 & 0 & 0 & 0 & 0 & 0 & 0 \\
\hline 15. & $\begin{array}{l}\text { Air Density at Fan } \\
\text { Inlet }(\mathrm{lb} / \mathrm{ft} 3)\end{array}$ & 0.07421 & 0.07420 & 0.07420 & 0.07418 & 0.07416 & 0.07416 & 0.07415 & 0.07413 & 0.07416 & 0.07415 \\
\hline 16. & $\begin{array}{l}\text { Air Density at Fan } \\
\text { Outlet (lb/ft3) }\end{array}$ & 0.07437 & 0.07442 & 0.07443 & 0.07448 & 0.07448 & 0.07446 & 0.07447 & 0.07449 & 0.07450 & 0.07454 \\
\hline 17. & $\begin{array}{l}\text { Air Density at Nozzle } \\
\text { Inlet }(\mathrm{lb} / \mathrm{ft} 3)\end{array}$ & 0.07457 & 0.07461 & 0.07461 & 0.07465 & 0.07464 & 0.07462 & 0.07463 & 0.07464 & 0.07464 & 0.07468 \\
\hline 18. & CFM at Nozzle Inlet & 1625.0 & 1589.2 & 1558.6 & 1514.6 & 1473.3 & 1445.0 & 1420.2 & 1379.5 & 1347.1 & 1308.8 \\
\hline 19. & CFM at Fan Outlet & 1620.8 & 1585.2 & 1554.9 & 1511.1 & 1470.1 & 1441.9 & 1417.3 & 1376.8 & 1344.6 & 1306.5 \\
\hline 20. & Fan Outlet Static Pres. & 0.389 & 0.496 & 0.581 & 0.695 & 0.818 & 0.921 & 0.989 & 1.106 & 1.196 & 1.301 \\
\hline 21. & Fan Outlet Vel. Pres. & 0.048 & 0.046 & 0.044 & 0.042 & 0.039 & 0.038 & 0.037 & 0.035 & 0.033 & 0.031 \\
\hline 22. & Fan Outlet Total Pres. & 0.437 & 0.542 & 0.625 & 0.737 & 0.857 & 0.959 & 1.026 & 1.141 & 1.229 & 1.332 \\
\hline \multicolumn{12}{|c|}{ Values Corrected for Standard Air Density } \\
\hline 23. & CFM at Nozzle Inlet & 1625.0 & 1589.2 & 1558.6 & 1514.6 & 1473.3 & 1445.0 & 1420.2 & 1379.5 & 1347.1 & 1308.8 \\
\hline 24. & Static Pressure & 0.391 & 0.499 & 0.584 & 0.698 & 0.822 & 0.926 & 0.994 & 1.111 & 1.202 & 1.307 \\
\hline 25. & Velocity Pressure & 0.048 & 0.046 & 0.044 & 0.042 & 0.040 & 0.038 & 0.037 & 0.035 & 0.033 & 0.031 \\
\hline 26. & Total Pressure of Fan & 0.439 & 0.545 & 0.628 & 0.740 & 0.861 & 0.964 & 1.031 & 1.146 & 1.235 & 1.338 \\
\hline 27. & Motor Amperage & 5.20 & 5.26 & 5.27 & 5.35 & 5.44 & 5.53 & 5.57 & 5.61 & 5.66 & 5.64 \\
\hline 28. & Motor Wattage & 636.6 & 641.2 & 643.5 & 651.9 & 662.9 & 666.1 & 670.2 & 673.0 & 675.5 & 681.4 \\
\hline 29. & CFM per Watt & 2.55 & 2.47 & 2.42 & 2.32 & 2.22 & 2.16 & 2.11 & 2.05 & 1.99 & 1.92 \\
\hline
\end{tabular}

Note: All pressures are in inches of water unless otherwise stated. 
Table A30 Summary data for ECM 4.0 furnace at high speed

\begin{tabular}{|c|c|c|c|c|c|c|c|c|c|c|}
\hline Point & 1 & 2 & 3 & 4 & 5 & 6 & 7 & 8 & 9 & 10 \\
\hline $\begin{array}{l}\text { Fan Static Pressure } \\
\text { (in/water) }\end{array}$ & 0.389 & 0.496 & 0.581 & 0.695 & 0.818 & 0.921 & 0.989 & 1.106 & 1.196 & 1.301 \\
\hline $\begin{array}{l}\text { Nozzle Diff. Pressure } \\
\text { (in/water) }\end{array}$ & 1.051 & 1.006 & 0.968 & 0.915 & 0.866 & 0.833 & 0.805 & 0.76 & 0.725 & 0.685 \\
\hline Nozzle Key (ID) & $3+4+5$ & $3+4+5$ & $3+4+5$ & $3+4+5$ & $3+4+5$ & $3+4+5$ & $3+4+5$ & $3+4+5$ & $3+4+5$ & $3+4+5$ \\
\hline $\begin{array}{l}\text { Nozzle Static Pressure } \\
\text { (in/H2O) }\end{array}$ & -0.683 & -0.525 & -0.405 & -0.238 & -0.066 & 0.051 & 0.145 & 0.293 & 0.414 & 0.561 \\
\hline $\begin{array}{l}\text { Fan Inlet Dry Bulb } \\
\text { Temp (F) }\end{array}$ & 70.892 & 70.882 & 70.937 & 71.128 & 71.194 & 71.209 & 71.308 & 71.415 & 71.209 & 71.277 \\
\hline $\begin{array}{l}\text { Fan Inlet Wet Bulb } \\
\text { Temp (F) }\end{array}$ & 66.674 & 66.7 & 66.769 & 66.692 & 66.898 & 66.86 & 66.956 & 66.976 & 67.067 & 67.035 \\
\hline $\begin{array}{l}\text { Chamber Dry Bulb } \\
\text { Temp (F) }\end{array}$ & 68.828 & 68.646 & 68.774 & 68.656 & 68.828 & 69.18 & 69.161 & 69.237 & 69.307 & 69.189 \\
\hline Barometric Pressure & 29.932 & 29.931 & 29.933 & 29.934 & 29.933 & 29.934 & 29.934 & 29.934 & 29.934 & 29.933 \\
\hline Fan Motor Volts & 115.949 & 115.201 & 115.237 & 114.043 & 114.757 & 114.977 & 114.489 & 115.169 & 114.649 & 115.201 \\
\hline Fan Motor Amps & 5.174 & 5.236 & 5.245 & 5.329 & 5.412 & 5.498 & 5.544 & 5.588 & 5.636 & 5.619 \\
\hline Fan Motor Watts & 632.904 & 637.848 & 640.137 & 648.865 & 659.729 & 662.659 & 666.901 & 669.769 & 672.272 & 678.497 \\
\hline Fan Motor RPM & 1931 & 1945 & 1959 & 1988 & 2017 & 2033 & 2033 & 2048 & 2079 & 2079 \\
\hline
\end{tabular}

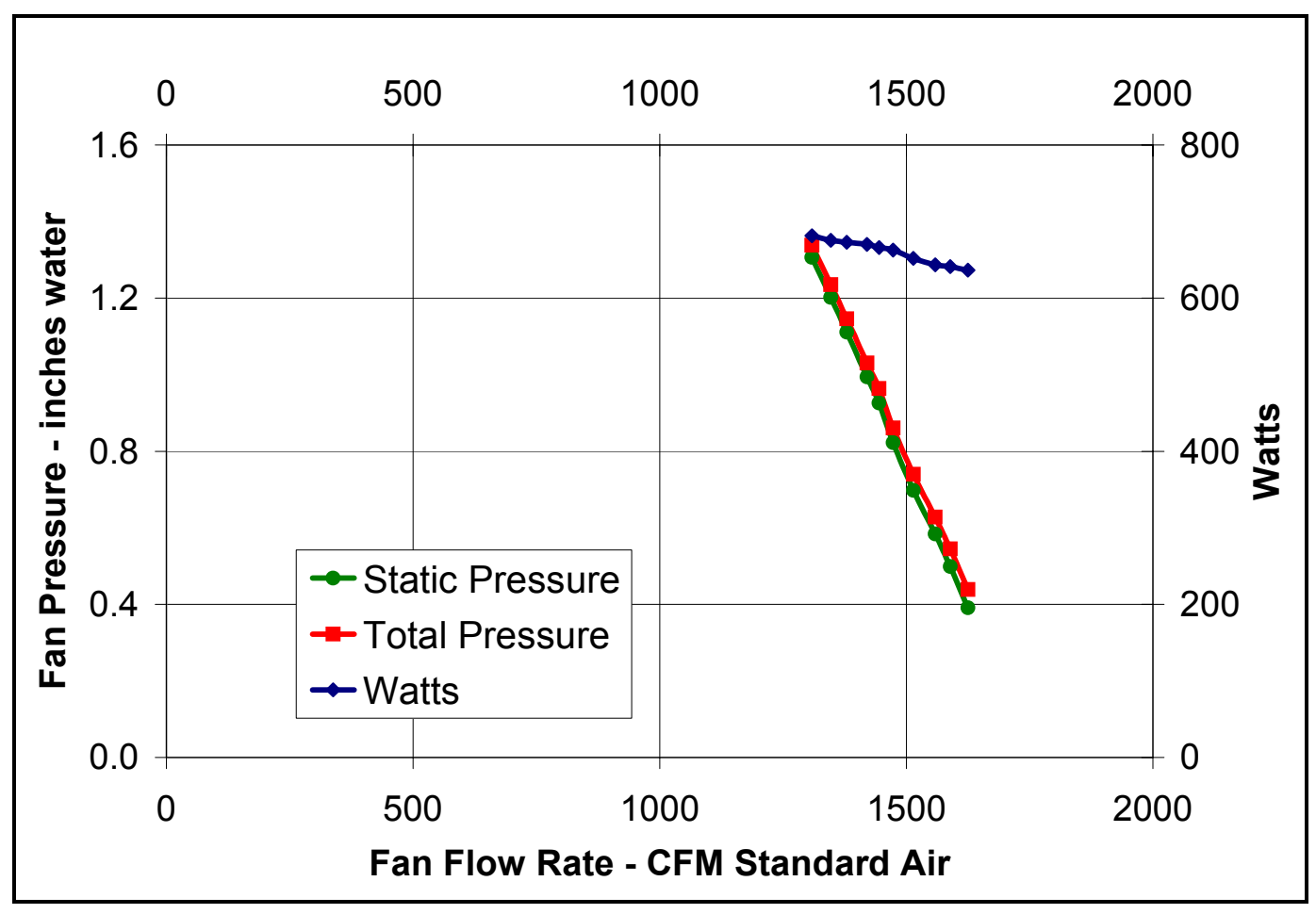

Figure 23 Airflow versus Pressure and Power ECM 4.0 furnace at high speed 


\section{APPENDIX B: Acronyms}

AMCA: Air Movement and Control Association

ANSI: American National Standards Institute

ASHRAE: American Society of Heating, Refrigerating and Air-Conditioning Engineers, Inc.

cfm: cubic feet per minute

ECM: refers to a type of electric motor; an electronically commutated motor

ESL: Energy Systems Laboratory

ESP: external static pressure

$G E$ : General Electric

LBNL: Lawrence Berkeley National Laboratory

$P S C:$ refers to a type of electric motor having a permanent split capacitor

rpm: revolutions per minute

TAMU: Texas A\&M University

$T P:$ total pressure

wg.: water gauge is a measurement of pressure as typically measured by a manometer in which a column of water is displaced by a number of inches. Also often referred to as water column or W.c. 


\section{APPENDIX C: Furnace Test Procedure}

The current Department of Energy (DOE, the Department) test procedure for residential furnaces does not measure airflow. However, the current test procedure includes a measurement of electricity consumption, Average Annual Auxiliary Electrical Energy Consumption $\left(\mathrm{E}_{\mathrm{AE}}\right)$. This is calculated and reported by furnace manufacturers. $\mathrm{E}_{\mathrm{AE}}$ is calculated as part of the DOE test procedure, ${ }^{13}$ which references the ASHRAE test procedure ${ }^{14}$ for furnaces. In the DOE test procedure, the $\mathrm{E}_{\mathrm{AE}}$ energy consumption is based on test measurements in heating mode when the furnace is adjusted to provide a specified temperature rise and static pressure at the furnace outlet. The specified static pressures in the DOE test may not realistically represent the static pressures as seen in an actual applications with an air-conditioning coil installed in the furnace air handler.

Setting limits on $\mathrm{E}_{\mathrm{AE}}$ could be a method of setting a maximum level of electrical energy consumption without requiring an extensive revision to the existing DOE furnace test procedure. However, the maximum $\mathrm{E}_{\mathrm{AE}}$ limit should depend on the airflow supplied by the circulating-air blower. In addition, the airflow should be measured at an ESP rise of $0.5 \mathrm{in}$. wg.. This is the static pressure at which manufacturers rate the cooling capacity of the air conditioners designed to be used with their furnaces. This is typically based on a furnace being able to move $400 \mathrm{cfm}$ per ton of air conditioning at a pressure drop of $0.5 \mathrm{in}$. wg. While the maximum airflow capacity of the furnace is measured for each furnace model, reported in product literature by the manufacturers, and used when selecting an appropriate air conditioner, it is not reported or certified to DOE. The test procedure that manufacturers follow for airflow capability are typically based on ANSI/AMCA 210/ASHRAE 51.

Another approach to setting an electrical energy consumption standard, would be to include an energy consumption test as well as a airflow capacity test the next time the existing furnace test procedure is updated.

\footnotetext{
${ }^{a}$ Testing done for this report has determined that simply referencing the AMCA 210 test procedure to measure furnace blower airflow at 0.5 inches static pressure is insufficient for new types of motors and blower control systems entering the market. In fact, for some blower/motor combinations, these conditions could not be met within the protocol as set in the AMCA 210 method of test.
} 


\section{APPENDIX D: Instrumentation and Testing Details}

\section{Instrumentation and Data Acquisition}

- $\quad$ The pressure transducers are calibrated every morning at 0 and 10 inches wg. against a micro-manometer. The Dwyer pressure sensors are set at null and span twice. The span is at $10 \mathrm{in.} \mathrm{wg.} \mathrm{The} \mathrm{micro} \mathrm{manometer} \mathrm{at} 10 \mathrm{in.} \mathrm{wg.} \mathrm{has} \mathrm{a} \mathrm{resolution} \mathrm{of} 0.001 \mathrm{in.} \mathrm{wg.}$

- $\quad$ ESL uses a variable transformer to set the input voltage

- Watts, amps, and voltage are measured by Ohio Semitronic Transducers.

- $\quad$ Because the static pressure measurements (used for both the ESP and delta pressure across the flow nozzles to calculate the airflow) are electronic (Dwyer), the pressure fluctuations are not self-dampened as they would be by measurement with a traditional manometer. Therefore, ESL takes a thousand readings over a 5-second interval, to average out any fluctuations. This is not an AMCA specification, just an ESL procedure.

- $\quad$ ESL measures the ambient dry bulb and wet bulb temperatures at a location in the center of the lab with a psychrometer.

- $\quad$ ESL also uses an electronic barometer to measure the barometric pressure.

- $\quad$ ESL used a Monarch brand tachometer to measure the blower speed in rpm. It counted the revolutions of a blower by a sensor monitoring the presence of a strip of reflective tape attached to the blower wheel.

- $\quad$ The static pressure at the inlet side of the airflow measuring apparatus is currently manually controlled by a variable-speed blower at the outlet side of the airflowmeasuring apparatus.

- $\quad$ The computer data acquisition system reads outputs from an electronic barometer, dry bulb and wet bulb temperature sensors, Watt meters, voltage meters and pressure transducers.

- $\quad$ The computer selects the Dwyer pressure sensors (eight sensors), by selecting the one that is in the correct pressure range for the current measurement. The lowest range possible is used for the best accuracy. The accuracy of these pressure transducers is a percentage of the range. All of the pressure transducers stay physically connected and have a maximum capacity of ten in. wg. The pressure sensor ranges are $0-1$ in. wg., 0 2 in. wg., and $0-10$ in. wg.

- The data acquisition uses three National Instrument Data Acquisition boards and the Visual Basic programing language.

\section{Procedure}

When a PSC motor is tested, very little time is needed to allow the airflow to settle after a change in ESP. However, ESL found that, with an ECM motor, more time was needed after a pressure change. In some cases, the controls caused the blower to hunt for a specific airflow i.e., the controls would overshoot and overcorrect before setting on an airflow at which to stabilize. Taking this into account, about five minutes were allowed for the airflow to stabilize for tests with an ECM motor. 
For all testing, the furnace blower is turned on first, before the test flow apparatus airflow, to allow the furnace blower to start turning in the correct direction. If the blower is left off and just the test fan is turned on, the blower wheel could start to spin counter to its normal operation.

\section{Setup}

The purpose was to measure the power consumption of the circulating-air blower and its control circuitry, without any other induced draft or other blowers or electricity consuming components operating. In all cases, ESL mounted the furnace horizontally for convenience. ESL made an effort to test the blower as in an actual installation, with the effect of the blower controls on the airflow being included. Unfortunately, controls had to be partially bypassed in some instances to get a steady airflow needed for measurement.

\section{PSC - Blower in Furnace}

Low Speed - ESL jumpered the thermostat R\&G terminals to set the lowest- speed setting for a fan-only setting on a thermostat. ESL used an amp probe to verify that the motor wire indicated as the lowest speed on the wiring diagram was indeed the one activated. ESL then measured the power supplied to the furnace input terminal; only the blower and the controls were running (no combustion fan was running).

High speed - to activate the highest-speed mode, ESL jumpered the thermostat wires R,G $\& \mathrm{Y}$, thereby supplying power to the highest speed (black lead) to the motor. However, the blower would start out at a high rpm and then abruptly change to a lower speed. ESL solved this problem by connecting $R \& G$ terminals and then connecting the high-speed lead to the motor to the fan relay, such that the high-speed mode was in continuous fan-operating condition enabled by the R \& $\mathrm{G}$ thermostat leads. In this way, ESL could run any speed by just moving the motor tap.

\section{PSC - Blower alone}

ESL connected motor leads for the three tests at low, medium-low, and high speed directly to 120 volts. When the static pressure was set below $0.7 \mathrm{in}$. wg., the motor started slowing down. When the static pressure was further decreased, the blower further slowed down until the rotation of the blower reversed.

The furnace itself blocks off part of the furnace outlet. If this is not blocked off, it can cause eddy (swirl) currents at the blower outlet. In other words, the blower may not have been intended to run with the scroll exit opening fully open, as it is when tested outside of the furnace. Other interactions between the furnace housing (especially at the blower exit) could have an important effect on the performance of the blower. 
In general, ESL found that it could test the furnace blower at lower blower outlet static pressures when the blower was in the furnace housing, or, if the total pressure drop across the blower was greater, by blocking off the inlet to the blower.

\section{PSC-Blower alone - High Speed}

When the static pressure at the blower outlet is brought down to $0.7 \mathrm{in}$. wg. with the airflow apparatus blower (with the furnace blower starting first), the rpm and the cfm of the furnace blower starts to decrease. If the static pressure (back pressure) is lowered further, the blower speed decreases even more until the blower wheel stops and runs backwards.

The general difference between testing the blower in the furnace and outside of the furnace, is the additional pressure drop due to the air resistence of the furnace housing. One purpose for testing the blower outside of the furnace was to determine the system effects of the furnace cabinet. Results showed that the exit conditions, as well as the input restrictions, have a significant effect on the system performance.

\section{ECM 2.3 - Blower in Furnace}

Because an ECM is integrally controlled by an electronic controller, it is not inherently as simple as testing a PSC blower. For the first test, ESL set the controls to heating mode; the blower started, but then shut down, possibly due to an interlock on the furnace controls.

The control board of the furnace has various settings that can be set. For example, dip switches allow the user to select from $350 \mathrm{cfm} /$ ton or $400 \mathrm{cfm} /$ ton. ESL set the dip switches to $400 \mathrm{cfm} /$ ton, to allow for a maximum airflow setting.

With the ECM motor/blower, the cfm and rpm fluctuated, after the static pressure was changed. It took about two minutes for the hunting to settle, i.e., for the pressures to approach a steady-state value. This is unlike the quick response of a PSC motor/blower, that does not have this hunting, or settling, time. 


\section{REFERENCES}

1. GE industrial motor web site to www.GEindustrial.com, enter keyword: ECM

2. Title 10, Code of Federal regulations, Part 430-Energy Conservation Program for Consumer Products, Appendix N to Subpart B of Part 430-Uniform Test Method for Measuring the Energy consumption of Furnaces and Boilers, January 1, 1999.

3. "Laboratory Method of Testing Fans for Aerodynamic Performance Rating", ANSI/AMCA 210-99, ANSI/ASHRAE 51-1999

4. ESL web site URL: http://www-esl.tamu.edu/about esl.html , 6 June 2003

5. Memorandum Integrated Intelligent Blower, November 1, 2002; Project DE-FC2600NT40993 for a complete description of the prototype.

6. Wang, S. and H. Wiegman, Topical Progress Report for the Variable Speed Integrated Intelligent HVAC Blower, November 14, 2001, GE Corporate Research and Development. Niskayuna, NY.

7. "Laboratory Method of Testing Fans for Aerodynamic Performance Rating", ANSI/AMCA 210-99, ANSI/ASHRAE 51-1999

8. Personnel communication with Bill Archer (GE Consumer \& Industrial)

9. Personnel communication with Roger Bercerra (GE Consumer \& Industrial)

10. Personnel communication with Bill Archer (GE Consumer \& Industrial)

11. Personnel communication with Roger Bercerra (GE Consumer \& Industrial)

12. Walden, Selecting and Using Transducers for the Measurement of Electric Power, Voltage, and Current, January 2000, Ohio Semitronics, Inc., www.ohiosemitronics/support.html

13. Title 10, Code of Federal regulations, Part 430-Energy Conservation Program for Consumer Products, Appendix N to Subpart B of Part 430-Uniform Test Method for Measuring the Energy consumption of Furnaces and Boilers, January 1, 1999.

14. American Society for Heating Refrigeration and Air-Conditioning Engineers, Method of Testing for Annual Fuel Utilization Efficiency of Residential Central Furnaces and Boilers, 1993, ANSI/ASHRAE, Atlanta, GA. Report No. Standard 103-1993. 